University of Louisville

ThinkIR: The University of Louisville's Institutional Repository

$12-2017$

\title{
Self-management as a mediator of the relationship between social support and health outcomes of African American adults with type 2 diabetes.
}

Tariq N. Al-Dwaikat

University of Louisville

Follow this and additional works at: https://ir.library.louisville.edu/etd

Part of the Public Health and Community Nursing Commons

\section{Recommended Citation}

Al-Dwaikat, Tariq N., "Self-management as a mediator of the relationship between social support and health outcomes of African American adults with type 2 diabetes." (2017). Electronic Theses and Dissertations. Paper 2863.

https://doi.org/10.18297/etd/2863

This Doctoral Dissertation is brought to you for free and open access by ThinkIR: The University of Louisville's Institutional Repository. It has been accepted for inclusion in Electronic Theses and Dissertations by an authorized administrator of ThinkIR: The University of Louisville's Institutional Repository. This title appears here courtesy of the author, who has retained all other copyrights. For more information, please contact thinkir@louisville.edu. 
SELF-MANAGEMENT AS A MEDIATOR OF THE RELATIONSHIP BETWEEN

SOCIAL SUPPORT AND HEALTH OUTCOMES OF AFRICAN AMERICAN

ADULTS WITH TYPE 2 DIABETES

By

Tariq N. Al-Dwaikat

B.S.N., Jordan University of Science and Technology, 2005

M.A., West Virginia University, 2011

\begin{abstract}
A Dissertation
Submitted to the Faculty of the

School of Nursing of the University of Louisville

In Partial Fulfillment of the Requirements

For the Degree of
\end{abstract}

Doctor of Philosophy in Nursing

School of Nursing

University of Louisville

Louisville, Kentucky

December 2017 
Copyright 2017 by Tariq N. Al-Dwaikat

All rights reserved 

SELF-MANAGEMENT AS A MEDIATOR OF THE RELATIONSHIP BETWEEN

SOCIAL SUPPORT AND HEALTH OUTCOMES OF AFRICAN AMERICAN

ADULTS WITH TYPE 2 DIABETES

By

Tariq N. Al-Dwaikat

B.S.N., Jordan University of Science and Technology, 2005

M.A., West Virginia University, 2011

A Dissertation Approved on

December 2, 2017

By the following Dissertation Committee

Dissertation Director

Diane Orr Chlebowy, PhD, RN

Lynne A. Hall, DrPH, RN

Timothy N. Crawford, PhD, MPH

Pamela A. Yankeelov, PhD 


\section{DEDICATION}

My dissertation is dedicated to the soul of my mother who passed away even before I got my first college degree, to her soul who inspired me and to her heart that is filled with warm love. To my father who never stopped supporting me, I owe him every success I made through my journey. To my wife Ala and my three little kids Ibrahim, Ahmad, and Yahya, I would not be able to accomplish this work without their continued passion and love. To my mother-in-law Dr. Fatheih Qutishat who showered me with her passionate support. To my brothers and sisters and to my extended family and dear friends, I dedicated this work. 


\section{ACKNOWLEDGMENTS}

I would like to acknowledge the great academic role that my dissertation committee chair, Dr. Diane Chlebowy, played over the course of my PhD studies. She adopted my ideas and turned them into this dissertation, and without her support and guidance this dissertation would not be accomplished. She involved me in every scholarly activity she did over the past four years, and she got me acquainted with conducting research to help people with diabetes.

I would like also to acknowledge the great support that I received from my dissertation committee members. I would like to express my deepest gratitude to Dr. Lynne Hall who worked with me on publishing my work and guided me to develop my writing and critiquing skills. I will never forget the great support that I received from Dr. Timothy Crawford who took care of me and provided sincere advice and consultations. I would like also to mention the great help of Dr. Pamela Yankeelov and her faithful dedication to my work.

I would like to express my special thanks to the great people at the Family Health Centers. I would like to acknowledge the support of Dr. Bart Irwin who opened the door widely for me and provided me with many great tools that helped me accomplish my data collection. I would like also to mention the great help that I received from the ladies at the front desk of the Family Health Centers; they were and still are my second family. 
Last but not least, I would like to express my thanks to my family, friends and colleagues. I would also mention the great people at Research Office in the School of Nursing, especially Mrs. Vickie Tencer who offered me a great help throughout my work as a research assistant. My deepest thanks to all of the people I worked with along my doctoral journey. 


\title{
ABSTRACT \\ SELF-MANAGEMENT AS A MEDIATOR OF THE RELATIONSHIP BETWEEN SOCIAL SUPPORT AND HEALTH OUTCOMES OF AFRICAN AMERICAN ADULTS WITH TYPE 2 DIABETES
}

\author{
Tariq N. Al-Dwaikat
}

December 2, 2017

Type 2 diabetes (T2D) is often associated with serious complications. African American adults have higher rates of diabetes-related complications than other ethnicities. Diabetes self-management reduces the risk of developing biological and psychological symptoms. Social support promotes positive behavior change and selfmanagement that leads to improved biobehavioral and psychosocial outcomes. Few studies explored the relationship between social support dimensions and selfmanagement behaviors, diabetes biomarkers, and psychosocial outcomes of African American adults with T2D.

The purpose of this dissertation was to examine the relationships of various dimensions of social support with self-management behaviors and diabetes biomarkers and psychosocial outcomes of African American adults with T2D. This dissertation consists of three manuscripts which include: (1) a state of the science systematic review of social support measurement in studies of persons with T2D; (2) a study of the relationships of sociodemographic characteristics with dietary adherence and glycemic 
control in persons diagnosed with T2D; and (3) a cross-sectional study in which the effects of self-management as a mediator in the relationship between social support and health outcomes in African American adults diagnosed with T2D was explored.

The systematic review of the literature revealed that the existing definitions of social support convey the need for uniform descriptions of the attributes of the concept. A majority of the studies used measures that assess perceived support. The desired outcomes of social support included positive behavior change, improved selfmanagement, and improved health outcomes. The use of a combination of social support measures was recommended to capture the multidimensionality of support necessary to improve outcomes.

The second manuscript examined the relationships of sociodemographic characteristics with adherence to American Diabetes Association (ADA) dietary guidelines and glycated hemoglobin (A1C) in adults with T2D. The results of this study showed that females, non-Hispanic Blacks, widowers, and those with less than a high school education had higher A1Cs than their counterparts. Race/ethnicity and marital status were significantly related to adherence to ADA dietary guidelines. In addition, sex, race/ethnicity, and marital status were significantly related to $\mathrm{A} 1 \mathrm{C}$. Thus, it is important to control for these sociodemographic characteristics in studying the impact of selfmanagement on health outcomes in persons with T2D.

The third manuscript results revealed that functional support, the quality of the primary intimate relationship, and the number of support persons were negatively correlated with depression. Functional support and satisfaction with support explained a 
significant amount of the variance in self-management. However, self-management failed to mediate the relationship between social support dimensions and health outcomes. 
TABLE OF CONTENTS

PAGE

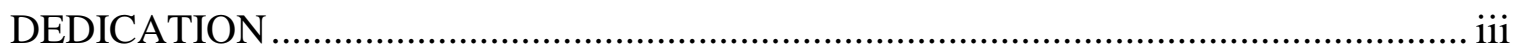

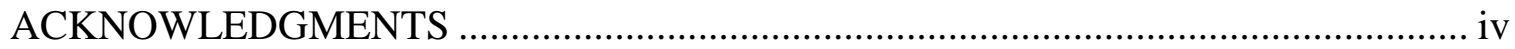

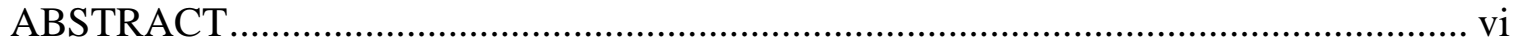

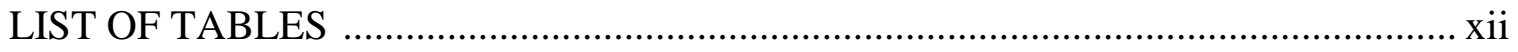

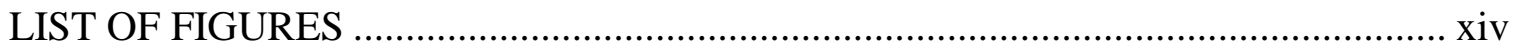

CHAPTER I

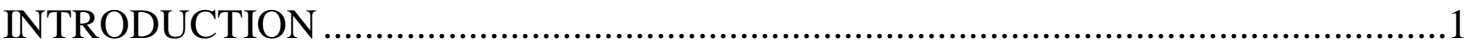

\section{CHAPTER II}

Systematic Review and Critical Analysis of Measures of Social Support

Used in Studies of Persons with Type 2 Diabetes ..........................................................14

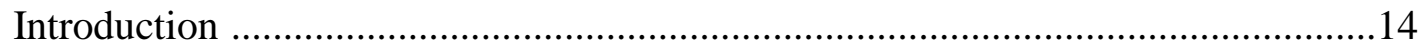

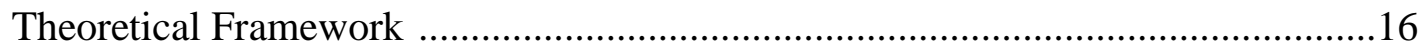

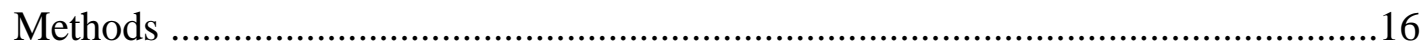

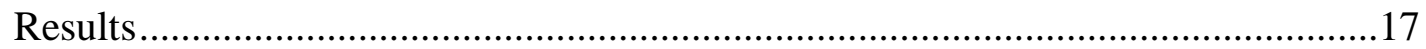

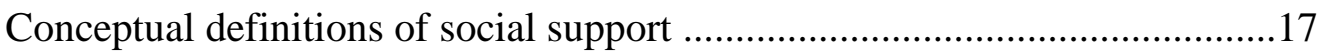

Evaluation of measures used to assess social support ....................................20

The desired outcomes of social support ......................................................21

Most frequently used measures of social support used in T2D selfmanagement and outcome studies .................................................................21

Comparison of three measures of social support ............................................23

Medical Outcomes Study Social Support Survey ……………………...23

Social Support Questionnaire Shortened Version (SSQ6) ......................26

The Multidimensional Scale of Perceived Social Support ....................29

Comparison of the strengths and weakness of the three self-report measures of social support 


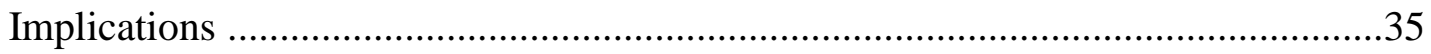

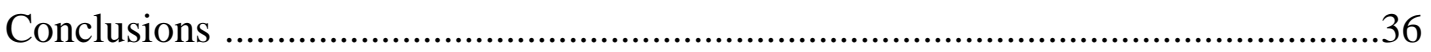

\section{CHAPTER III}

Relationships of Sociodemographic Characteristics with Glycemic Control and Dietary Adherence in Adults with Type 2 Diabetes: Findings from National Health and Nutrition

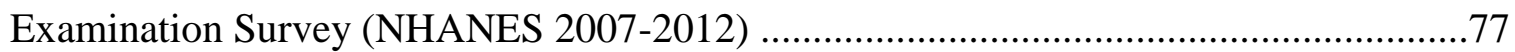

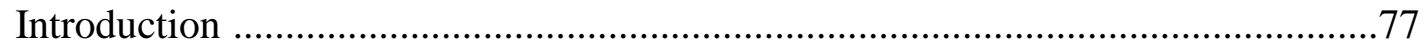

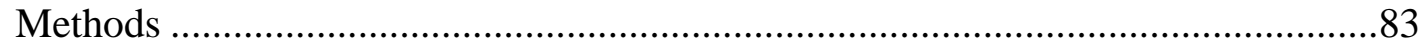

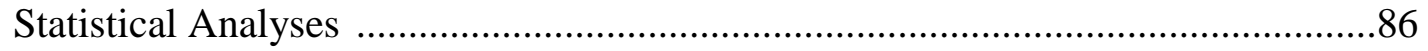

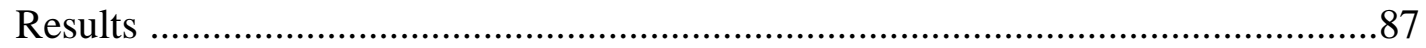

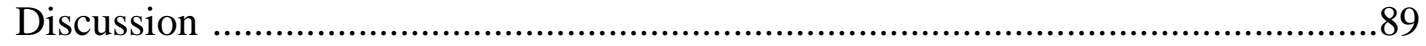

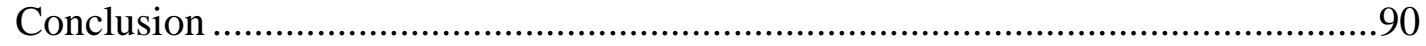

\section{CHAPTER IV}

Self-Management as a Mediator of the Relationship between Social Support and Health Outcomes of African American Adults with Type 2 Diabetes ........................................107

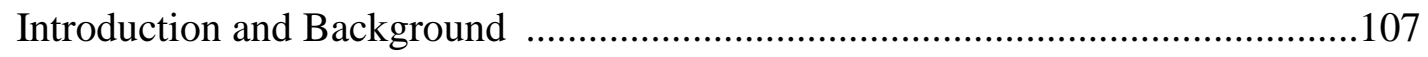

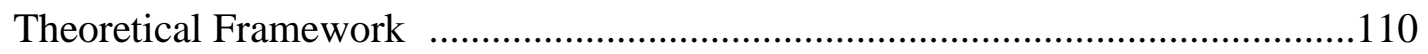

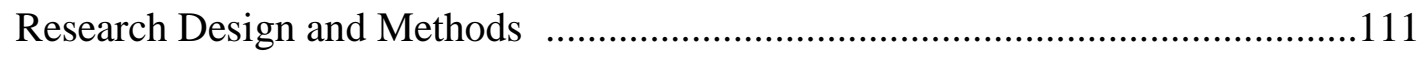

Design and Setting ...…………………………………………….....111

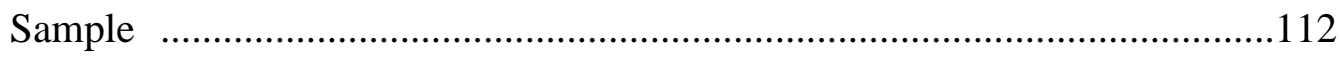

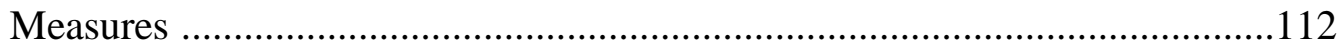

Demographic characteristics and medical history …………………......112

Social support (functional support) ......................................................113

Social support questionnaire shortened version (SSQ6) .........................113

The Autonomy and Relatedness Inventory (ARI) …………………......114

The Summary of Diabetes Self-Care Activities Measure (SDSCA) .....115

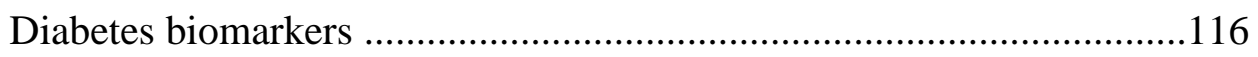

Depression, anxiety, and stress ........................................................116

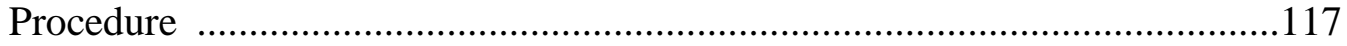

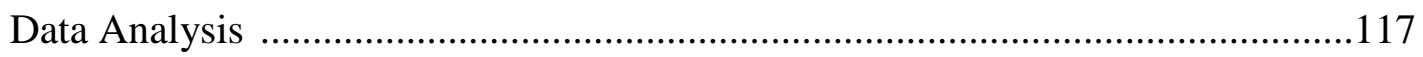

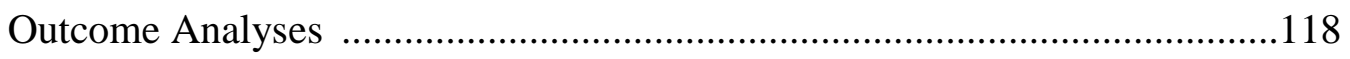

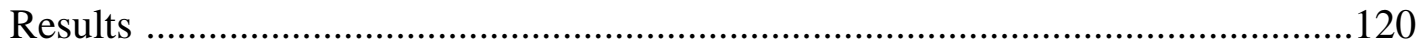




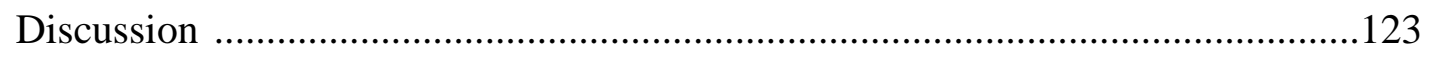

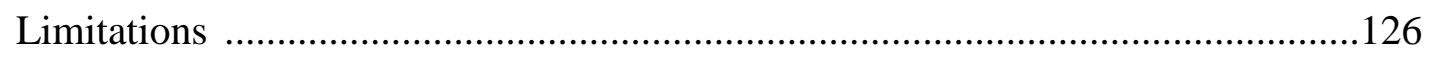

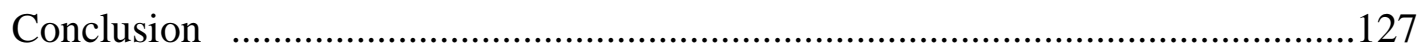

CHAPTER V

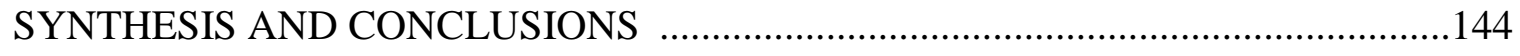

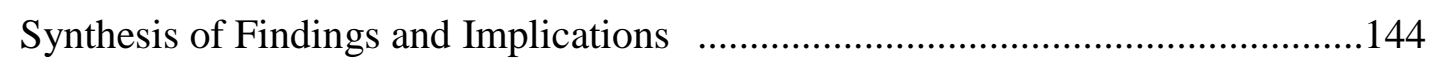

Recommendations for Future Research and Practice ......................................148

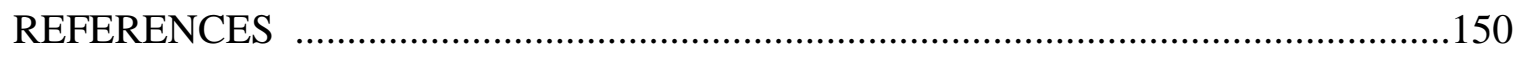

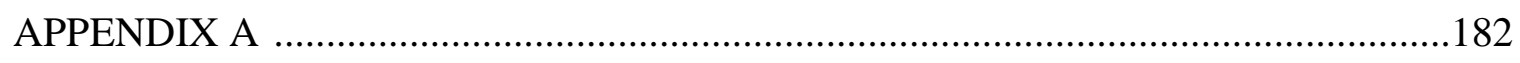

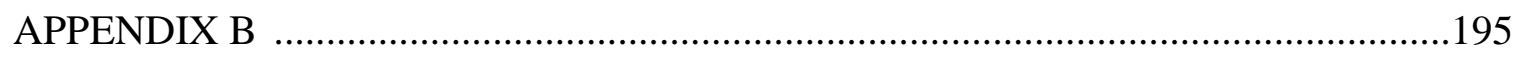

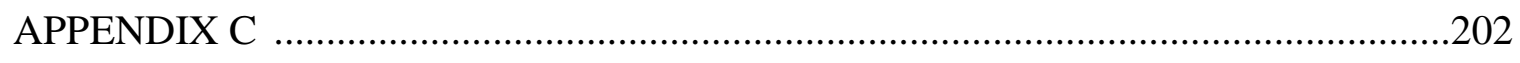

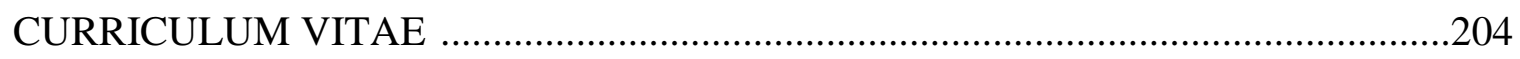


TABLE

\section{LIST OF TABLES}

PAGE

1. A Summary of the Conceptual Definitions of Social Support in T2D Literature .......37

2. Summary of the Studies of Social Support and T2D Self-Management and

Outcomes

3. Comparison of the Three Self-Report Measures of Social Support

4. Descriptive Characteristics of Adults with T2D (> 17 Years of age) Obtained from NHANES (2007-2012) Survey Data $(\mathrm{N}=17.14 \times 106)$

5. Associations between Demographic Characteristics and Dietary Adherence Among Those Who Tried to Lose Weight in The Past Year Obtained from NHANES (20072012) Survey Data $(\mathrm{N}=2.69 \times 106)$

6. T-Test and One-Way ANOVA results Applied to the A1C Related to Sex, Race, Education, Marital Status, Income, and Dietary Adherence Obtained from NHANES (2007-2012) Survey Data $(\mathrm{N}=17.14 \times 106)$ .98

7. A Multiple Linear Regression Model of the A1C Obtained from NHANES (20072012) Survey Data $(\mathrm{N}=17.14 \times 106)$ 101

8. Logistic Regression Results Modeling the Odds of Dietary Non-Adherence Among Those Who Tried to Lose Weight in The Past Year Obtained from NHANES (20072012) Survey Data $(\mathrm{N}=2.69 \times 106)$ 104

9. The Distribution of Adults with T2D Who Tried to Lose Weight in Past Year in 


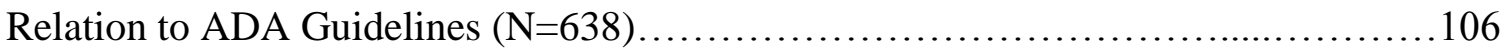

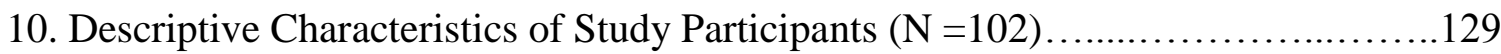

11. Descriptive Characteristics of Study Participants' Social Support Scores and Outcome

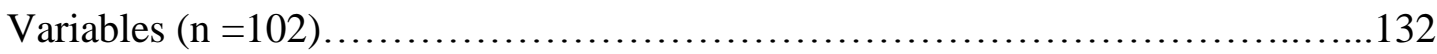

12. Descriptive Characteristics of Study Participants' Self-Management Scores

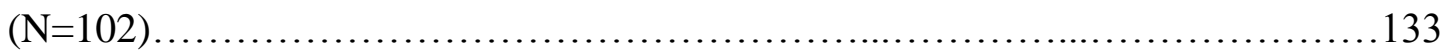

13.Pearson-Moment Correlations of Study Variables ...............................134

14. Regression Results for Self-Management, BMI, Depression, Anxiety, and Stress

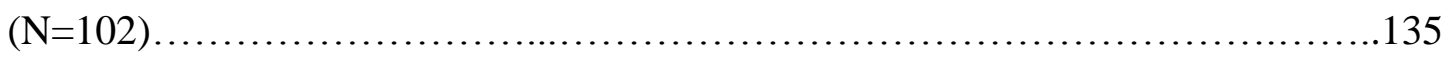

15. Regression Results for BMI, Depression, Anxiety, and Stress $(n=102) \ldots \ldots \ldots \ldots . . .138$ 


\section{LIST OF FIGURES}

FIGURE

PAGE

1. Revised Health Promotion Model .............................................11

2. Variables of Interest as Conceptualized within the HPM..........................12

3. Measurement of the Variables of Interest as Conceptualized within the HPM....13

4. An adaptation of the Peer Support Conceptual Model of Heisler (2006)............75

5. Systematic Review Flow Using PRISMA 2009 Flow Diagram ..................76

6. Relationships between Social Support Dimensions, Self-management, and Health Outcomes in African Americans with T2D Based on Regression Analyses......141 


\section{CHAPTER I}

\section{INTRODUCTION}

The primary purpose of this dissertation was to examine the relationships of various dimensions of social support with self-management behaviors and diabetes biomarkers and psychosocial outcomes in African American adults with type 2 diabetes (T2D). This dissertation comprises an introduction chapter, three manuscripts, and a conclusion chapter that evaluates and ties together the findings of these manuscripts. First, a systematic review and critical analysis of the measures of social support used in prior research with patients diagnosed with T2D was presented. Next, the relationships of sociodemographic characteristics with adherence to the American Diabetes Association (ADA) dietary guidelines and glycemic control among adults diagnosed with T2D was studied. Finally, the relationships of various dimensions of social support with selfmanagement behaviors and diabetes biomarkers and psychosocial outcomes in African American adults with T2D was studied.

Chapter Two is a systematic review and critical analysis of the state of measurement of social support within the studies of persons with T2D . ${ }^{1}$

\footnotetext{
${ }^{1}$ Chapter Two is a published manuscript "Systematic Review and Critical Analysis of Measures of Measures of Social Support Used in Studies of Persons With Type 2 Diabetes” By T.N. Al-Dwaikat and L. A. Hall, 2017, Journal of Nursing Measurement, 25, pp. E74- E107. Copyright [2017]. By Springer Publishing Company. Reprinted with permission.
} 
In the United States, African Americans have been affected significantly by diabetes; $12.7 \%$ of diagnosed adults with diabetes aged 20 years or older are African American, whereas the non-Hispanic Whites are only $7.4 \%$ of that population (Centers for Disease Control and Prevention [CDC], 2017). African Americans have higher rates of diabetes-related complications than non-Hispanic Whites; African Americans have higher rates of end-stage renal disease and lower limb amputations than non-Hispanic Whites (American Diabetes Association [ADA], 2015). In addition, African Americans are twice as likely as non-Hispanic Whites to die as a result of diabetes (CDC, 2016).

African American adults with diabetes or prediabetes have higher levels of A1C than non-Hispanic Whites; these differences increased as their glucose tolerance worsened (Ziemer et al., 2010). Despite the fact that African Americans' diabetes biomarkers indicated their increased risk for complications, their perception of the risk is low (Calvin et al., 2011). African Americans are less likely to adhere to their diabetes medications than non-Hispanic Whites (Osborn et al., 2011). In addition, adherence to glucose monitoring standards is low among African Americans (Trinacty et al., 2007). This health disparity warrants a need for further exploration and development of interventions to help African Americans effectively manage their blood glucose levels (Kirk et al., 2006). Thus, it is important to study how social support dimensions are related to self-management and health outcomes of African American adults with T2D to reduce the disparity among this vulnerable population.

Individuals diagnosed with $\mathrm{T} 2 \mathrm{D}$ experience higher rates of depression than those without T2D (Semenkovich, Brown, Svrakic, \& Lustman, 2015). In addition, Ali, Stone, Peters, Davies, and Khunti (2006) found that depression was higher in females than 
males diagnosed with T2D. In a more recent systematic review, Nouwen et al. (2010) reported that persons diagnosed with $\mathrm{T} 2 \mathrm{D}$ were at a $24 \%$ increased risk of developing depression than persons without the disease.

Depression was significantly correlated with higher rates of diabetes-related complications due to poor metabolic control and non-adherence to dietary and medication regimens (Katon, 2008; Lustman \& Clouse, 2005). In addition, depression among persons diagnosed with T2D is associated with higher rates of myocardial infarctions and strokes (Lin et al., 2010). Compared to patients with T2D only, those with T2D and a comorbid depression are at a $30 \%$ increased risk of developing a myocardial infarction (Scherrer et al., 2011).

Diabetes-related complications, including depression, are associated with poor glycemic control (ADA, 2015). Depression and T2D are comorbid conditions that often occur frequently together (Katon, 2008; Pan et al., 2010). A bidirectional relationship exists between the two conditions (Pan et al., 2010).

Furthermore, Penckofer and colleagues (2014) recommended that more studies are needed to examine the role of self-care and non-adherence outcomes in mediating this relationship. Thus, the relationship between self-management and diabetes-related health outcomes should be explored, taking into consideration the biological and psychosocial impact of the disease on adults diagnosed with T2D.

The psychological impact of T2D was not limited to depression; it includes also the symptoms of anxiety and stress (Fisher et al., 2008; Lloyd, Smith, \& Weinger, 2005). Patients diagnosed with diabetes are at a higher risk (25\%) of developing anxiety symptoms than people without diabetes (Smith et al., 2013). Conversely, individuals with 
higher levels of anxiety are at an increased risk of developing T2D (Engum, 2007). Anxiety occurs as a result of excessive stress due to a threating life event that has already happened or is expected in the future; this in turn can lead to a state of fear that interferes with daily-life functioning (American Psychiatric Association [APA], 2013). Obviously, the diagnosis of diabetes and its related burden on the lives of diagnosed people would be a possible threat.

Anxiety symptoms are positively correlated with depressive symptoms. In addition, Collins-McNeil (2006) found negative correlations between perceived functional social support and both anxiety and depressive symptoms. Functional social support decreased the odds of diagnosis of depression and anxiety among African Americans with T2D (Thomas, Jones, Scarinci, \& Brantley, 2007).

Besides depression and anxiety, stress related to diabetes is another psychological burden that affects the lives of persons with T2D (Hilliard et al., 2016; Walker, Gebregziabher, Martin-Harris, and Egede, 2014). Stress is linked to diabetes in many different ways, stress may be conceptualized as the psychological reaction to the overwhelming responsibilities that are associated with the diagnosis of diabetes or its related management (Lloyd, Smith, \& Weinger, 2005). On the other hand, stress is thought to affect persons' control of diabetes and consequently their health outcomes (Lloyd, Smith, \& Weinger, 2005; Penckofer, Doyle, Byrn, \& Lustman, 2014).

The impact of stress on T2D persons' outcomes is varied by race/ethnicity (Hilliard et al., 2016; Kim et al., 2009; Shallcross et al., 2015). Shallcross and colleagues found that under conditions of high stress, African Americans experience poorer mental 
health. They also found that high stress impedes the effects of functional social support on the mental health of African Americans with T2D.

In conclusion, depression, anxiety, and stress are associated with diagnosis of T2D. These psychological disorders could be also the precursor for developing T2D, especially among African Americans. Depression, anxiety, and stress impede the ability of the person to perform self-care behaviors, consequently worsening the outcomes of T2D both physically and psychologically (Gonzalez et al., 2008; Samuel-Hodge, Watkins, Rowell, \& Hooten, 2008; Wu et al., 2013).

Diabetes self-management includes lifestyle changes that are important to minimize and prevent complications (ADA, 2015). Diabetes self-management requires persons diagnosed with $\mathrm{T} 2 \mathrm{D}$ to change their behaviors and maintain a diabetes-related healthy lifestyle (Haas et al., 2013). These lifestyle changes are related to diet, physical exercise, medications, and personal care behaviors, such as glucose monitoring and foot care. Diabetes self-management is challenging, especially for older adults (Suhl \& Bonsignore, 2006) and African Americans (Murrock, Taylor, \& Marino, 2013). Murrock and colleagues' (2013) found that African American women diagnosed with T2D had challenges in self-management of their dietary regimens. These challenges were attributed to difficulties in changing dietary behavior, lack of information, and lack of support.

Lack of functional social support along with other barriers, such as physical inactivity and depression, were among the challenges that older adults may face in managing T2D (Suhl \& Bonsignore, 2006). Low income, other comorbidities, the presence of diabetes-related complications, and lack of financial support may also hinder 
older adults' self-management ability (Bayliss, Ellis, \& Steiner, 2007). Middle-aged adults were also a disadvantaged group when self-management and T2D outcomes were measured (Ahn, Smith, Dickerson, \& Ory, 2012; Chiu \& Wray, 2010). Physical and mental wellbeing of older and middle-aged adults were associated with higher levels of functional social support (Gallegos-Carrillo, García-Peña, Durán-Muñoz, Flores, \& Salmeron, 2009; Sukkarieh-Haraty \& Howard, 2015).

Social support dimensions promote positive behavior change and selfmanagement that leads to improved biobehavioral and psychosocial outcomes (CollinsMcNeil et al., 2009; Egede \& Osborn, 2010; Osborn \& Egede, 2010). Social support is defined as the presence of a social network that exhibits supportive reinforcing behaviors that are categorized functionally as instrumental, informational, emotional, and appraisal (Langford, Bowsher, Maloney, \& Lillis, 1997). Food preparation and assisting with medications are examples of instrumental support. An active reciprocal exchange of information is the core of informational support (Finfgeld-Connett, 2005). Appraisal support is the intangible (verbal and nonverbal) support that reinforces changes in patient behavior related to self-management (Vest et al., 2013). Emotional support occurs through the empathetic expression of feelings, which is mainly varied by the nature of the relationship between the patient and the caregiver (Furler et al., 2008).

The functional attributes of social support described by Langford et al. (1997) were frequently used throughout the literature (Strom \& Egede, 2012). Psychosocial variables (e.g., sex, culture, and race of both the support person and the patient are impacting the effectiveness of social support dimensions (Cosansu \& Erdogan, 2013; 
Hempler, Ekholm, \& Willaing, 2013; Mathew et al., 2012; Strom \& Egede, 2012;

Venkatesh \& Weatherspoon, 2013; Vest et al., 2013).

Social support dimensions are linked to a group of outcomes that are related to the wellbeing of patients with T2D. These outcomes are classified into three categories: $(-1)$ positive health behavior change (Strom \& Egede, 2012); (2) improved self-management, adherence to regimen, and glycemic control (Cosansu \& Erdogan, 2013; Nicklett \& Liang, 2010; Strom \& Egede, 2012; Vest et al., 2013), and (3) improved mental health and psychosocial outcomes (Finfgeld-Connett, 2005; Fortmann, Gallo, \& PhilisTsimikas, 2011; Glasgow et al., 2012; Strom \& Egede, 2012). Conversely, negative outcomes were observed. These negative consequences are associated with the patient's feelings of being a burden to the social network members (Strom \& Egede, 2012), being stigmatized due to the diagnosis of T2D (Bhattacharya, 2012), and being criticized for following the T2D therapeutic regimen (Mayberry \& Osborn, 2012).

Although African Americans reported fear and uncertainty in following therapeutic guidelines, they consider their families the main source of support for T2D self-management, followed by their friends and churches (Bhattacharya, 2012). Furthermore, Ahia, Holt, and Krousel-Wood (2014) found that glycemic control among African Americans differed by the source of support; patients who received support from a non-spouse family member or a friend had worse A1C than those received support from a spouse or a health care professional.

Age is another variable that affects the perception of social support dimensions among African Americans with T2D (Hessler, Fisher, Naranjo, \& Masharani, 2011). Hessler and colleagues (2011) found that younger African Americans (ages 29-49) were 
less likely to trust their health care providers, less likely to rely on their close partners, less involved in the church, and had poorer glycemic control than their older counterparts. In addition, other variables such as self-efficacy, environmental barriers, and body image should be taken into consideration when studying the effects of social support dimensions on self-management and thus glycemic control among African Americans (Komar-Samardzija, Braun, Keithley, \& Quinn, 2012).

Studies on the impact of social support dimensions on diabetes biomarkers and psychosocial outcomes of African Americans with T2D are limited; few studies have been conducted recently. A literature review was performed using five databases looking for the peer-reviewed studies published in the last five years that were written in English. Only 10 studies met the inclusion criteria; three of them were qualitative studies (Bhattacharya, 2012; Murrock, Taylor, \& Marino, 2013; Nundy, Dick, Solomon, \& Peek, 2013), which limit the generalizations of their conclusions due to small sample sizes. In addition, three of the reviewed studies were conducted only with women (KomarSamardzija, Braun, Keithley, \& Quinn, 2012; Miller, 2011; Murrock et al., 2013). Thus, there is a need to quantify the impact of social support dimensions on diabetes biomarkers and psychosocial outcomes and the mediational effect of self-management on the relationship between social support dimensions and health outcomes of African American adults with T2D.

Pender's Health Promotion Model (HPM) was used as a theoretical framework for this study. Pender's HPM first appeared in 1982 and was revised in 1996 based on theoretical and empirical perspectives (Pender, 2011). The primary purpose of the model is to assist nurses to better understand the determinant variables of health behavior that 
will form a basis for behavior change leading to a healthier lifestyle (Pender, 2011, p. 3). The components of the HPM are organized into three categories (Figure 1): individual characteristics and experiences, behavior-specific cognitions and affect, and behavioral outcome/ health-promoting behavior. Based on the evaluation of the HPM, there are several concepts and relationships that could be useful to answer the question related to the relationships between social support dimensions, self-management, diabetes biomarkers and psychosocial outcomes in African American adults with T2D.

The relationships of social support dimensions with self-management behaviors, diabetes biomarkers, and psychosocial outcomes in African American adults with T2D was conceptualized within the three major components of the HPM. The influences of being African American along with the participants' sociodemographic characteristics were conceptualized under the "individual characteristics and experiences" component (personal factors: biological, psychological, and sociocultural). Social support dimensions were congruent with the understanding of the "behavior-specific cognitions and affect" component within the concept of "interpersonal influences," self-management behaviors were congruent with the "commitment to plan of action" concept within the "behavioral outcome", and diabetes biomarkers and psychosocial outcomes were congruent with the "health-promoting behavior" concept (Figure 2).

The conceptualization of the variables within the HPM will help in delineating the relationships between the concepts of interest. A modified model of the HPM was created (Figure 3). This model showed that a possible direct relationship of the sociodemographic characteristics on diabetes health outcomes should be taken into consideration when studying the impact of social support dimensions on these outcomes. In addition, a direct 
relationship is expected between social support dimensions and health outcomes. Furthermore, self-management behaviors are expected to mediate the relationship between social and health outcomes of T2D.

The primary purpose of this manuscript was to systematically review the measures of social support used in prior research with persons diagnosed with T2D. Conceptual definitions of social support are presented then the state of measurement of social support within the T2D literature is critically reviewed. A detailed description of the most commonly used measures and their psychometric properties is presented followed by a comparison of the strengths and weaknesses of these measures. Future directions in the measurement of social support in persons with T2D are recommended.

Chapter Three is a study of the relationships of sociodemographic characteristics (age, age at diagnosis, sex, race/ethnicity, marital status, education, and income) with adherence to the ADA dietary guidelines and A1C among adults diagnosed with T2D. The data for this study were obtained from the National Health and Nutrition Examination Survey (NHANES) from 2007-2012. Results and conclusions were presented for this study in addition to a group of limitations and future recommendations.

Chapter Four presents the main study of this dissertation. This study explored the relationships between the various dimensions of social support, self-management, and health outcomes in African American adults with T2D. Chapter Five is the final chapter that includes a synthesis of the results, a summary of the conclusions of the previous chapters, and recommendations for future studies. 
Figure 1. Revised Health Promotion Model

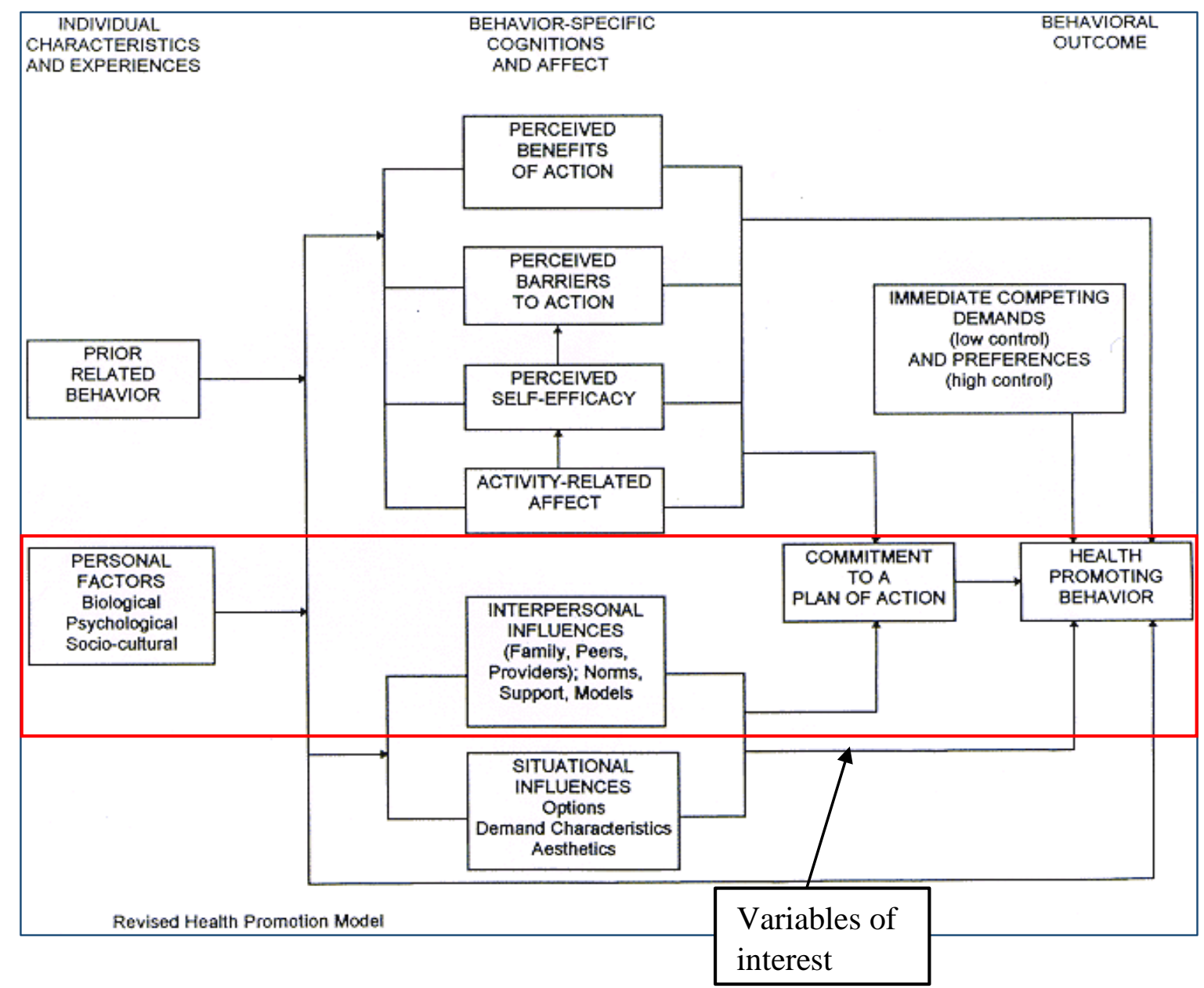

Adapted from Pender (2011). Retrieved from http://nursing.umich.edu/faculty-staff/nolaj-pender 
Figure 2. Variables of Interest as Conceptualized within the HPM

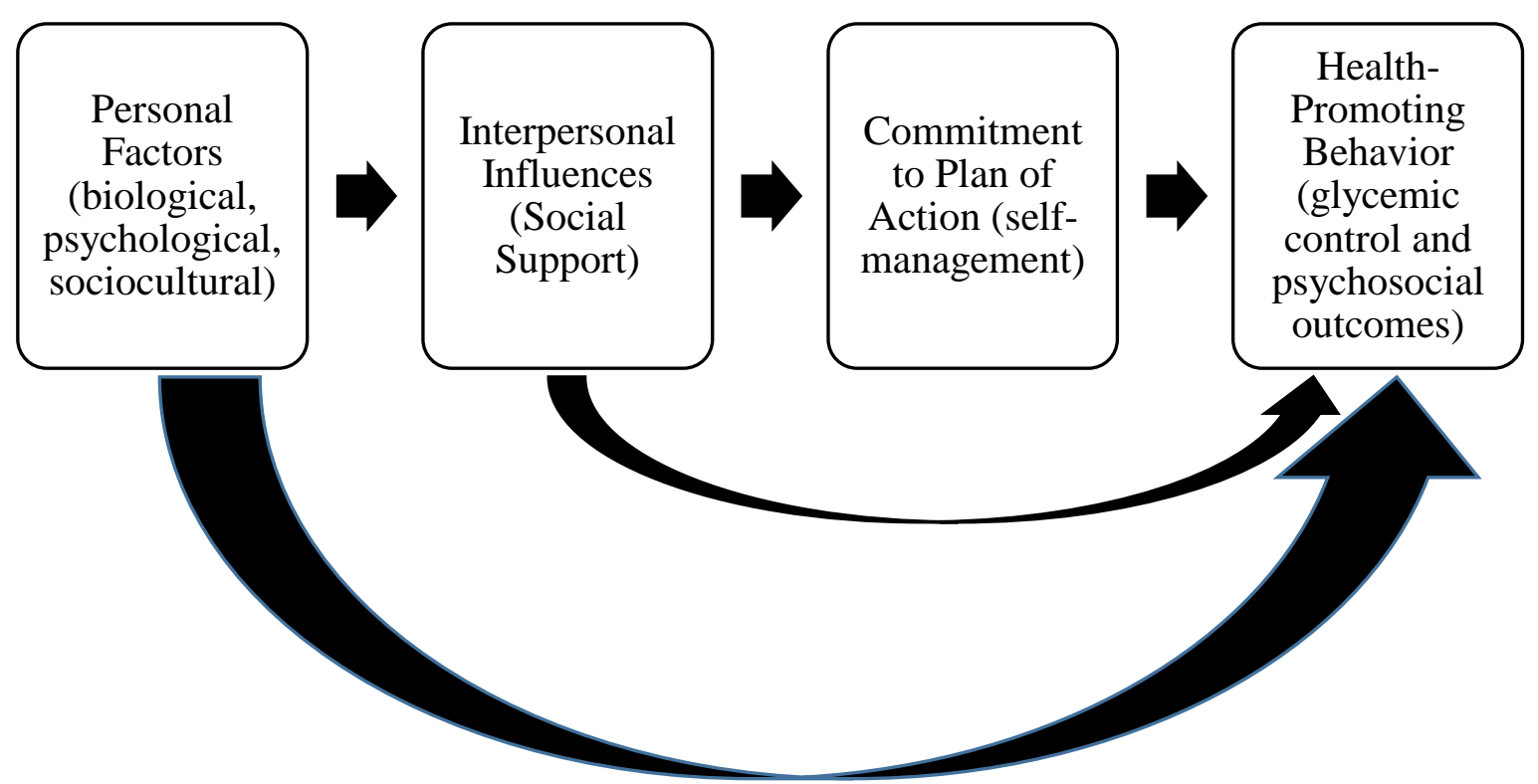


Figure 3. Measurement of the Variables of Interest as Conceptualized within the HPM

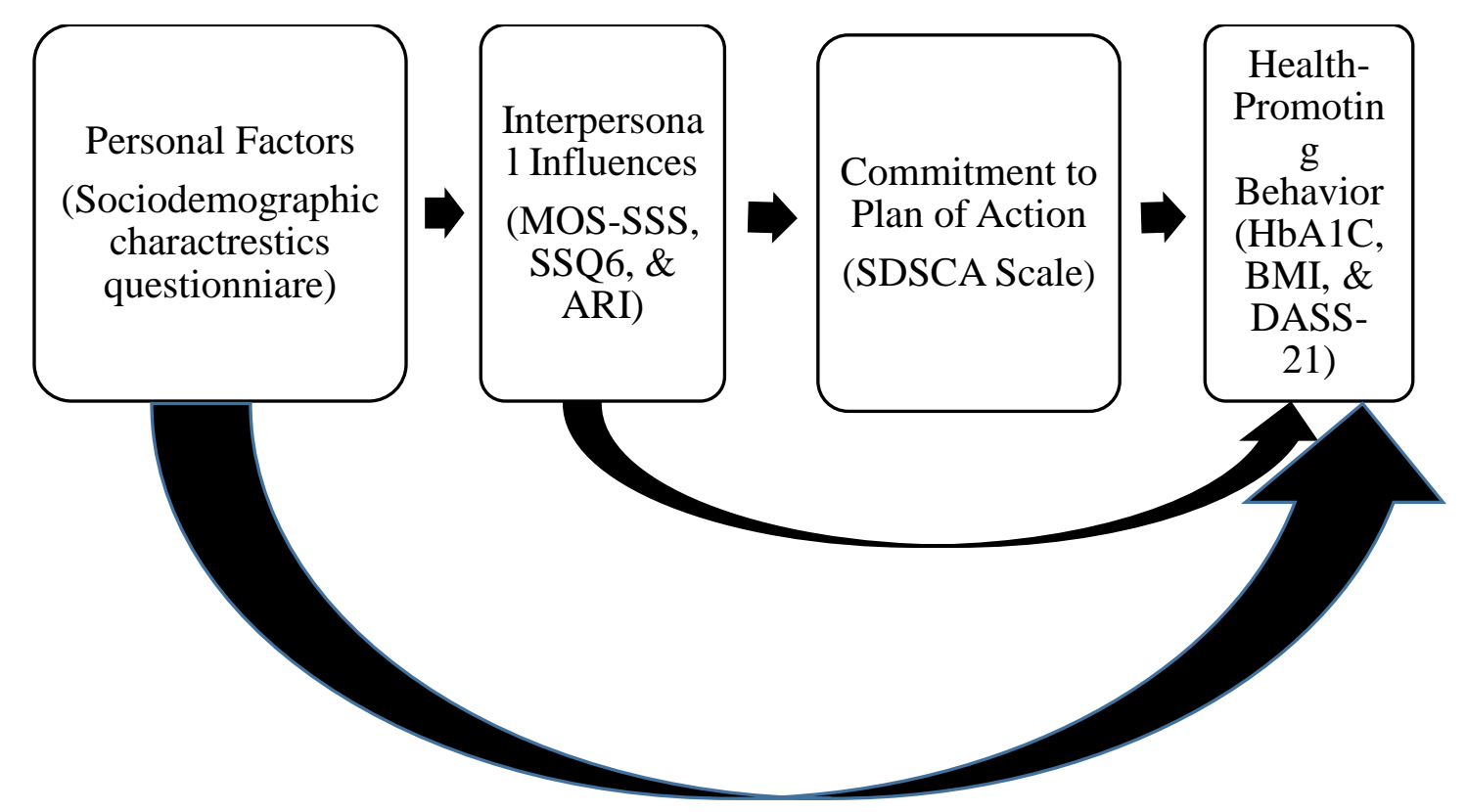




\section{CHAPTER II}

\section{SYSTEMATIC REVIEW AND CRITICAL ANALYSIS OF MEASURES OF SOCIAL SUPPORT USED IN STUDIES OF PERSONS WITH TYPE 2 DIABETES \\ Introduction}

It is estimated that 29.1 million of the United States population have diabetes (Centers for Disease Control and Prevention [CDC], 2014). Ninety percent to 95\% have Type 2 diabetes (T2D; (American Diabetes Association [ADA], 2014). T2D is associated with a relative insulin deficiency and/or insulin resistance rather than absolute insulin deficiency (Chlebowy \& Wagner, 2005). Complications can be minimized or prevented by lifestyle changes that constitute the diabetes self-management (ADA, 2014). It is essential for patients diagnosed with diabetes to modify their health-related behaviors to gain control over their T2D. Social support was positively related to improved selfefficacy and self-care which in turn predicted glycemic control (Cosansu \& Erdogan, 2013). Social support promotes self-efficacy, self-competence, and self-confidence in self-management of T2D (Ahia, Holt, \& Krousel-Wood, 2014; Osborn, Bains, \& Egede, 2010; Walker, Gebregziabher, Martin-Harris, \& Egede, 2014). Bhattacharya (2012) explored the psychosocial variables that underlie self-management behaviors following a T2D diagnosis. Social support was essential to strengthen the patient's belief in his or her ability to engage in a behavior change and to strengthen the commitment to adhere to a T2D regimen. Hempler, Ekholm, and Willaing (2013) studied the differences in social relations between the general population and patients diagnosed with T2D. Those with 
T2D tended to have fewer social relations as a result of the diagnosis itself and the severity of the disease.

Measures used to assess social support vary across studies of persons with T2D. Most measures used were developed and validated with populations not diagnosed with T2D. Some of these measures were developed and evaluated with college students (e.g., the Multidimensional Scale of Perceived Social Support [MSPSS]; Zimet, Dahlem, Zimet, \& Farley, 1988). Others were developed for patients with chronic diseases but not specifically for patients with T2D (e.g., the Chronic Illness Resources Survey [CIRS]; Glasgow, Toobert, Barrera, \& Strycker, 2005). Other measures were not well-established for use with patients with T2D. For example, Nielsen, de Fine Olivarius, Gannik, Hindsberger, and Hollnagel (2006) asked patients whether they received the support and understanding they needed from family and significant others.

The purpose of this article was to systematically review the measures of social support used in prior research with patients diagnosed with T2D. Conceptual definitions of social support are presented then the state of measurement of social support within the T2D literature is critically reviewed. A detailed description of the most commonly used measures and their psychometric properties is presented followed by a comparison of the strengths and weaknesses of these measures. Future directions in the measurement of social support in persons with T2D are recommended.

To assess the quality of a measure, a conceptual analysis and the objectives of the measure must be taken into consideration (Waltz, Strickland, \& Lenz, 2010). Social support is defined as the informational, emotional, instrumental, and appraisal reinforcing support derived from the existing support network (Langford, Bowsher, Maloney, \& 
Lillis, 1997). According to Streiner, Norman, and Cairney (2015), a critical review of the existing instruments should be performed to determine the appropriateness of instruments to measure the concept of interest. This review should include a careful assessment of the items of the scale and be supplemented by the evidence that supports the use of the instrument. Streiner et al. identified specific dimensions that should be reviewed, which are face validity, content validity, reliability/internal consistency, criterion-related validity, construct validity, feasibility, sensitivity, and specificity of the instrument. These criteria were evaluated for measures included in this review.

\section{Theoretical Framework}

This review was based on an adaptation of the peer support conceptual model of Heisler (2006). In this model (Figure 4), informational and emotional social support are critical for increasing self-efficacy, perception of social support, positive mood, and understanding of self-care. In turn, increases in these factors lead both directly and indirectly to improvement in health-related quality of life, self-management, and diabetes control, and fewer diabetes-related complications. This model helps to increase our understanding of the relationship between social support and diabetes-related outcomes and provides a foundation for future studies to improve outcomes of persons with T2D.

\section{Methods}

A literature search was performed using the following keywords: $T 2 D$ OR diabetes, AND self-management, AND diabetes outcomes OR glycemic control OR psychosocial outcomes, AND social support $\mathrm{OR}$ social support networks. Cumulative Index to Nursing and Allied Health Literature (CINAHL), MEDLINE, PubMed, 
PsycINFO, and Google Scholar databases were searched for peer-reviewed articles published in English between 2005 and 2016. The search yielded 48 non-duplicated articles (Figure 5). Titles, abstracts, and methods sections were reviewed for the following inclusion criteria: (a) the sample included patients diagnosed with T2D; (b) measurement of social support; and (c) the impact of social support on patients' selfmanagement of T2D, glycemic control, and psychosocial outcomes was studied. Studies involving animals, Type 1 diabetes, gestational diabetes, and qualitative studies were excluded from the review. Meta-analyses and systematic reviews were also not included in this review. Forty-eight articles met the inclusion and exclusion criteria. Most of the studies were cross-sectional (79\%); $10 \%$ were randomized controlled trials. Three were longitudinal studies, one was a pretest-posttest quasi-experimental study, and one was a mixed methods study. The following data were extracted from the articles: author, publication year, study design, purpose, type (s) of social support measure used, type (s) of social support measured, and reliability and validity information. The review of measures also was based on the Streiner et al. (2015) criteria as well as the utility of the measure for studying the impact of social support on outcomes of patients diagnosed with T2D.

\section{Results}

\section{Conceptual Definitions of Social Support}

Conceptual definitions of social support are discussed in self-management and outcome studies of T2D. The definitions of social support (Table 1) convey the need for a uniform description of the attributes that delineate the concept. In their concept analysis of social support, Langford et al. (1997) identified four attributes: (a) instrumental, (b) 
informational, (c) appraisal, and (d) emotional support. Instrumental support in the context of T2D requires that social support sources, such as family members, provide the patient with tools that will help him or her change health behaviors and adhere to the regimen, such as preparing diabetic food or monitoring blood glucose. Informational support is characterized by active reciprocal exchange of information (Finfgeld-Connett, 2005); it could be provided by health care professionals, family members, or friends. Appraisal support is an intangible support that positively reinforces changes in patient behavior in following predetermined self-management guidelines (Vest et al., 2013). Emotional support is achieved through the empathetic expression of feelings that is determined mainly by the nature of the relationship between the patient and the caregiver (Furler et al., 2008).

These attributes of social support described by Langford et al. (1997) were consistently used throughout the literature (Strom \& Egede, 2012). Venkatesh and Weatherspoon (2013) mentioned other attributes such as companionship and empowerment. They argued that companionship provides an external source of motivation and support, whereas Langford et al. insisted that companionship is an intrinsically motivated attribute and not related to social support. Furthermore, connectedness, relatedness, and a feeling of social support are used to describe social support (Bhattacharya, 2012). In addition, personal variables such as gender, culture, and race of both the support person and the patient were important variables that strengthen or hinder social support (Cosansu \& Erdogan, 2013; Hempler et al., 2013; Mathew et al., 2012; Strom \& Egede, 2012; Venkatesh \& Weatherspoon, 2013; Vest et al., 2013). For example, Strom and Egede (2012) found that racial differences had a great impact on the 
mode of delivery of social support. Gender also is an important variable. Mathew et al. (2012) found that men's and women's experiences with self-management of T2D were different and require gender-sensitive support.

A group of preexisting conditions and events necessary for social support to occur were identified in the literature. Langford et al. (1997) described three preexisting conditions to social support: social network, social embeddedness, and social climate. Having a social network is an integral prior condition to social support; it is the structure in which social support functions. Social embeddedness denotes the strength of social connectedness required to draw support. The term social climate describes the characteristics of the environment where social support occurs. These preexisting conditions have been described consistently throughout the literature and are crucial for social support to occur (Strom \& Egede, 2012).

The literature on social support included other qualities that should precede the concept; among those were informational and instrumental needs (Finfgeld-Connett, 2005). The other T2D-related needs that should be fulfilled are emotional and psychological needs (Finfgeld-Connett, 2005). These emotional needs are feelings fulfilled by social support and they impact the connectedness and relatedness (Bhattacharya, 2012).

In summary, social support is the presence of a supportive social network that exhibits supportive, reinforcing behaviors, whether tangible or intangible reinforcement, which promote positive behavior change and disease self-management that lead to improved biobehavioral and psychosocial outcomes of patients with T2D. Social network members could be health care professionals, families, spouses, children, coworkers, 
church members, community members, or internet support groups. The facets of positive reinforcement include instrumental, informational, emotional, and appraisal support.

\section{Evaluation of Measures Used to Assess Social Support}

Face validity, feasibility, sensitivity, and specificity of the social support measures were not reported in any of the studies reviewed (Table 2). Only one study evaluated criterion-related validity of the measure of social support used (Barrera et al., 2002). Ninety-two percent of the studies used a single measure to assess social support. Only four studies (Barrera et al., 2002; Barrera et al., 2006; Brody et al., 2008; Karlsen et al., 2012) used more than one measure of social support. Of the studies reviewed, 25\% were conducted using the Medical Outcomes Study Social Support Survey (MOS-SSS) as a measure of social support; most of these studies were cross-sectional. The construct validity of the MOS-SSS was supported by most of the studies; however, the internal consistency reliability was reported in only one study. The second most commonly used measure was the MSPSS (8\%). Construct validity and internal consistency reliability were supported for this measure.

Most studies used measures that assess the availability of perceived support. Four studies (Fortmann et al., 2011; Fortmann et al., 2010; Piette et al., 2013; SukkariehHaraty \& Howard, 2015) used measures of the actual received support. Ninety percent of studies used measures that assess general support, and only $10 \%$ of the studies used diabetes-specific measures.

Most of the studies (83\%) used measures that were designed to assess for positive and constructive support whereas only $17 \%$ of the studies used measures that assess both 
positive and negative supportive behaviors exhibited by social network members. Fortytwo percent of the studies used measures that assess all aspects of functional support (tangible, emotional, informational, and instrumental), whereas the rest of the studies (58\%) used measures that assess for one or two types of functional support.

\section{The Desired Outcomes of Social Support}

The outcomes of social support can be grouped into three categories: (a) improvement in self-management of T2D that is manifested in regimen adherence (Cosansu \& Erdogan, 2013; Nicklett \& Liang, 2010; Strom \& Egede, 2012; Vest et al., 2013), (b) positive health behavior change (Strom \& Egede, 2012), and (c) improvement in mental health and psychosocial outcomes (Finfgeld-Connett, 2005; Fortmann et al., 2011; Glasgow et al., 2012; Strom \& Egede, 2012). In addition to these favored outcomes, negative consequences were observed. Bhattacharya (2012), Strom and Egede (2012), and Mayberry and Osborn (2012) discussed the negative impact of social support on a patient's self-management behaviors and emotional outcomes. These negative consequences were associated with the patient's feelings of being a burden to the social network members (Strom \& Egede, 2012), being stigmatized because of the diagnosis (Bhattacharya, 2012), and being criticized for following certain regimens (Mayberry \& Osborn, 2012).

\section{Most Frequently Used Measures of Social Support Used in T2D Self-Management and Outcome Studies}

Social support was assessed in terms of the availability of its contributing functional aspects (functional support). Sherbourne and Stewart (1991) created the MOS- 
SSS to assess for the availability of informational, emotional, instrumental, tangible, affectionate, and positive social interaction. Other measures of social support assessed the structural aspect of support (Social Support Network Inventory [SSNI]; Flaherty et al., 1983) such as the size of support network or the number of the available support persons. Other measures were designed to assess the degree of satisfaction with or the quality of the perceived social support, in addition to the structure such as the Social Support Questionnaire (SSQ6) by Sarason et al. (1987).

Social support measures were also constructed to assess social support specific to health-related behaviors such as dieting and exercising (Sallis, Grossman, Pinski, Patterson, \& Nader, 1987). In addition, two distinctions were made using the measures of social support: the received versus perceived social support. Perceived social support was defined as belief of the availability of support from its various network resources, whereas received social support is the report of the actual support received (Gottlieb \& Bergen, 2010). Another aspect of social support is the directionality of the support to determine whether the support is unidirectional or mutual (Gottlieb \& Bergen, 2010). Social support measures were designed also to assess the perceived support in different age groups. For example, Zimet et al. (1988) developed the MSPSS to assess adolescents' subjective perception of support derived from various resources.

In conclusion, a good measure of social support is defined by the stated objectives of study in addition to the degree of inclusiveness of the aspects of the social support. Some of the measures were developed to assess the quality or quantity of social support and others assess the functional or structural characteristics of support. Although some of 
the measures were designed and evaluated in specific populations, others could be used as generic measures in different populations (Gottlieb \& Bergen, 2010).

\section{Comparison of Three Measures of Social Support}

The MOS-SSS, the MSPSS, and the SSQ6 were selected for further review and evaluation of their psychometric properties (Table 3). The MOS-SSS and the MSPSS were mostly commonly used in the reviewed studies, and their use was supported by their very good reliability and validity. The MOS-SSS assess for various dimensions of perceived functional support, whereas the MSPSS assess for the adequacy of support from family, friends, and significant others. This means that these two measures assess different types of social support. In addition, both of these measures were brief which makes them more appropriate to use with patients with T2D, especially, if we consider the burden on the patients and the time factor. The SSQ6 was developed to assess different types of social support, namely, the structure of support, the number of support persons, and the satisfaction with support. The SSQ6 is also a brief measure of social support that has good psychometric properties which makes it worthy for inclusion in this critical analysis.

\section{Medical Outcomes Study Social Support Survey. The MOS-SSS was}

developed by Sherbourne and Stewart (1991) as a part of a longitudinal Medical Outcomes Study (MOS) that assessed the outcomes of care of patients with chronic conditions. The items included in the MOS-SSS were generated from a literature review of the exiting social support measures. MOS-SSS was developed to assess the perception of the availability of functional support. Structural support was not assessed by the items generated. The authors of the MOS-SSS intended to measure how various functions of 
social support were related to health outcomes. They did not intend to measure received support because they thought it did not reflect the available amount of support for the person (Sherbourne \& Stewart, 1991).

The MOS-SSS is a brief, comprehensive measure of available functional support. The MOS-SSS is composed of 19 items that assess emotional support, informational support, tangible support, positive social interaction, and affectionate support. Informational and emotional subscales were merged together to form the informationalemotional subscale because of the overlap between items. The respondents were asked to indicate the available amount of support by selecting one of the following choices: (a) none of the time, (b) a little of the time, (c) some of the time, (d) most of the time, and (e) all of the time. An item was added to the measure asking for the number of support persons, such as relatives and friends, who were available to the respondent. In a sample of 2,987 who were diagnosed of one or chronic disease at the time of the study, internal consistency reliability coefficients (Cronbach's alpha) for the subscales (EmotionalInformational Support, Tangible Support, Positive Social Interaction, and Affectionate Support) ranged between .91 and .96 . The alpha for the total scale was .97 . The testretest reliability correlation was .78 for the overall support measure; subscales' correlations range between .72 and .76 . All of the items showed strong correlations with their hypothesized subscales (.72).

Face validity was demonstrated and a pilot study was conducted to assess the internal consistency of the measure. Convergent validity was demonstrated by evaluating the correlations between the items and their related subscales. Emotional-Informational Support, Tangible Support, Positive Social Interaction, and Affectionate Support 
subscales were not correlated with the measures of loneliness and other measures of social function, thus supporting discriminant validity. Both principal component analysis and confirmatory factor analysis were performed; the results of both analyses supported the hypothesis of the existence of the four subscales. Thus, Sherbourne and Stewart (1991) suggested that a score for each subscale could be calculated by averaging the scores of each item in the subscale and then transforming the score to range from 0 to 100 , such that higher scores indicate more available support. The total support index can also be calculated using the average and transformed approaches.

The MOS-SSS showed strong evidence of reliability and validity as a measure of social support. However, it was developed to measure the functional aspects of support which means that other aspects of support, such as the structure and satisfaction with support, cannot be assessed using the MOS-SSS. In addition, the MOS-SSS does not include an assessment of support available from other resources such as health care workers and church members, which are considered a valuable sources of support especially for African American adults with T2D (Samuel-Hodge et al., 2009). In addition, it was suggested that this measure could be used in general populations; however, there are no available psychometric evaluations of the measure in the general population which limits its utility (McDowell, 2006).

The MOS-SSS subscales distinguished between the four types of support. Sherbourne and Stewart (1991) did not demonstrate that informational and emotional supports are distinct types of support. This understanding of informational and emotional support could be attributed to the fact that people perceive those two types of support as one type because they are transmitted through the same vehicle of communication 
(Sherbourne \& Stewart, 1991). Also, the distinction was made between affectionate support, which is the behavioral manifestation of emotions, and emotional support. Although it may appear like affectionate support and emotional support measure the same construct, further evaluations are recommended to determine whether there is a difference between these two attributes (Sherbourne \& Stewart, 1991).

The MOS-SSS has been translated into French (Anderson, Bilodeau, Deshaies, Gilbert, \& Jobin, 2005), Chinese (Yu, Lee, \& Woo, 2004), and Taiwanese (Shyu, Tang, Liang, \& Weng, 2006). The results of the psychometric evaluation of the French and Chinese versions of the MOS-SSS support the dimensionality of the English version. The Taiwanese version, however, supported a two-factor solution, namely, emotional support and tangible support. All of the versions including the original English version had strong internal consistency coefficients which indicated that an issue of redundancy was obvious in the items of the MOS-SSS. The issue of redundancy is a controversial term; redundancy is needed to capture the concept of interest; however, it should be evaluated carefully (DeVellis, 2012).

Social Support Questionnaire shortened version. The SSQ6 was developed by Sarason and colleagues (1987) from the 27-item social support questionnaire developed by Sarason et al. (1983). The SSQ6 was developed to measure perceived social support in terms of the number of support persons and the satisfaction with the support derived from these persons. The SSQ6 is composed of 12 items, 6 items for each category. The responses for the number $(\mathrm{N})$ items range from no one to 9 persons for each item. Six responses were used for satisfaction (S), which ranges from very satisfied to very dissatisfied. The score of the SSQ6 is calculated by taking the average of the number of 
support persons to get the SSQN score, which ranges from 0 to 9 , and the average of the satisfaction score, which ranges from 1 to 6. Sarason et al. (1983) used principal factor analyses to explore the dimensionality of the support $\mathrm{N}$ items and the support $\mathrm{S}$ items. They found that each category of items was unidimensional and that the correlation between the scores on both categories was .34 . This result indicated that the $\mathrm{N}$ items and $\mathrm{S}$ items measure different concepts.

Sarason et al. (1987) suggested the use of the short form of the Social Support Questionnaire (SSQ) to lessen the burden on subjects when time constraints are an issue for subjects and for researchers. Sarason et al. (1987) administered the full SSQ along with other measures of social support to three different samples. Then they performed factor analyses on the $\mathrm{N}$ items and $\mathrm{S}$ items. The highest six loadings on both categories of items were averaged to form the number-satisfaction six items scale. Then, the correlations of SSQ6 with the full SSQ were evaluated and found to be very strong (.95.96) for both categories of items. In addition, the correlations between SSQ6 scores and other social support measures were comparable with the results of the full SSQ correlations. For example, the correlation between the satisfaction items' scores of the SSQ with the Interpersonal Support Evaluation List (ISEL; Cohen et al., 1985) was .66 and the SSQ6 satisfaction items' score correlation with the ISEL was .62. The correlations between the SSQ6 and Beck Depression Inventory (BDI; Beck, Ward, Mendelson, Mock, \& Erbaugh, 1961) scores were evaluated. The SSQ6 N and S scores were negatively correlated with BDI scores; these correlations were comparable with correlations between the full SSQ and the BDI. Thus, the concurrent and predictive validity of the SSQ6 were supported, and they were comparable to the full SSQ results. 
The internal consistency of the SSQ6 was evaluated in samples of 217 college students. The Cronbach's $a$ for the SSQ6 ranged between .90 and .93 for $\mathrm{N}$ and S items. This result was comparable to the coefficients of reliabilities for the full SSQ which ranged between .96 and .98 for the $\mathrm{N}$ and the $\mathrm{S}$ items. Inter-item correlations, corrected item-total correlations, and test-retest reliability were not evaluated.

The SSQ6 demonstrated good reliability and validity as a measure of social support; however, its performance was evaluated only with samples of college students (Sarason et al., 1987). Another issue identified by Sarason et al. (1987) was the unidimensionality of the SSQ6; the items included in this measure were intended to assess the global affective domain of social support. The tangible and informational support dimensions were not covered by the SSQ6 items. Furthermore, the SSQ6 was intended to measure the perceived support but not the actual received support. Finally, the validation studies of the SSQ6 were conducted only by the authors of this measure (McDowell, 2006).

Although the SSQ6 was developed and validated with college students, it has been used widely in different populations including those with chronic conditions such as dementia (Clay, Roth, Wadley, \& Haley, 2008), heart failure (Friedman, Son, Thomas, Chapa, \& Lee, 2013), rheumatoid arthritis (Treharne, Lyons, \& Kitas, 2004), and hypertension (Steffen, Hinderliter, Blumenthal, \& Sherwood, 2001). The full SSQ has been used with patients diagnosed with T2D to study the impact of social support on their outcomes (Chlebowy \& Garvin, 2006). However, none of these studies reported information about the reliability and validity of the SSQ6. Another critique of the SSQ and SSQ6 was the breadth of coverage of items developed for both measures; McDowell 
(2006) discussed the effectiveness of relying on counting the number of support persons to estimate perceived social support. McDowell argued that the same person could be included in each and every item of the SSQ6, which would inflate the estimation of number of support persons.

Regarding the reliability and validity of the SSQ6, the shortening procedure should be discussed. Sarason et al. (1987) developed the SSQ6 based on their selection of the items with the strongest loadings on the full SSQ; their justification for doing so was to reduce subject burden. Although there is no universal procedure to shorten the existing measures (Dekker et al., 2011), Sarason et al. (1987) inappropriately conceptualize the shortening process and relied only on one statistical measure (Coste, Guillemin, Pouchot, \& Fermanian, 1997) to shorten the full SSQ, which makes the time consideration and subject burden the only reasons to use the SSQ6.

The Multidimensional Scale of Perceived Social Support. The MSPSS was developed by Zimet and colleagues (1988) to assess the perceptions and adequacy of social support from family, friends, and significant others. They developed a short measure of perceived social support that would be useful in situations where time consideration was an issue. Zimet et al. (1988) created a 24-item measure that addresses respect, popularity, and perceived social support. Several pilot studies were conducted to evaluate the factor structure that underlies the original 24 items; the factor analysis and the conceptual analysis of the items resulted in retaining 12 items that addressed perceived social support and excluding the respect and popularity items.

The MSPSS 12-item version intended to assess the perceived social support from family, friends, and significant others. For example, the study participant might state, 
"My family really tries to help me." The responses for the 12 items were assessed on 7point Likert scale, ranging from very strongly agree to very strongly disagree. The total score of the MSPSS is calculated by averaging the scores of the 12 items which results in the mean score; the higher the score, the higher the level of perceived social support. Three sub-scores could be calculated for perceived support from family, friends, or significant others. Zimet et al. (1988) suggested that, for both total score and subscores, a score of 1-2.9 is a low score, a score of 3-5 is a moderate score, and a score of 5.1-7 is a high score. Higher scores indicate more support.

The MSPSS and other measures of depression and anxiety were introduced to a group of undergraduate college students to assess its dimensionality, reliability, and construct validity. A principal component analysis with a direct Oblimin rotation was conducted. Three distinctive factors were identified: family, friends, and significant others. Perceived social support, as assessed by the MSPSS, was negatively related to the self-reported depression and anxiety, with different magnitudes for family, friends, and significant others. In addition, the correlations between the MSPSS subscales were examined; Zimet et al. (1988) found that friends' scores were moderately correlated with significant other scores $(r=.63)$, and that family scores had low correlations with both friends and significant others ( $r=.34$ and .24 , respectively).

The internal consistency was evaluated using Cronbach's alpha coefficient. The results of Zimet et al. (1988) study showed that the MSPSS demonstrated very good reliability with family, friends, and significant others reliability coefficients, which were: $.87, .85$, and .90 , respectively. The coefficient for the overall scale was .88 . Test-retest reliability (2- to 3 -month period) was also checked; the correlations were $.75, .85$, and .72 
for family, friends, and significant others, respectively. The correlation coefficient for the whole scale was .85. This strong correlation coefficient means that the MSPSS demonstrated a good stability.

Further testing of the MSPSS was warranted with different populations (Zimet et al., 1988). Psychometric properties of the MSPSS with three different samples: a group of pregnant women, adolescent students living with their families, and a group of pediatric residents were tested by Zimet, Powell, Farley, Werkman, and Berkoff (1990). The results were similar to those of the 1988 study; the factor analysis confirmed the dimensionality of the MSPSS, and the MSPSS showed similar estimates of reliability, for all groups, of those obtained by Zimet et al. (1988). This means that the MSPSS was useful to assess the perceived social support in different populations.

The psychometric properties of the MSPSS were further evaluated in 959 patients diagnosed with schizophrenia (Vaingankar, Abdin, \& Chong, 2012). A confirmatory factor analysis, a principal component analysis, and the internal consistency reliability coefficients were examined. The indices of goodness of fit and the factor structure analysis results supported the multidimensionality of the MSPSS previously proposed by Zimet et al. (1988) and Zimet et al. (1990). The reliability coefficients for the subscales were strong: $.90, .91$, and .90 for the Family, Friends, and Significant Other subscales, respectively. These strong reliability coefficients indicated that the MSPSS was a sound measure of perceived social support in patients diagnosed with schizophrenia.

Further testing of the MSPSS has been done with youths of diverse ethnic backgrounds (Bruwer, Emsley, Kidd, Lochner, \& Seedat, 2008; Canty-Mitchell \& Zimet, 2000). Both Bruwer et al. (2008) and Canty-Mitchell and Zimet (2000) supported the 
dimensionality and the internal consistency reliability of the MSPSS. In addition, construct validity of the MSPSS was evaluated by Bruwer et al.; they found that the perceived social support as measured by the MSPSS was negatively related to depression and anxiety. Further assessment of construct validity of the MSPSS was examined by Canty-Mitchell and Zimet which supported the validity of the family subscale.

The MSPSS has been used with patients with chronic conditions such as heart failure (Paukert, LeMaire, \& Cully, 2009). In addition, the MSPSS has been evaluated with older adults (Stanley, Beck, \& Zebb, 1998). Stanley et al. (1998) found that the MSPSS demonstrated very good validity and reliability when used with older adult populations who were either diagnosed or not diagnosed with mental illness. The latter study was an additional demonstration of the support to use the MSPSS with various populations.

The MSPSS has been used extensively in clinical and nonclinical populations. Several studies described earlier evaluated the dimensionality of the measure and tested its reliability to be used in various populations. All of these studies supported the existence of three subscales, Family, Friends, and Significant Other, as components of perceived social support. The studies mentioned earlier support the stability of the MSPSS over time and demonstrated its internal consistency. In addition, these studies showed its utility to be used with various age groups and multiple populations.

The MSPSS has shown very good reliability and validity in various populations; however, it was designed to measure the perceived support from family, friends, and significant others. This means that other sources of support were not included in the measure such as the support from care providers or other health care professionals. 
Furthermore, the MSPSS does not account for other forms of support such as functional support, quantitative support, or qualitative support. The 12 items of the MSPSS were developed to address emotional and/or companionship support, but they do not address informational support, instrumental support, or positive interaction. In addition, the MSPSS did not assess the number of people available for support or the satisfaction with support as the SSQ6 did.

Another aspect of the MSPSS that could be critiqued is the tendency to generate socially desirable responses (Canty-Mitchell \& Zimet, 2000; Zimet et al., 1988; Zimet et al., 1990). All of these studies showed that scores on the MSPSS among college students and adolescents were moderate to high. The problem of social desirability that resulted in high scores for both the total and subscales was found also in older adult populations, whether they are diagnosed or not with a chronic physical or psychiatric disease (Paukert et al., 2009; Stanley et al., 1998). This result means that a problem with the specificity or sensitivity of the MSPSS could exist or that the scoring of the MSPSS could be problematic which creates a limitation to its utility as a measure of perceived social support.

\section{Comparison of the Strengths and Weakness of the Three Self-Report Measures of Social Support}

The MOS-SSS, the SSQ6, and the MSPSS are having their strengths and weaknesses. The MOS-SSS and the MSPSS both are multidimensional measures, but they measure different dimensions of support. The MOS-SSS is used to the measure the perceived availability of various types of functional social support, whereas the MSPSS measures the adequacy of perceived social support regarding its resources. On the other 
hand, the SSQ6 is a unidimensional measure of perceived social support regarding the number of support persons and the satisfaction with that support. Thus, when the researcher intends to measure perceived social support, the choice from the mentioned measures should be based on the specific aspect of support that is intended to be measured, such as functional versus structural support.

The reliability of the three measures described earlier has been well documented in the literature, with research devoted to both internal consistency and test-retest reliability. In addition, the validity of all of the measures discussed was also welldescribed and showed the soundness of using each. However, it is worth mentioning here that the MOS-SSS psychometric evaluation was with chronically ill patients; this is not the case for the SSQ6 and the MSPSS, which both evaluated chronically ill patients and general populations. All of the reviewed measures were translated into different languages, which made them available for use in international studies.

Usually researchers study the impact of social support on several other variables such as patients' clinical outcomes (Chlebowy \& Garvin, 2006), depression (Friedman et al., 2013), or anxiety (Zimet et al., 1990). The MOS-SSS, the SSQ6, and the MSPSS were used successfully to assess the relationships of social support with the various outcome variables (Ahia et al., 2014; Arora \& McHorney, 2000; Barrera et al., 2006; Clay et al., 2008; Zimet et al., 1988).

The scoring of the MOS-SSS is well described for each subscale and for the total scale as well. Both total and subscale scores can be used to classify the respondents according to their level of perceived social support. For the SSQ6, two types of scores can be calculated; the number of support persons' score and the satisfaction score. The 
MSPSS scoring, as discussed earlier, was problematic in that it resulted in false positives, such as being skewed to generate perceived social support scores that appear to be too high (Zimet et al., 1988; Zimet et al., 1990).

All of the reviewed measures were brief and will not contribute to respondent burden. Thus, these measures are available to use when the time for administration is limited such as when using these measures with chronically ill patients or when a battery of instruments is used. In addition, a combination of two measures could be used together; for example, the MOS-SSS could be used with the SSQ6. The use of such a combination will enable the researcher to measure various aspects of social support such as functional support, number of support people, and satisfaction with support at the same time.

\section{Implications}

Several implications have been suggested regarding the use of social support measures in nursing research, education, and practice. First, nurse scientists should clearly identify the aspects of social support to be measured in their studies. The choice of social support measures should be determined by the specific aims of each study and how the relationships between social support and the outcomes are conceptualized within a specific theoretical framework. Next, researchers and practitioners who plan to measure social support should perform a critical review of the psychometric properties for each measure to be used focusing on the population with whom the measure was evaluated.

Nurse researchers should conduct further studies to evaluate the psychometric properties of the three reviewed measures with patients diagnosed with T2D. In addition, 
more than one measure of social support should be used for better identification of various aspects of support associated with outcomes in persons with T2D, especially if social support measures are selected for use in practice settings. Qualitative studies could be conducted to explore social support experiences for patients with T2D to delineate the most important aspects that determine the relationships of social support with patients' outcomes.

\section{Conclusions}

Social support has been used interchangeably with social networks, social integration, and support systems by the medical community (Gottlieb \& Bergen, 2010). Therefore, the measurement of social support is not an easy task for the researchers. However, several instruments exist to measure the concept of social support. The choice between social support measures should be backed up with a critical evaluation of their validity and reliability in addition to a careful attention to the aspects of social support being measured. Thus, there is no one perfect measure of social support and the use of a combination of social support measures will increase the likelihood of identifying the most important dimensions of support necessary to improved outcomes in persons with T2D. 


\section{Tables}

Table 1. A Summary of the Conceptual Definitions of Social Support in T2D Literature

Authors

Bhattacharya (2012)

Cosansu \& Erdogan

(2013)

Glasgow et al. (2012)

Vest et al., 2013

Melo, \& Barata (2012)

\section{Conceptual Definitions of Social Support}

A patient's expectancy of support from family, peers, and
community members following the diagnosis of T2D.

A patient's perceived diabetes-related support that determines glycemic control mediated by self-care and self-efficacy.

A patient's social network that exhibit supportive behaviors, A patient's social network of relationships.

A patient's social networks that interact together to influence self-management either positively or negatively.

Langford, Bowsher, A patient's social network is the structure for social Maloney, \& Lillis (1997) support and social support is a function of this network. 
McEwen, Pasvogel,

Gallegos, \& Barrera
A patient's support that is intended to help taking control of owns management of diabetes. 
Table 2. Summary of the Studies of Social Support and T2D Self-Management and Outcomes

\begin{tabular}{|c|c|c|c|c|c|c|}
\hline $\begin{array}{l}\text { Author } \\
\text { (date) }\end{array}$ & Purpose & Design & Measure & Type of Social Support & Reliability & Validity \\
\hline Egede \& & Test whether depression & Cross- & Medical & 19-items; measures four & Not & Construct \\
\hline Osborn & is related to self-care & sectional & Outcomes & categories of functional & reported & validity \\
\hline \multirow[t]{6}{*}{ (2010) } & behavior through social & & Study Social & social support: tangible & & supported \\
\hline & motivation and & & Support Survey & support, affectionate & & \\
\hline & indirectly related to & & (MOS-SSS; & support, positive social & & \\
\hline & glycemic control & & Sherbourne \& & interaction and & & \\
\hline & through self-care & & Stewart,1991) & emotional/informational & & \\
\hline & behavior. & & & support & & \\
\hline
\end{tabular}




\begin{tabular}{|c|c|c|c|c|c|c|}
\hline $\begin{array}{l}\text { Author } \\
\text { (date) }\end{array}$ & Purpose & Design & Measure & $\begin{array}{l}\text { Type of Social } \\
\text { Support }\end{array}$ & Reliability & Validity \\
\hline
\end{tabular}




\begin{tabular}{|c|c|c|c|c|c|c|}
\hline Author (date) & Purpose & Design & Measure & $\begin{array}{l}\text { Type of Social } \\
\text { Support }\end{array}$ & Reliability & Validity \\
\hline $\begin{array}{l}\text { Osborn \& } \\
\text { Egede (2010) }\end{array}$ & $\begin{array}{l}\text { Evaluate the } \\
\text { information } \\
\text { and motivation } \\
\text { components of } \\
\text { the } \\
\text { Information- } \\
\text { Motivation } \\
\text { Behavioral } \\
\text { Skills model }\end{array}$ & Cross-sectional & 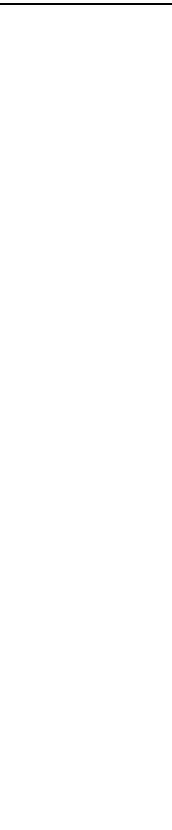 & MOS-SSS & Not reported & $\begin{array}{l}\text { Construct } \\
\text { validity } \\
\text { supported }\end{array}$ \\
\hline
\end{tabular}




\begin{tabular}{|c|c|c|c|c|c|c|}
\hline Author (date) & Purpose & Design & Measure & $\begin{array}{l}\text { Type of Social } \\
\text { Support }\end{array}$ & Reliability & Validity \\
\hline Chew, Khoo, & Examine the prevalence & Cross- & MOS-SSS & & Not & Construct \\
\hline \& Chia & of social support and its & sectional & & & reported & validity \\
\hline \multirow[t]{3}{*}{ (2015) } & association with glycemic & & & & & not \\
\hline & control in patients with & & & & & supported \\
\hline & $\mathrm{T} 2 \mathrm{D}$. & & & & & \\
\hline Collins- & Examine the associations & Cross- & MOS-SSS & & Cronbach's & Construct \\
\hline McNeil et al. & among physical & sectional, & & & $\alpha=.88$ & validity \\
\hline \multirow[t]{5}{*}{ (2009) } & activity, depressive & correlational & & & & supported \\
\hline & symptoms, and perceived & & & & & \\
\hline & social support in & & & & & \\
\hline & African-American women & & & & & \\
\hline & with T2D. & & & & & \\
\hline
\end{tabular}




\begin{tabular}{|c|c|c|c|c|c|c|}
\hline Author (date) & Purpose & Design & Measure & $\begin{array}{l}\text { Type of Social } \\
\text { Support }\end{array}$ & Reliability & Validity \\
\hline Walker, & Investigate if self-care is & Cross- & MOS-SSS & & Not & Construct \\
\hline Gebregziabher, & the pathway through & sectional & & & reported & validity \\
\hline Martin-Harris, & which social determinants & & & & & supported \\
\hline \& Egede & of health impact $\mathrm{T} 2 \mathrm{D}$ & & & & & \\
\hline (2015) & outcomes. & & & & & \\
\hline Smalls, & Determine whether & Cross- & MOS-SSS & & Not & Construct \\
\hline Gregory, & neighborhood factors have & sectional & & & reported & validity \\
\hline Zoller, \& & direct or indirect effects & & & & & supported \\
\hline Egede (2015) & on glycemic control. & & & & & \\
\hline
\end{tabular}

(Continued) 


\begin{tabular}{|c|c|c|c|c|c|c|}
\hline Author (date) & Purpose & Design & Measure & $\begin{array}{l}\text { Type of Social } \\
\text { Support }\end{array}$ & Reliability & Validity \\
\hline Walker, & Validate a conceptual & Cross- & MOS-SSS & & Not & Construct \\
\hline Gebregziabher, & framework linking social & sectional & & & reported & validity \\
\hline Martin-Harris, & determinants of health to & & & & & supported \\
\hline \& Egede & outcomes in persons with & & & & & \\
\hline (2014) & T2D. & & & & & \\
\hline Osborn, Bains, & Examine the relationships & Cross- & MOS-SSS & & Not & Construct \\
\hline \& Egede, & between health literacy, & sectional & & & reported & validity \\
\hline \multirow[t]{4}{*}{ (2010) } & determinants of diabetes & & & & & supported \\
\hline & self-care, and glycemic & & & & & \\
\hline & control in persons with & & & & & \\
\hline & $\mathrm{T} 2 \mathrm{D}$ & & & & & \\
\hline
\end{tabular}




\begin{tabular}{|c|c|c|c|c|c|c|}
\hline Author (date) & Purpose & Design & Measure & $\begin{array}{l}\text { Type of Social } \\
\text { Support }\end{array}$ & Reliability & Validity \\
\hline Ahia, Holt, \& & Examine the relationships & Cross- & MOS-SSS & & Not & Construct \\
\hline Krousel- & of patients' source of most & sectional & & & reported & validity \\
\hline Wood (2014) & $\begin{array}{l}\text { help and diabetes care and } \\
\text { their A1c levels. }\end{array}$ & & & & & supported \\
\hline Gallegos- & Determine the associations & Cross- & MOS-SSS & & Not & Construct \\
\hline Carrillo, & of social support with & sectional & & & reported & validity \\
\hline García-Peña, & certain indicators of & & & & & supported \\
\hline Durán- & physical and mental well- & & & & & \\
\hline Muñoz, & being in older adults with & & & & & \\
\hline Flores, \& & T2D. & & & & & \\
\hline \multicolumn{7}{|l|}{ Salmeron } \\
\hline (2009) & & & & & & \\
\hline
\end{tabular}




\begin{tabular}{|c|c|c|c|c|c|c|}
\hline Author (date) & Purpose & Design & Measure & $\begin{array}{l}\text { Type of Social } \\
\text { Support }\end{array}$ & Reliability & Validity \\
\hline Westaway, & Determine the & Cross- & MOS-SSS & & Cronbach's & Construct, \\
\hline Seager, & underlying structure of a & sectional & & & $\alpha=.97$ for & convergent, \\
\hline Rheeder, \& & social support measure & & & & socio- & $\&$ \\
\hline Van Zyl & and examine the effects & & & & emotional & discriminant \\
\hline \multirow[t]{7}{*}{ (2005) } & of social support on & & & & support, & validity \\
\hline & health, well-being, and & & & & 0.95 for & were \\
\hline & management of T2D. & & & & tangible & supported \\
\hline & & & & & support & \\
\hline & & & & & and 0.97 & \\
\hline & & & & & for the full & \\
\hline & & & & & scale & \\
\hline
\end{tabular}




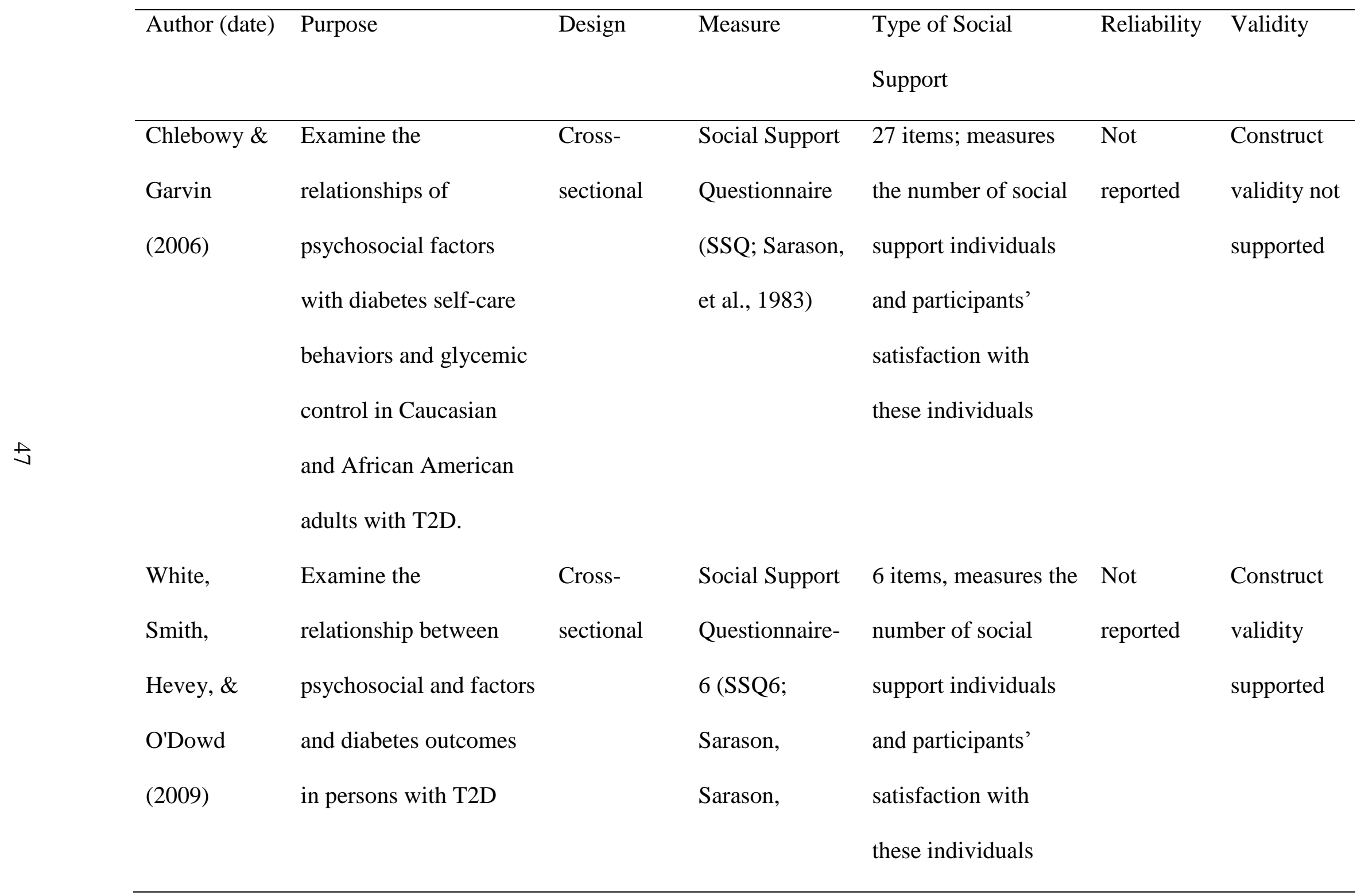


and their family

members.
Shearin, \&

Pierce, 1987) 


\begin{tabular}{|c|c|c|c|c|c|c|}
\hline Author (date) & Purpose & Design & Measure & $\begin{array}{l}\text { Type of Social } \\
\text { Support }\end{array}$ & Reliability & Validity \\
\hline Goz et al. & Examine effects of the & Cross- & Multidimensional & 12 items; measures & Not & Construct \\
\hline (2007) & $\begin{array}{l}\text { perceived social support } \\
\text { on the quality of life in } \\
\text { persons with T2D. }\end{array}$ & sectional & $\begin{array}{l}\text { Scale of } \\
\text { Perceived Social } \\
\text { Support } \\
\text { (MSPSS; Zimet, } \\
\text { Dahlem ,Zimet, } \\
\text { \& Farley,1988) }\end{array}$ & $\begin{array}{l}\text { adequacy of support } \\
\text { from family, friends } \\
\text {, and significant } \\
\text { others }\end{array}$ & reported & $\begin{array}{l}\text { validity } \\
\text { supported }\end{array}$ \\
\hline Yang, Li, \& & Examine levels of & Cross- & MSPSS & & Cronbach's & Construct \\
\hline Zheng (2009) & $\begin{array}{l}\text { perceived social support, } \\
\text { depression and identify } \\
\text { the predictors of } \\
\text { depression among } \\
\text { Chinese community- }\end{array}$ & $\begin{array}{l}\text { sectional, } \\
\text { correlational }\end{array}$ & & & $\alpha=0.84$ & $\begin{array}{l}\text { validity } \\
\text { supported }\end{array}$ \\
\hline
\end{tabular}


dwelling persons with

T2D.

(Continued) 


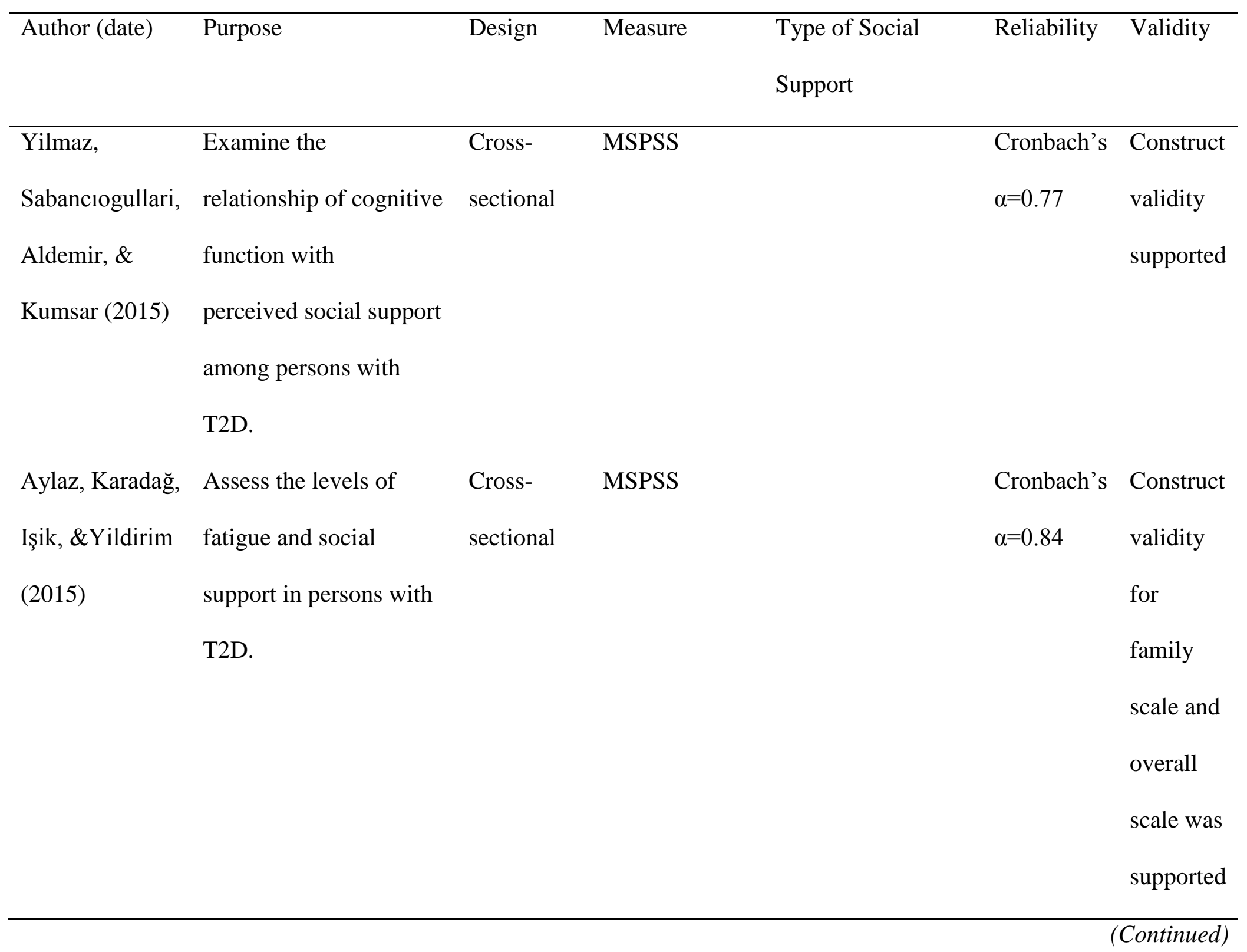




\begin{tabular}{|c|c|c|c|c|c|c|}
\hline Author (date) & Purpose & Design & Measure & $\begin{array}{l}\text { Type of Social } \\
\text { Support }\end{array}$ & Reliability & Validity \\
\hline $\begin{array}{l}\text { Murano et al. } \\
\text { (2014) }\end{array}$ & $\begin{array}{l}\text { Investigate the variables } \\
\text { involved in increasing } \\
\text { physical activity levels in } \\
\text { persons with T2D. }\end{array}$ & $\begin{array}{l}\text { Cross- } \\
\text { sectional }\end{array}$ & $\begin{array}{l}\text { Social Support } \\
\text { Scale } \\
\text { (Kim et al., } \\
\text { 1998) }\end{array}$ & $\begin{array}{l}20 \text { items, measures } \\
\text { emotional support in } \\
\text { daily life and } \\
\text { behavioral support } \\
\text { for disease }\end{array}$ & $\begin{array}{l}\text { Not } \\
\text { reported }\end{array}$ & $\begin{array}{l}\text { Construct } \\
\text { validity } \\
\text { supported }\end{array}$ \\
\hline $\begin{array}{l}\text { Nozaki et al. } \\
\text { (2009) }\end{array}$ & $\begin{array}{l}\text { Evaluate the relationship } \\
\text { of psychosocial variables } \\
\text { with glycemic control of } \\
\text { persons with T2D. }\end{array}$ & $\begin{array}{l}\text { Prospective } \\
\text { and cross- } \\
\text { sectional }\end{array}$ & $\begin{array}{l}\text { Social Support } \\
\text { Scale (Kim et } \\
\text { al., 1998) }\end{array}$ & & $\begin{array}{l}\text { Cronbach's } \\
\alpha=0.95\end{array}$ & $\begin{array}{l}\text { Construct } \\
\text { validity } \\
\text { supported }\end{array}$ \\
\hline $\begin{array}{l}\text { Sukkarieh- } \\
\text { Haraty \& }\end{array}$ & $\begin{array}{l}\text { Assess the relationship of } \\
\text { diabetes self-care. }\end{array}$ & $\begin{array}{l}\text { Cross- } \\
\text { sectional/ }\end{array}$ & A subscale of & $\begin{array}{l}\text { 12-items; measures } \\
\text { social support }\end{array}$ & $\begin{array}{l}\text { Not } \\
\text { reported }\end{array}$ & $\begin{array}{l}\text { Construct } \\
\text { validity }\end{array}$ \\
\hline $\begin{array}{l}\text { Haraty \& } \\
\text { Howard } \\
\text { (2015) }\end{array}$ & $\begin{array}{l}\text { diabetes self-care, } \\
\text { emotional distress, and } \\
\text { social support with } \\
\text { glycemic control. }\end{array}$ & $\begin{array}{l}\text { sectional/ } \\
\text { correlational }\end{array}$ & $\begin{array}{l}\text { the Diabetes } \\
\text { Care Profile } \\
\text { (Fitzgerald et } \\
\text { al., 1996) }\end{array}$ & $\begin{array}{l}\text { social support } \\
\text { perceived by the } \\
\text { participants from } \\
\text { family and friends }\end{array}$ & reported & $\begin{array}{l}\text { validity } \\
\text { supported }\end{array}$ \\
\hline
\end{tabular}




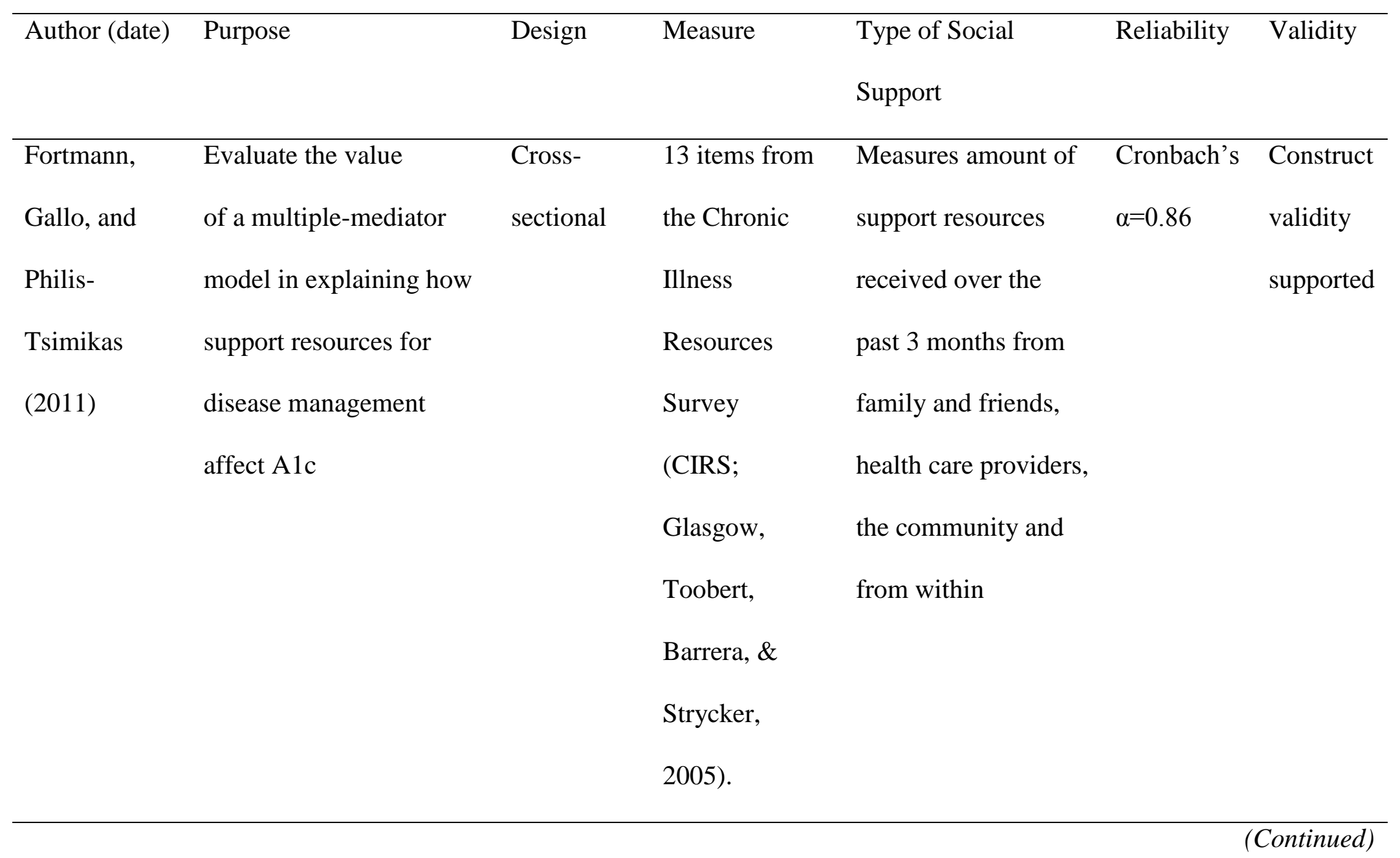




\begin{tabular}{|c|c|c|c|c|c|c|}
\hline Author (date) & Purpose & Design & Measure & $\begin{array}{l}\text { Type of Social } \\
\text { Support }\end{array}$ & Reliability & Validity \\
\hline Fortmann, & Examine predictor factors & Cross- & 10 items from & Measures amount of & Not & Construct \\
\hline Gallo, & of depression, diabetes & sectional & the CIRS & support resources & reported & validity \\
\hline Walker, and & self-management, and & & & received over the past & & supported \\
\hline Philis- & clinical indicators of & & & 3 months from family & & \\
\hline Tsimikas & health risk among & & & and friends, health & & \\
\hline (2010) & Hispanics with T2D. & & & $\begin{array}{l}\text { care providers, the } \\
\text { community and from } \\
\text { within }\end{array}$ & & \\
\hline An and $\mathrm{Kim}$ & Examine the relationship & Cross- & A method & Measures emotional, & Cronbach's & Construct \\
\hline \multirow[t]{4}{*}{ (2012) } & of powerlessness, social & sectional & developed by & informational, & $\alpha=.98$ for & validity \\
\hline & support, with glycemic & & Cho (1995) in & materialistic, and & satisfaction & supported \\
\hline & control in Korean persons & & an unpublished & evaluational support & (evaluation) & \\
\hline & with T2D. & & masters' thesis & & score & \\
\hline
\end{tabular}




\begin{tabular}{|c|c|c|c|c|c|c|}
\hline $\begin{array}{l}\text { Author } \\
\text { (date) }\end{array}$ & Purpose & Design & Measure & $\begin{array}{l}\text { Type of Social } \\
\text { Support }\end{array}$ & Reliability & Validity \\
\hline Kim et al. & Examine the role of & Cross- & Duke-UNC & 8-items; measures & Cronbach's & Construct \\
\hline \multirow[t]{6}{*}{ (2015) } & social support on the & sectional & Functional Social & the amount and & $\alpha=0.91$ & validity \\
\hline & relationship of & & Support & types of perceived & & supported \\
\hline & depression with & & Questionnaire & emotional social & & \\
\hline & medication adherence & & (Broadhead et al. & support & & \\
\hline & and self-care in persons & & 1988) & & & \\
\hline & with T2D. & & & & & \\
\hline Costa, & Examine the relationship & Cross- & Multidimensional & 8-item subscale & Not & Construct \\
\hline Pereira, \& & of spousal support, & sectional/ & Diabetes & measuring spouse & reported & validity \\
\hline Pedras & social-cognitive & correlational & Questionnaire & support (positive & & supported \\
\hline \multirow[t]{4}{*}{ (2012) } & variables with self- & & (MDQ; Talbot, & and negative) & & \\
\hline & monitoring of blood & & Nouwen,Gingras, & behaviors in & & \\
\hline & glucose. & & Gosselin, \& & diabetes self-care & & \\
\hline & & & Audet, 1997) & & & \\
\hline
\end{tabular}




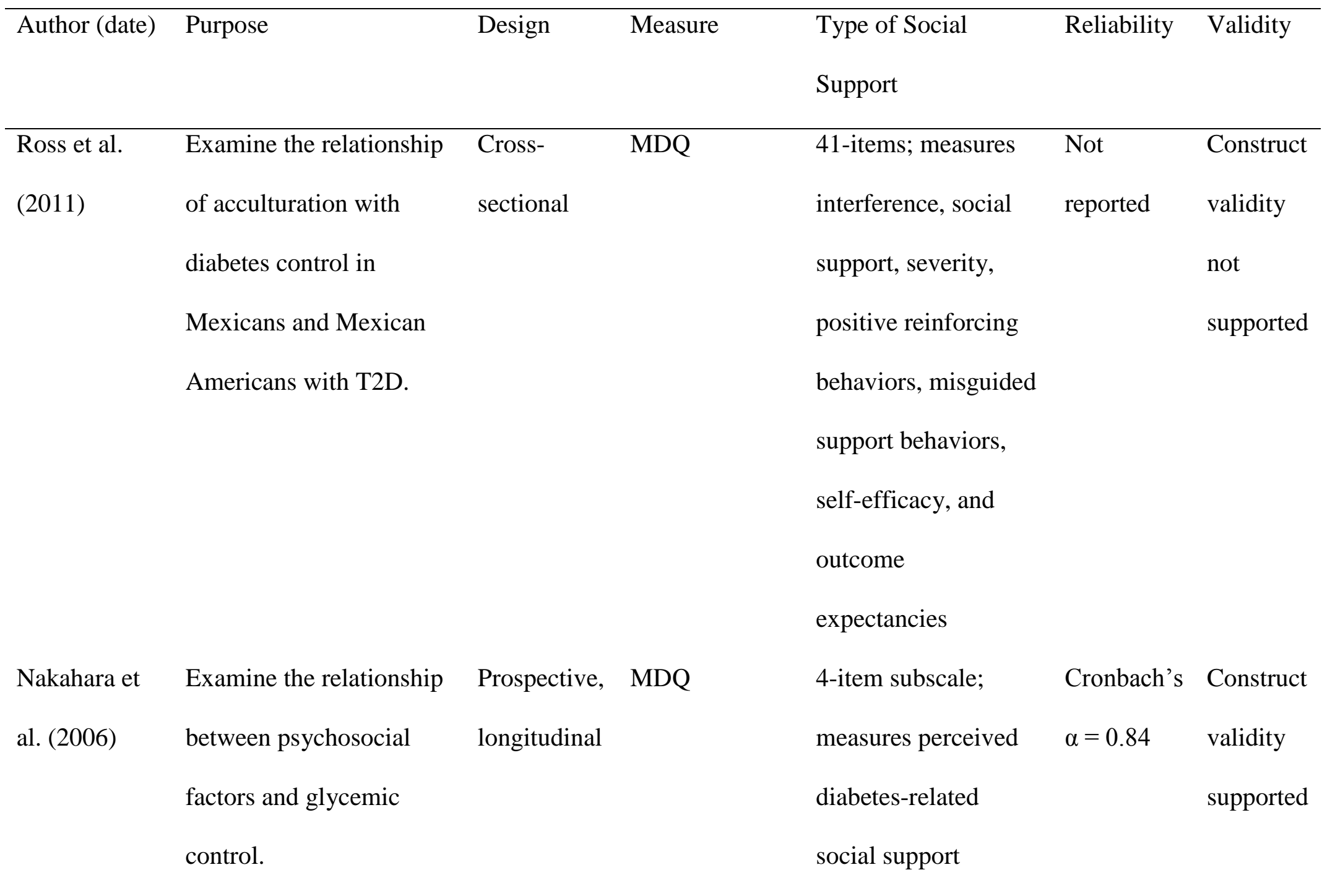




\begin{tabular}{|c|c|c|c|c|c|c|}
\hline Author (date) & Purpose & Design & Measure & $\begin{array}{l}\text { Type of Social } \\
\text { Support }\end{array}$ & Reliability & Validity \\
\hline Gomes-Villas & Analyze the relationship & Cross- & Social Support & 11 items; measures & Cronbach' & Construct \\
\hline Boas, Foss, & of social support, & sectional & Network & social network & s $\alpha=0.94$ & validity \\
\hline de Freitas, \& & adherence to non- & & Inventory & variables (source and & & supported \\
\hline \multirow[t]{5}{*}{ Pace (2012) } & pharmacological and & & (Flaherty, & type of contact) and & & \\
\hline & pharmacological & & Gaviria, \& & perceived social & & \\
\hline & treatments with clinical & & Pathak, 1983) & support & & \\
\hline & and metabolic control of & & & & & \\
\hline & T2D persons. & & & & & \\
\hline Newlin, & Examine the relationships & Cross- & A subscale of & 5-item subscale; & Not & Construct \\
\hline Melkus, & of religion and spirituality & sectional/ & Diabetes Care & measures support & reported & validity \\
\hline Tappen, & to glycemic control. & correlation & Profile & from friends or family & & not \\
\hline Chyun, \& & & al & (Fitzgerald et & in terms of self-care & & supported \\
\hline Koenig & & & al., 1996) & practices and related & & \\
\hline (2008) & & & & emotions & & \\
\hline
\end{tabular}




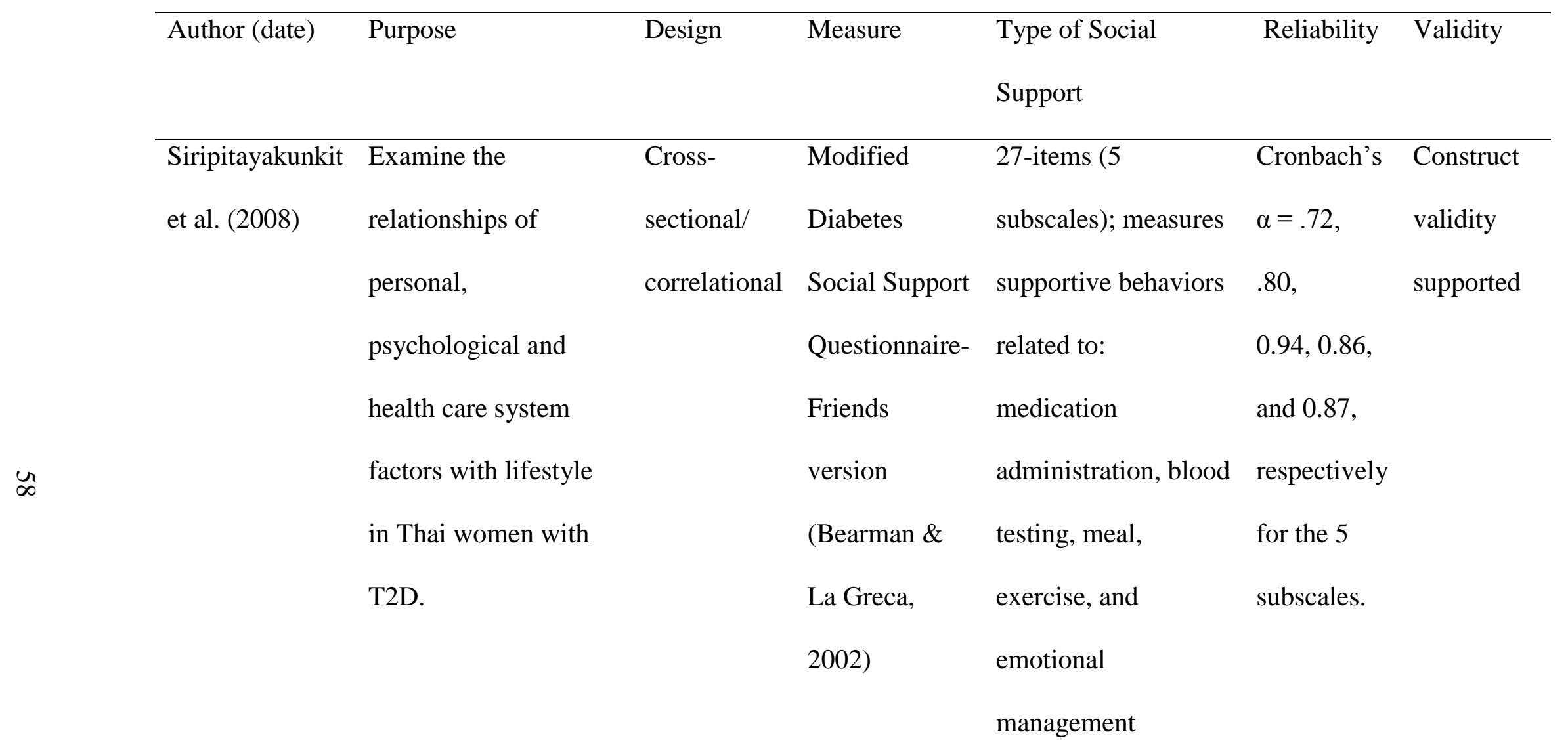




\begin{tabular}{|c|c|c|c|c|c|c|}
\hline Author (date) & Purpose & Design & Measure & $\begin{array}{l}\text { Type of Social } \\
\text { Support }\end{array}$ & Reliability & Validity \\
\hline Bauman, & Test the feasibility of a & Pretest- & Diabetes Self- & 2-item subscale & Not & Construct \\
\hline Frederick, & peer support & posttest & Care & measuring the & reported & validity not \\
\hline Betty, & intervention by a nurse- & quasi- & Questionnaire & perceptions of social & & supported \\
\hline Jospehin, \& & led interdisciplinary & experimental & (Peyrot, & support & & \\
\hline Agatha & team. & & Peeples, & & & \\
\hline \multirow[t]{5}{*}{ (2015) } & & & Tomky, & & & \\
\hline & & & Charron- & & & \\
\hline & & & Prochownik, & & & \\
\hline & & & \& Weaver, & & & \\
\hline & & & 2007) & & & \\
\hline
\end{tabular}




\begin{tabular}{|c|c|c|c|c|c|c|}
\hline Author (date) & Purpose & Design & Measure & $\begin{array}{l}\text { Type of Social } \\
\text { Support }\end{array}$ & Reliability & Validity \\
\hline Karlsen, & Examine the degree to & Cross- & Diabetes & 16-items; scale & Cronbach's & Construct \\
\hline Oftedal, \& & which clinical & sectional & Family & measuring supportive & $\alpha=0.94$ for & validity \\
\hline \multirow[t]{6}{*}{ Bru (2012) } & indicators, coping & & Behavior & and non-supportive & 12-item & supported \\
\hline & styles and perceived & & Checklist & behaviors specific to & subscale & for the 18 \\
\hline & support are related to & & (DFBC; & diabetes & and 0.85 for & items \\
\hline & diabetes-related & & Schafer et al., & & 6-item non- & \\
\hline & distress. & & 1986) & & constructive & \\
\hline & & & & & subscale & \\
\hline Karlsen \& & Investigate the & Prospective/ & A scale & 18 items; measures & Not & Construct \\
\hline \multirow[t]{5}{*}{ Bru (2014) } & predictive effect of & longitudinal & created by the & experiences in & reported & validity \\
\hline & clinical factors and & & authors & routine diabetes & & supported \\
\hline & perceived social & & & follow-up & & \\
\hline & support on diabetes- & & & consultations. & & \\
\hline & related distress. & & & & & \\
\hline
\end{tabular}




\begin{tabular}{|c|c|c|c|c|c|c|}
\hline Author (date) & Purpose & Design & Measure & $\begin{array}{l}\text { Type of Social } \\
\text { Support }\end{array}$ & Reliability & Validity \\
\hline $\begin{array}{l}\text { Brody et al. } \\
(2008)\end{array}$ & $\begin{array}{l}\text { Test a contextual- } \\
\text { ecological model of } \\
\text { variables related to } \\
\text { glycemic control in an } \\
\text { understudied and } \\
\text { vulnerable population of } \\
\text { persons with T2D. }\end{array}$ & $\begin{array}{l}\text { Cross- } \\
\text { sectional }\end{array}$ & $\begin{array}{l}\text { Two subscales } \\
\text { of Diabetes Care } \\
\text { Profile (Fitzgerald } \\
\text { et al., 1996) } \\
\text { Adaptation of the } \\
\text { Family } \\
\text { Intrusiveness } \\
\text { Questionnaire } \\
\text { (Gavazzi et al., } \\
\text { 1998) } \\
\text { The Diabetes } \\
\text { Discussion } \\
\text { Quality Scale ( } \\
\text { Brody et al.,1998) }\end{array}$ & $\begin{array}{l}\text { Measures } \\
\text { Support for diabetes } \\
\text { self-management and } \\
\text { relationship quality }\end{array}$ & $\begin{array}{l}\text { Not } \\
\text { reported }\end{array}$ & $\begin{array}{l}\text { Construct } \\
\text { validity } \\
\text { supported }\end{array}$ \\
\hline
\end{tabular}




\begin{tabular}{|c|c|c|c|c|c|c|}
\hline Author (date) & Purpose & Design & Measure & $\begin{array}{l}\text { Type of Social } \\
\text { Support }\end{array}$ & Reliability & Validity \\
\hline Cosansu \& & Examine the direct and & Cross- & A social & 11 items; measures & Not & Construct \\
\hline Erdogan & indirect effects of & sectional & support & the perceived social & reported & validity \\
\hline \multirow[t]{5}{*}{ (2014) } & psychosocial factors on & & subscale & support provided by & & supported \\
\hline & self-care behavior and & & created by the & family, friends, and & & \\
\hline & glycemic control in & & authors & intimate partners in & & \\
\hline & Turkish persons with & & & the life of a patient & & \\
\hline & T2D. & & & with diabetes & & \\
\hline Nielsen et al. & Explore the relationship & Cluster- & Patients' report & & Not & Construct \\
\hline \multirow[t]{5}{*}{ (2006) } & of A1c, sex, treatment & randomized & of support and & & reported & validity \\
\hline & allocation, and their & control trail & understanding & & & supported \\
\hline & interactions with & & from family & & & \\
\hline & behavioral and & & and significant & & & \\
\hline & attitudinal & & others & & & \\
\hline
\end{tabular}


characteristics of

persons with T2D. 


\begin{tabular}{|c|c|c|c|c|c|c|}
\hline Author (date) & Purpose & Design & Measure & $\begin{array}{l}\text { Type of Social } \\
\text { Support }\end{array}$ & Reliability & Validity \\
\hline Arigo, Smyth, & Explore the mediating & Cross- & Social Support & 23 items; measures & Cronbach's & Construct \\
\hline Haggerty, \& & effects of social & sectional & Appraisals & perceived social & $\alpha=0.93$ & validity \\
\hline \multirow[t]{5}{*}{ Raggio (2015) } & comparison and social & & Scale (Vaux et & support from family & (total & supported \\
\hline & support on the & & al., 1986) & and friends & score), 0.85 & \\
\hline & relationship of glycemic & & & & (family), & \\
\hline & control with depressive & & & & and 0.86 & \\
\hline & symptoms & & & & (friends) & \\
\hline Gao et al. & Explore the relationships & Cross- & A subscale of & 5 items; measures & Cronbach's & Construct \\
\hline \multirow[t]{6}{*}{ (2013) } & of self-efficacy, social & sectional & the Health & social integration & $\alpha=0.93$ & validity not \\
\hline & support and patient- & & Education & and support & & supported \\
\hline & provider & & Impact & & & \\
\hline & communication, with & & Questionnaire & & & \\
\hline & self-care behaviors and & & (Osborne et & & & \\
\hline & glycemic control. & & al., 2007) & & & \\
\hline
\end{tabular}




\begin{tabular}{|c|c|c|c|c|c|c|}
\hline Author (date) & Purpose & Design & Measure & $\begin{array}{l}\text { Type of Social } \\
\text { Support }\end{array}$ & Reliability & Validity \\
\hline Mayberry \& & Explore the & Mixed & Adapted & 16 items; measures & Cronbach's & Construct \\
\hline \multirow[t]{10}{*}{ Osborn (2012) } & relationships of & methods & subscales from & supportive and non- & $\alpha=0.82$ for & validity \\
\hline & participants' perceptions & (focus & the Diabetes & supportive behaviors & the & was \\
\hline & of family members' & groups and & Family & & supportive & supported \\
\hline & diabetes self-care & cross- & Behavior & & subscale & for both \\
\hline & knowledge, specific & sectional) & Checklist & & and 0.74 & subscales \\
\hline & supportive and non- & & (DFBC; & & for non- & \\
\hline & supportive behaviors & & Schafer et al., & & supportive & \\
\hline & with medication & & 1986) & & subscale & \\
\hline & adherence and glycemic & & & & & \\
\hline & control. & & & & & \\
\hline Kaplan et al. & Examine potential & Cross- & Perceived & 7 items; measures & Not & Construct \\
\hline \multirow[t]{2}{*}{ (2013) } & contributors to & sectional & Support Scale & perceived social & reported & validity not \\
\hline & disparities in diabetes & & & support related to & & supported \\
\hline
\end{tabular}


care and glycemic

control.
(Stephens et

al., 2009) diabetes

management 


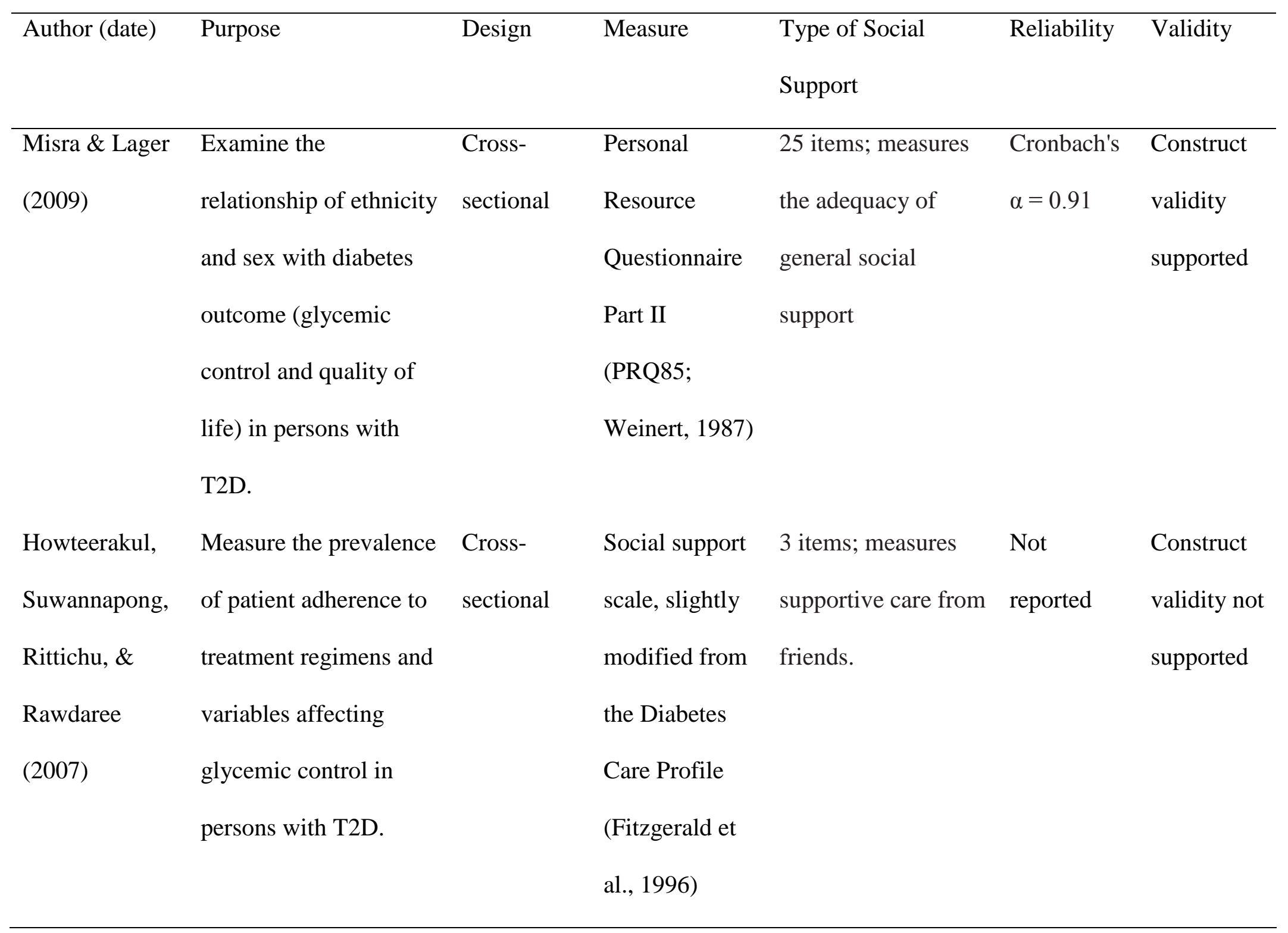




\begin{tabular}{|c|c|c|c|c|c|c|}
\hline Author (date) & Purpose & Design & Measure & $\begin{array}{l}\text { Type of Social } \\
\text { Support }\end{array}$ & Reliability & Validity \\
\hline Mayberry, & Assess the difference in & Secondary & Diabetes & 16 items; measures & Not & Construct \\
\hline Rothman, \& & the relationship of & analysis of & Family & how often patient's & reported & validity \\
\hline \multirow[t]{7}{*}{ Osborn (2014) } & obstructive family & cross- & Behavior & family members & & supported \\
\hline & behaviors with & sectional & Checklist-II & have performed & & \\
\hline & glycemic control among & data & (Glasgow \& & diabetes-specific & & \\
\hline & persons with limited & & Toobert,1988) & behaviors in the past & & \\
\hline & health literacy and & & & month & & \\
\hline & persons with adequate & & & & & \\
\hline & health literacy. & & & & & \\
\hline
\end{tabular}




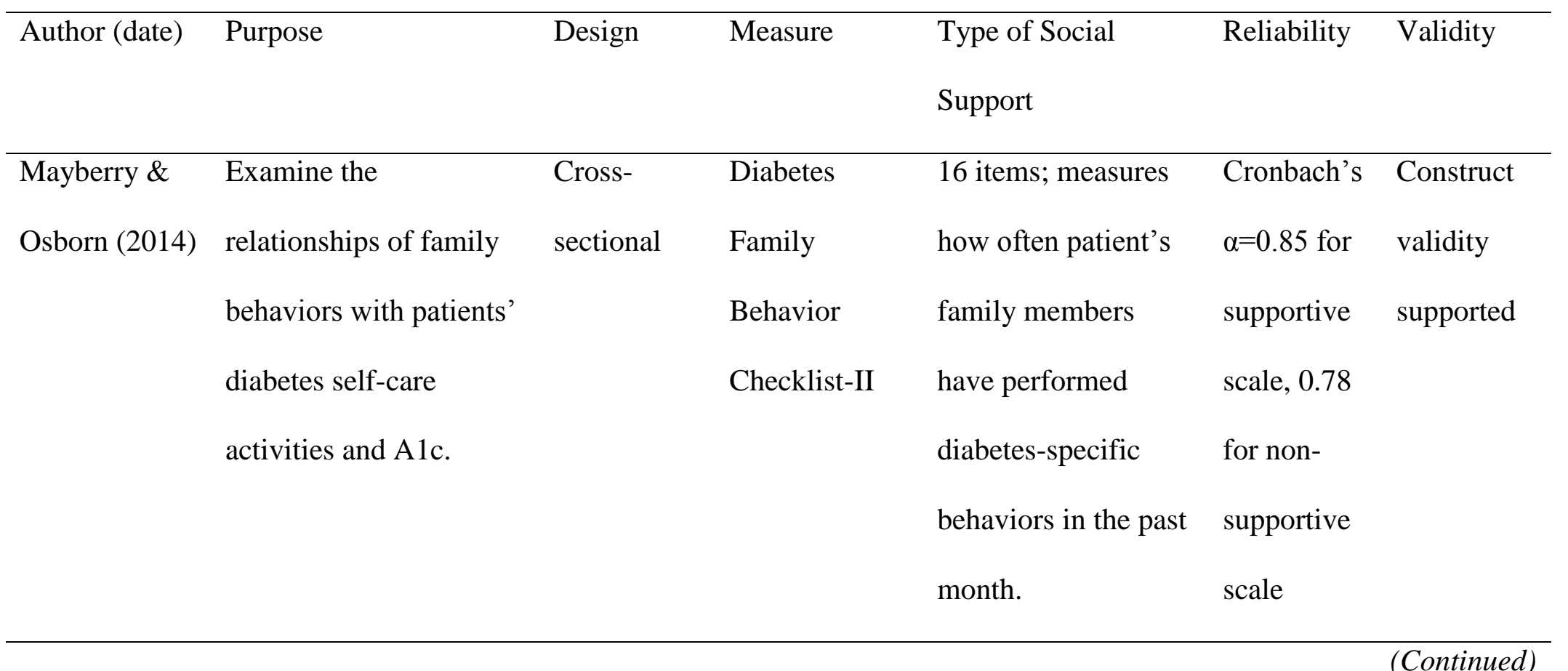




\begin{tabular}{|c|c|c|c|c|c|c|}
\hline Author (date) & Purpose & Design & Measure & $\begin{array}{l}\text { Type of Social } \\
\text { Support }\end{array}$ & Reliability & Validity \\
\hline $\begin{array}{l}\text { Wolever et al. } \\
\text { (2010) }\end{array}$ & $\begin{array}{l}\text { Evaluate the } \\
\text { effectiveness of } \\
\text { integrative health } \\
\text { coaching on } \\
\text { psychosocial variables, } \\
\text { behavior change, and } \\
\text { glycemic control in } \\
\text { persons with T2D. }\end{array}$ & RCT & $\begin{array}{l}\text { Interpersonal } \\
\text { Support } \\
\text { Evaluation List } \\
\text { (ISEL-12; } \\
\text { Cohen, } \\
\text { Mermelstein, } \\
\text { Kamarck, \& } \\
\text { Hoberman, } \\
\text { 1985) }\end{array}$ & $\begin{array}{l}40 \text { items; measures } \\
\text { the perceived } \\
\text { availability of } \\
\text { potential social } \\
\text { resources }\end{array}$ & $\begin{array}{l}\text { Not } \\
\text { reported }\end{array}$ & $\begin{array}{l}\text { Construct } \\
\text { validity } \\
\text { supported }\end{array}$ \\
\hline Piette, & Examine the mediation & RCT & Diabetes & 12 items; measures & Not & Construct \\
\hline Resnicow, & effects of insulin uptake & & Social Support & received diabetes- & reported & validity not \\
\hline Choi, \& & and perceived social & & Scale (DSS; & social support over & & supported \\
\hline Heisler (2013) & support on & & $\begin{array}{l}\text { Barrera et al., } \\
\text { 2002) }\end{array}$ & the past 3 months & & \\
\hline
\end{tabular}


intervention's influence

on A1c. 


\begin{tabular}{|c|c|c|c|c|c|c|}
\hline Author (date) & Purpose & Design & Measure & $\begin{array}{l}\text { Type of Social } \\
\text { Support }\end{array}$ & Reliability & Validity \\
\hline $\begin{array}{l}\text { Barrera et al. } \\
(2002)\end{array}$ & $\begin{array}{l}\text { Determine the } \\
\text { effectiveness of a } \\
\text { computer-based } \\
\text { intervention } 1 \text { in } \\
\text { changing participants' } \\
\text { perceptions of social } \\
\text { support. }\end{array}$ & RCT & $\begin{array}{l}\text { (1) DSS } \\
\text { (2) ISEL-12 }\end{array}$ & 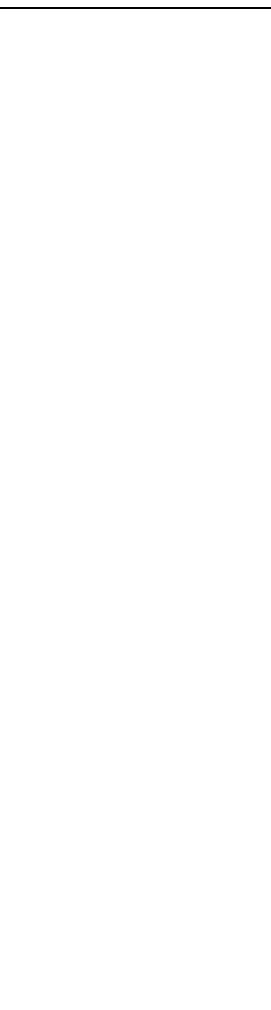 & $\begin{array}{l}\text { (1) } \\
\text { Cronbach's } \\
\alpha=0.90 \\
(2) \\
\text { Cronbach's } \\
\alpha=0.77\end{array}$ & $\begin{array}{l}\text { (1) Content } \\
\text { and } \\
\text { criterion- } \\
\text { related } \\
\text { validity } \\
\text { supported } \\
\text { (2) ISEL- } \\
12 \\
\text { construct } \\
\text { validity } \\
\text { supported }\end{array}$ \\
\hline
\end{tabular}


Table 3. Comparison of the of Three Self-Report Measures of Social Support

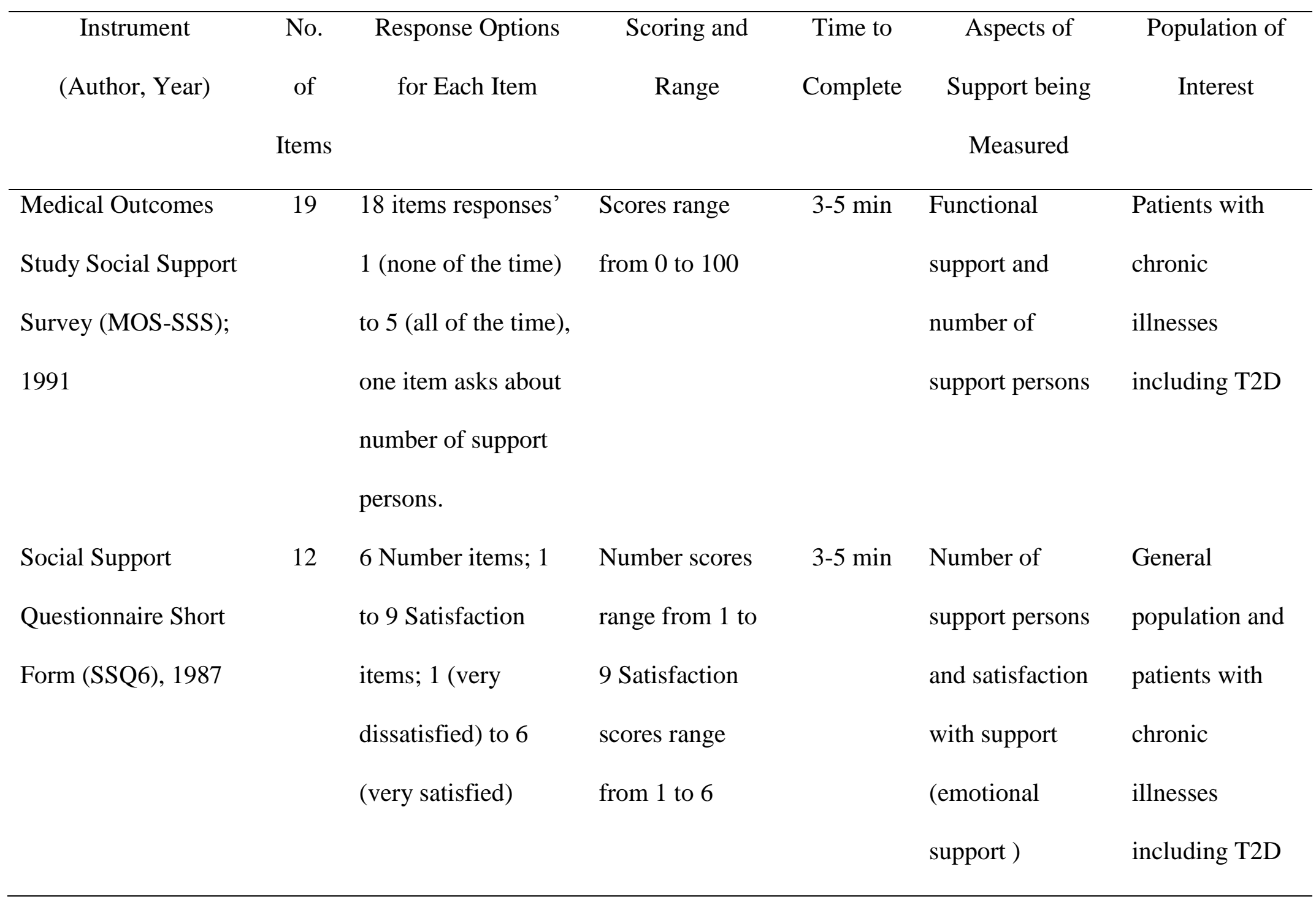




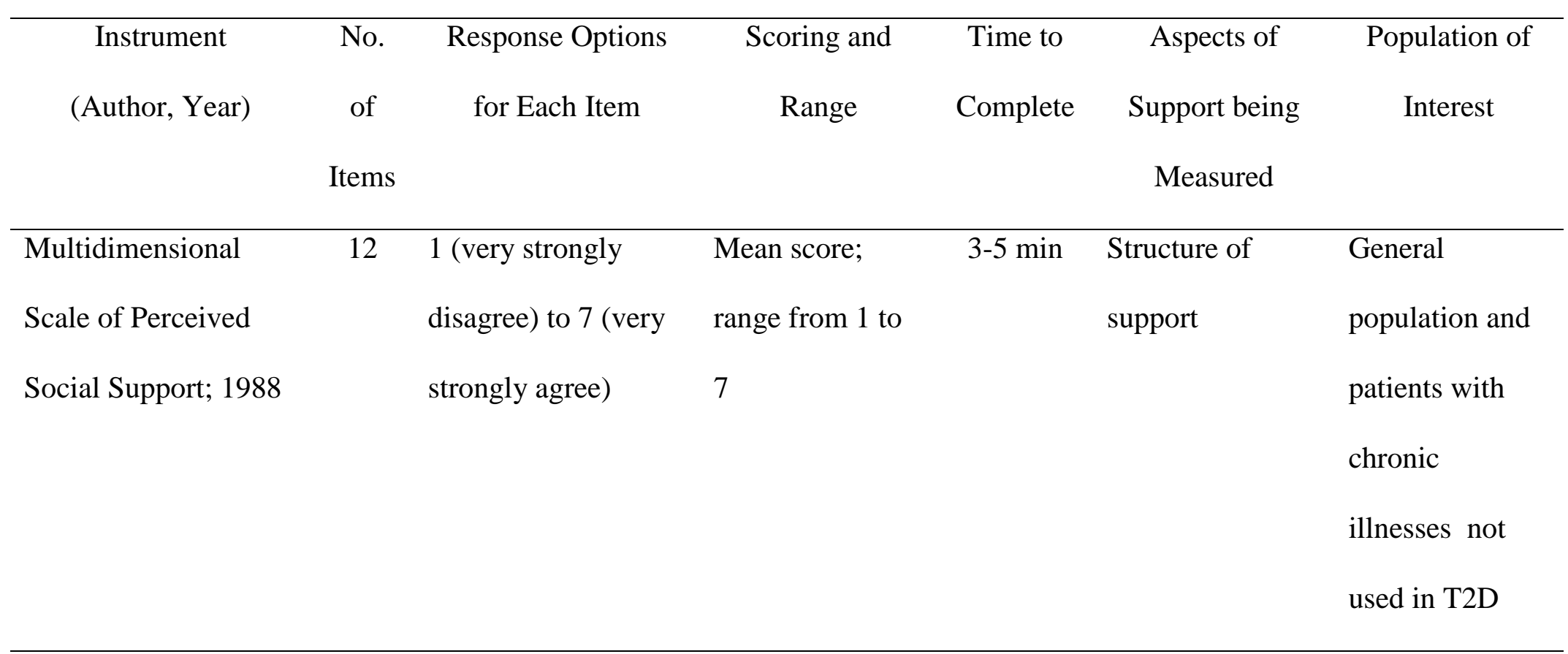




\section{Figures}

Figure 4. An adaptation of the Peer Support Conceptual Model of Heisler (2006)

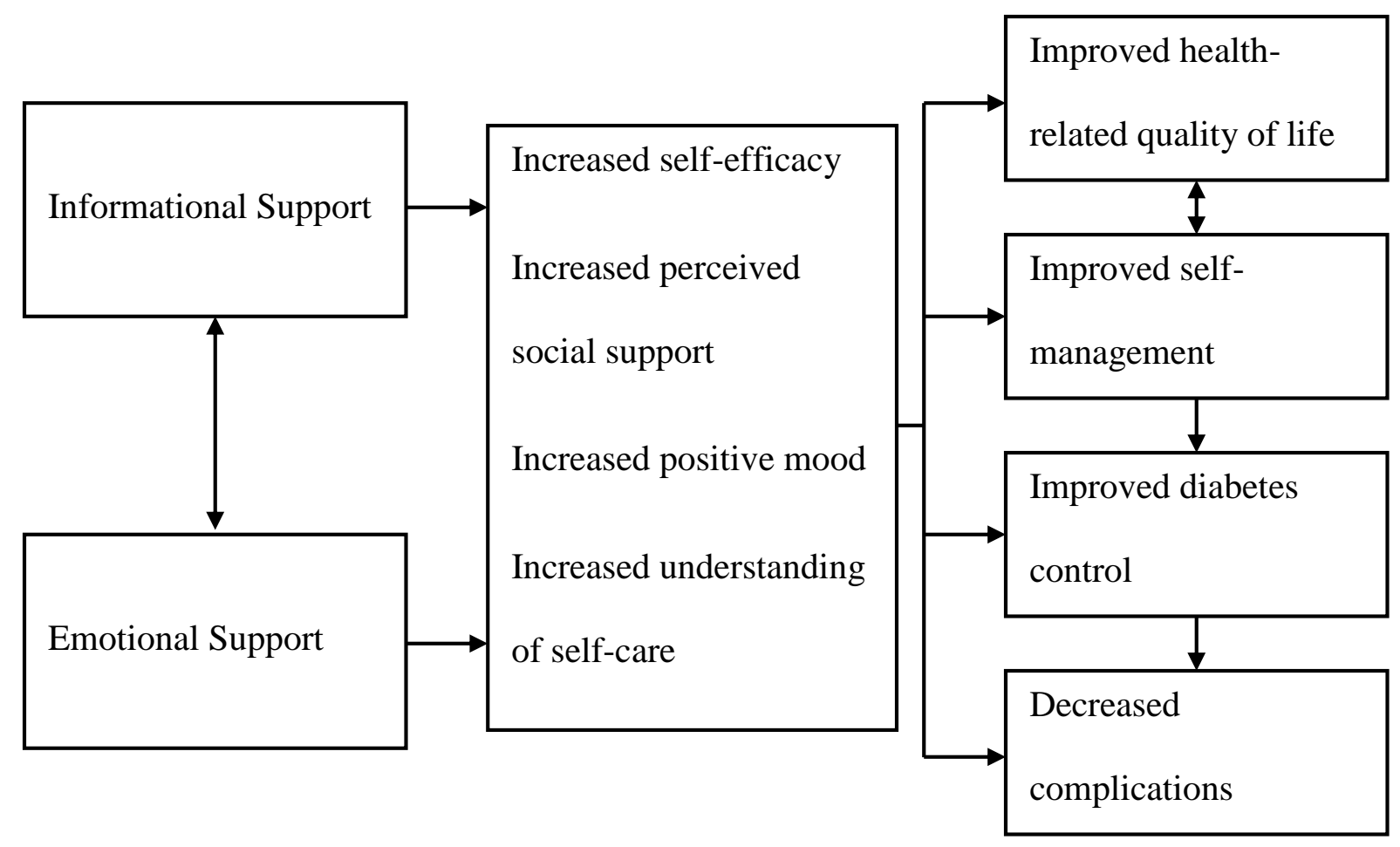


Figure 5. Systematic Review Flow Using PRISMA 2009 Flow

\section{Diagram}

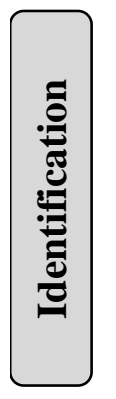

Records identified through
database searching
$(\mathrm{n}=218)$

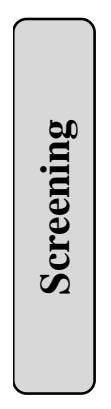

Records after duplicates removed

Additional records identified through other sources

$$
(\mathrm{n}=38)
$$

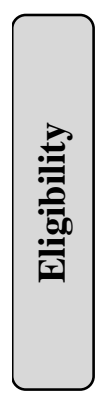

$$
(\mathrm{n}=197)
$$
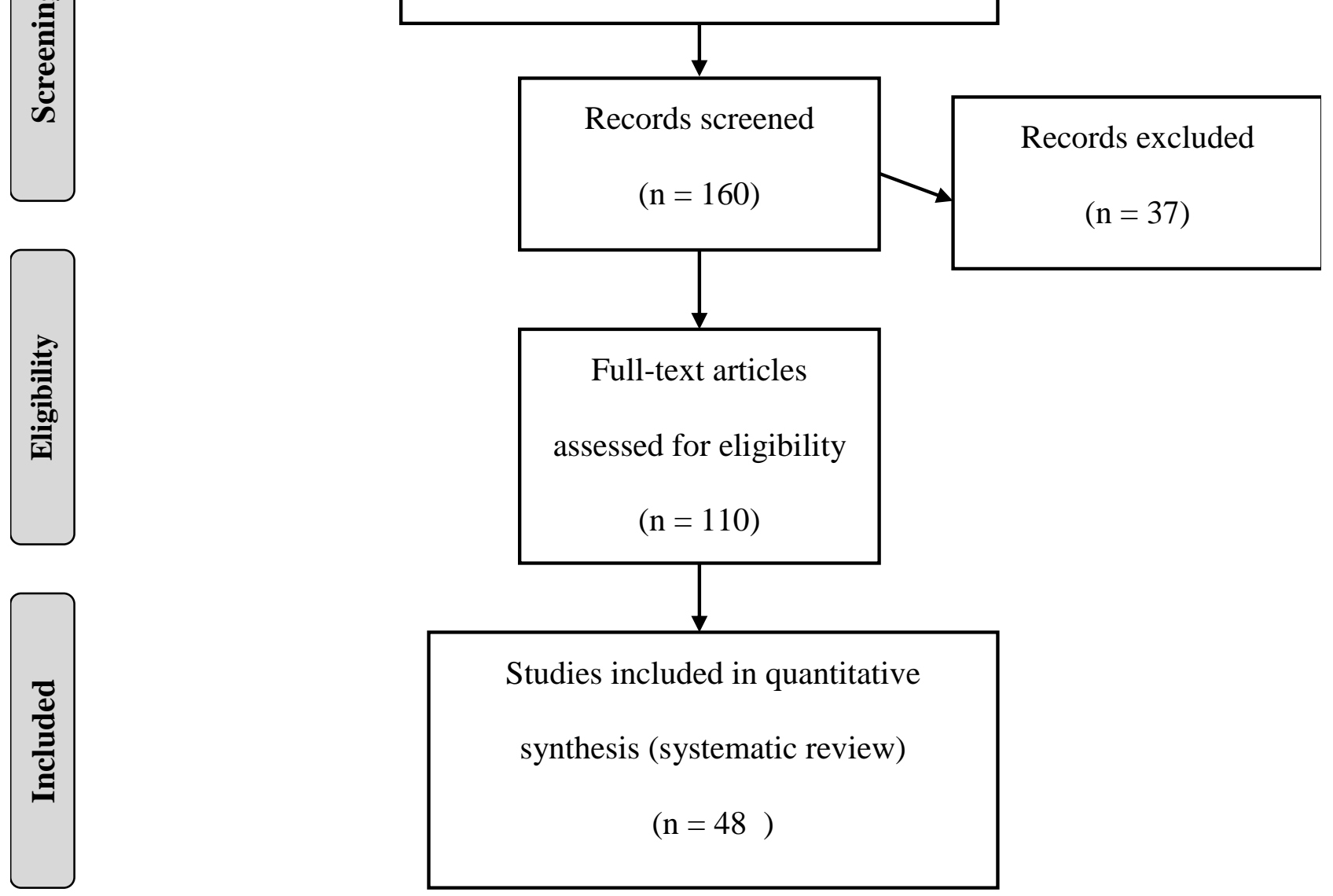

Full-text articles assessed for eligibility

$$
(\mathrm{n}=110)
$$

turies included in quantitative

synthesis (systematic review)

$$
(\mathrm{n}=48)
$$


CHAPTER III

RELATIONSHIPS OF SOCIODEMOGRAPHIC CHARACTERISTICS WITH

GLYCEMIC CONTROL AND DIETARY ADHERENCE IN ADULTS WITH TYPE 2

DIABETES: FINDINGS FROM NATIONAL HEALTH AND NUTRITION

EXAMINATION SURVEY (NHANES 2007-2012)

\section{Introduction}

In 2014, approximately 29.1 million adults in the United States had diabetes; the largest percentage (13.4 million) were between 45 to 64 years of age followed by those 65 years of age or older (11.2 million) (Centers for Disease Control and Prevention [CDC], 2014). According to the CDC (2014), about 15.5 million male adults and 13.4 million female adults have diabetes. Type 2 diabetes (T2D) is often associated with serious complications. African American and Hispanic adults with T2D are more adversely affected by diabetes-related complications in comparison with other ethnic and racial groups (CDC,2014; Lopez, Bailey, Rupnow, \& Annunziata, 2014).

Diabetes-related complications are often preventable by adhering to diabetes treatment regimens and implementing the necessary self-management behaviors (CDC,2014). Self-management is the cornerstone of diabetes control (Gomersall, Madill, $\&$, Summers, 2011). The goal of self-management for persons diagnosed with diabetes is often to modify their behaviors and prevent diabetes-related complications (Hass et al., 2014). 
Behavior modification interventions varied greatly in their effectiveness, and patients' responses toward behavior change differ according to their readiness (Brawley, Rejeski, \& King, 2003). Behavior change strategies for patients diagnosed with diabetes are directed toward improving physical activity, nutrition, and medication adherence (American Diabetes Association [ADA], 2016a).

The purpose of the study was to examine the relationships of sociodemographic characteristics (age, age at diagnosis, sex, race/ethnicity, marital status, education, and income) with adherence to the ADA dietary guidelines and glycated hemoglobin (A1C) in adults diagnosed with T2D. Previous research has supported that sociodemographic characteristics (e.g., age, sex, race/ethnicity, marital status, education, and income) have been significantly associated with dietary adherence and glycemic control in adults with T2D (Ahn, Smith, Dickerson, \& Ory, 2012; Chiu \& Wray, 2010; Rothman et al., 2008; Wong, Gucciardi, Li, \& Grace, 2005). Different age groups had various needs and perceptions of dietary management plans, with the older adults being the most disadvantaged group; older adults showed higher A1C and higher rates of diabetesrelated complications (Casagrande, Franking, Saydah, Rust, \& Cowie, 2013; Rothman et al., 2008). Sex differences were also prominent especially if they were discussed within the context of marital status and spousal support; women were more adherent to dietary management plans than men (Beverly, Wray, Chiu, \& LaCoe, 2014; Rothman et al., 2008). Race/ethnicity also affected dietary management and glycemic control among adults with T2D; African Americans and Hispanics were most adversely affected by diabetes-related complications compared to non-Hispanic Whites (Chlebowy, Kubiak, Myers, \& Jorayeva, 2016; Kollannoor-Samuel et al., 2011; Trinacty et al., 2007). 
Dietary adherence aims to improve glycemic control and prevent diabetes-related complications in adults with T2D. The ADA recommends that nutritional plans for patients with T2D be individually designed by the healthcare team (ADA, 2016b). According to the ADA, the major goal of the medical nutrition therapy (MNT) is to promote healthy eating patterns to maintain body weight goals, improve glycemic control (ADA, 2016b). MNT recommendations include: (1) encouraging moderate weight loss; (2) reducing calorie intake from fats and carbohydrates; (3) increasing intake of carbohydrates from vegetables and fruits; and (4) avoiding sugar-sweetened beverages and foods with added sugars (Pastors, Warshaw, Daly, Franz \& Kulkarni, 2002). The ADA recommends that individually designed nutritional plans consider the sociodemographic characteristics of the patients which may affect the ability to adhere to these plans (ADA, 2016b).

Age is an important characteristic that contributes to dietary adherence. For example, poor adherence to the diabetes diet has been found in adolescents diagnosed with T2D, and race/ethnicity is an added factor that contributes to poorer glycemic control in this age group (Ahia, Holt, \& Krousel-Wood, 2014; Rothman et al., 2008). Young and middle aged Hispanics have poorer glycemic control than older adults (ADA, 2016a); this often occurs as a result of low income and a lack of or inadequate insurance coverage (Kollannoor-Samuel et al., 2011).

Dietary nonadherence is of concern in the older adult population. Hispanics, especially older adults, have poorer glycemic control when compared to non-Hispanic Whites (Lopez et al., 2018; Weinstock et al., 2011). Poor glycemic control in older adults could be explained by decreased food consumption, weight loss, and loss of appetite that 
result from dietary prescriptions (ADA, 2016a). Thus, personal preferences and goals as well as culture should be taken into consideration when individualizing older adults' nutrition plans to improve their satisfaction and quality of life (Dorner, 2010). Dietary adherence is affected by older adults' beliefs of the stability of their symptoms; older adults who believe that their symptoms are stable showed greater ability to adhere to their dietary regimens (Hemphill, Stephens, Rook, Franks, \& Salem, 2013).

Dietary adherence is often challenging for older adults due to cognitive impairment that hinders their abilities to self-manage diabetes (Feil, Zhu, \& Sultzer, 2012). Other comorbidities (e.g., obesity, high cholesterol, high blood pressure, and depression) are additional obstacles to dietary adherence in older adults (Ahn, Smith, Dickerson, \& Ory, 2012). Older adults expressed feelings of frustration, uncertainty, and distress when they integrate multiple lifestyle and behavior changes associated with other comorbid conditions with diabetes (Beverly, Wray, Chiu, \& LaCoe, 2014). These emotions place additional burden on older adults as they attempt to adhere to the prescribed dietary regimens. Furthermore, dietary adherence in this age group is affected by sex, education, and economic status (Bai, Chiou, \& Chang, 2009). Female, highly educated, and higher income older adults reported better adherence to their diabetes diets (Bai et al., 2009; Kirkman et al., 2012).

Older and middle-aged adults are the most disadvantaged age groups among those diagnosed with T2D (Ahn, Smith, Dickerson, \& Ory, 2012; Chiu \& Wray, 2010). However, middle aged adults are slightly different from older adults in regards to the factors that predict glycemic control (Chiu \& Wray, 2010). Sociodemographic characteristics (age, sex, marital status, and education) are the strongest predictors of 
glycemic control for middle-aged adults; treatment modality (e.g., diet only, medication, or insulin) is the most significant predictor of glycemic control in older adults (Chiu \& Wray, 2010).

Sex differences have a profound impact on dietary adherence in patients diagnosed with T2D (De Melo, De Sa, \& Gucciardi, 2013). In a large survey data, women were more adherent to their therapeutic regimen; however, they had higher rates of diabetes-related complications than men, furthermore, women were more likely to restrict unhealthy food items from their diets; men reported consuming moderate amounts of unhealthy food especially in social gatherings (De Melo, De Sa, \& Gucciardi, 2013).

Spousal support influences dietary adherence of persons with T2D (Beverly, Wray, Chiu, \& LaCoe, 2014; Wong, Gucciardi, Li, \& Grace, 2005). Women were more likely engage in dietary self-management activities than men (Beverly et al, 2014). In addition, women were negatively influenced by their husbands; women expressed that their husbands exhibited more control and hostile behaviors in relation to their diet adherence (Wong et al., 2005). On the other hand, men were positively supported by their wives; this support is usually described as instrumental support (e.g., with food preparation) (Wong et al., 2005)

Spouses attempt to regulate health behaviors of their partners who are diagnosed with T2D; this regulation was conceptualized as spousal support that occurs within the context of social control and social influence of spouses upon each other (Stephens, Rook, Franks, Khan, \&Iida, 2010). Health promoting behaviors of spouses were positively related to better dietary adherence; for example, spouses encouraged selecting 
healthier foods. On the other hand, spousal behaviors that were negative, such as warning of adverse consequences of non-healthy food choices, were associated with poor dietary adherence (Stephens et al., 2010).

Adherence to the dietary regimen improves with the appraisal and support of spouses and leads to decreased distress among adults with T2D. Conversely, pressure and persuasion aimed to negatively control spousal behavior leads to increased distress and decreased dietary adherence (Stephens et al., 2013). Distress and depressive symptoms both increased as patients faced more difficulties in managing their diet (Franks et al., 2012). Spouses' attempts to help their partners regain control and manage their diet as the challenges increased (Franks et al., 2012).

Ethnic backgrounds sometimes affect dietary adherence in persons with T2D (Trinacty et al., 2007). Patients from different ethnic backgrounds differ in their perceptions of the difficulty of self-management practices, acceptance of the disease, and glycemic control (Trinacty et al., 2007). Hispanic participants felt restricted by diabetes dietary regimens more than any other ethnic group (Misra \& Lager, 2009). Furthermore, African Americans reported fear and uncertainty in following therapeutic guidelines; they consider their families the main source of support for T2D self-management, followed by their friends and churches (Bhattachary, 2012). In addition, African Americans' abilities to adhere to their regimens differed by the sources of support (Ahia, Holt, \& KrouselWood, 2014).

In summary, sociodemographic characteristics (age, sex, marital status, race/ethnicity, education, and income) affect dietary adherence and glycemic control in 
adults with T2D. Different age groups showed various needs and perceptions of T2D dietary management plans, with the older adults being the most disadvantaged group. Sex differences were also prominent especially if they were discussed within the context of marital status and spousal support. Race/ethnicity was also a determining factor in the differences of dietary management and thus glycemic control among adults with T2D.

Dietary non-adherence is one of the most challenging problems confronting persons with T2D (Halali, Mahdavi, Mobasseri, Jafarabadi, \& Avval, 2016; Marcy, Britton, \& Harrison, 2011; Martin, Williams, Haskard, \& DiMatteo, 2005). In review of the existing literature, few studies have been conducted to examine the impact of sociodemographic characteristics on adherence to the ADA dietary guidelines and A1C in adults with T2D (ADA, 2016a, Weinstock et al., 2011; Chiu \& Wray 2011). Thus, it is important to examine the relationships of sociodemographic characteristics with adherence with ADA dietary guidelines and glycemic control in adults with T2D.

\section{Methods}

\section{Design and Sample}

A secondary analysis of existing de-identified cross-sectional data from the 20072012 National Health and Nutrition Examination Survey (NHANES) was conducted. NHANES is one of a series of health-related surveys conducted by the Centers for Disease Control (CDC) and Prevention's National Center for Health Statistics (NCHS) (CDC, 2016). A unique feature of this survey is the collection of health examination data for a nationally representative sample of the resident civilian non-institutionalized United States population. The survey used a stratified, multistage probability cluster design. For 
NHANES 2007-2010, the Hispanic population and adolescents were oversampled to ensure sample sizes for these populations. The Asian population was oversampled to ensure sample sizes for this population for the NHANES 2011-2014 cycle (CDC, 2016).

\section{Measures}

The NHANES consists of questionnaires administered in the home followed by a standardized health examination in specially equipped mobile examination centers. The demographic data collected during the interview provided information regarding age, sex, race, marital status, education, and household income (CDC, 2016). Data were obtained for adults who were 17 years or old at the time of the interview and had been diagnosed with T2D. Age at diagnosis was obtained from the NHANES Diabetes Questionnaire (CDC, 2016).

The NHANES Weight History section of the Sample Person Questionnaire provides personal interview data on several topics related to body weight, including selfperception of weight, attempted weight loss during the past 12 months, and methods used to try to lose weight (CDC, 2016). Nine questions of the Weight History section were selected to determine dietary adherence (with ADA guidelines) in patients diagnosed with T2D. The first question was: During the past 12 months, \{have you/has SP\} tried to lose weight? Subsequent questions asked the respondents to identify how they tried to lose weight by choosing one or more of 20 options. For the purpose of this study, nine options that include ADA dietary guidelines were selected: (1) ate less to lose weight; (2) switched to foods with lower calories; (3) ate less fat to lose weight; (4) ate diet foods or 
products; (5) followed a special diet (6) ate fewer carbohydrates; (7) ate more fruits, vegetables, salads; (8) changed eating habit; and (9) ate less sugar, candy, sweets.

Internal consistency reliability was tested for the nine questions (Cronbach's $\alpha$ was 0.79 ) measuring adherence with the ADA dietary guidelines. A total score was created for adherence with ADA dietary guidelines. The total score was created for participants who tried to lose weight a year before the questionnaire was administered and at least tried one of the methods to lose weight as suggested by the Weight History Questionnaire. The total score was created by summing the scores of the responses to the selected nine questions. The scores ranged between 1 and 9, the distribution of the scores appeared to be bimodal; thus, the median was used as a cutoff point to categorize the respondents into adherent and non-adherent to the ADA dietary guidelines (see Table 4), the median was found to be 4 .

In accordance with a standardized protocol, a trained professional drew a blood sample A1C) from each participant's antecubital vein. A1C, a diabetes test that reflects plasma glucose for the previous 120 days, has been used to monitor diabetes for many years (Bohanny et al., 2013). In recent years, new clinical recommendations included applying hemoglobin $\mathrm{A} 1 \mathrm{C}$ to the diagnoses of diabetes $(6.5 \%$ [48 $\mathrm{mmol} / \mathrm{mol}]$ or greater) and pre-diabetes $(5.7 \%-6.4 \%$ [39 mmol/mol-46 mmol/mol]). A1C measurements were performed on the A1c G7 HPLC Glycohemoglobin Analyzer (Tosoh Medics, Inc., 347 Oyster Pt. Blvd., Suite 201, So. San Francisco, Ca 94080) (CDC, 2016).

\section{Procedure}


The data for this secondary analysis are publically available; thus, this study did not require institutional review board approval. Informed consents were obtained from all participants by the CDC. In addition, participants were informed that their blood specimens would be stored for future research (CDC, 2016).

\section{Statistical Analyses}

Sample weights were used for all data analysis. Data were weighted according to NHANES weighting procedures and guidelines (CDC, 2016). First, descriptive statistics were calculated to describe the study sample using frequencies and percentages for all categorical variables and means and standard deviations for all continuous variables. The distribution of adults with T2D who tried to lose weight in the past year in relation to ADA guidelines was calculated. Second, bivariate analyses were conducted to determine associations of sociodemographic characteristics with A1C and adherence to ADA dietary guidelines. A $\chi^{2}$ test was employed to determine associations between adherence with ADA dietary guidelines and the sociodemographic characteristics. Third, unadjusted odds ratios and their respective $95 \%$ confidence intervals were calculated to determine the odds of non-adherence with ADA dietary guidelines for each characteristic. Fourth, independent t-tests and one-way ANOVAS were employed to evaluate potential associations between $\mathrm{A} 1 \mathrm{C}$ and each sociodemographic variable. All data were analyzed using SPSS version 22 (Armonk, NC), and p-values $<0.05$ were regarded as statistically significant.

To determine the factors associated with non-adherence to the ADA dietary guidelines, a logistic regression model was developed to model the probability of non- 
adherence to the ADA dietary guidelines. Unadjusted and adjusted odds ratios were calculated. Characteristics with a p-value less than 0.05 for $\chi 2$ test were initially included in the model. A simultaneous method was used and -2 Log Likelihood goodness of fit test was conducted to determine goodness of fit for the model. All models were compared using the likelihood ratio test.

Multiple regression was performed to identify sociodemographic characteristics (age, age at diagnosis of T2D, sex, race/ethnicity, marital status, education, and income level) association with A1C. Prior to conducting multiple regression, linearity and normality of the dependent variable for each level of the independent variables and homoscedasticity assumptions were all verified. Multicollinearity statistics were obtained and assessed. Then, all of the variables were entered simultaneously into the multiple regression model.

\section{Results}

A total of 1,401 individuals diagnosed with T2D responded to the NHANES between 2007 and 2012. A majority were female (52.7\%), married or in a relationship (61.5\%), and non-Hispanic Whites (66.1\%). Approximately $27 \%$ had a college degree or higher. Approximately $32 \%$ of participants reported they tried to lose weight in the past 12 months; of those, 59\% were adherent to the ADA dietary guidelines (see Table 4). The most common method used in an attempt to lose weight was eating less food (11.3\%), followed by eating less fat $(7.1 \%)$ and eating lower calorie food (6.6\%) (Table 9).

Adherence to the ADA guidelines was significantly associated with sex, race/ethnicity, marital status, education, and income (see Table 6). Participants who were 
adherent were more likely to be males, non-Hispanic Whites, and married compared to their counterparts.

Although effect sizes were small (Cohen's $d$ ranged between 0.0002 to 0.2 ), sex, race/ethnicity, marital status, education, income, trying to lose weight in the past 12 months, and adherence to the ADA dietary guidelines were significantly $(p<0.0001)$ related to A1C. Females, non-Hispanic Blacks, widowed, and those with less than high school education had higher A1C than their counterparts (Table 7).

Table 8 presents the results of the logistic regression modeling the odds of being non-adherent to the ADA dietary guidelines. After controlling for the other variables in the model, non-Hispanic Whites had much lower odds of reporting non-adherence to the ADA dietary guidelines compared to Hispanics (odds ratio $(\mathrm{OR})=0.46 ; 95 \%$ confidence interval $(\mathrm{CI})=0.45-0.46)$. Individuals who were single had 1.35 times $(95 \% \mathrm{CI}=1.34$ 1.36) the odds of reporting non-adherence to the ADA dietary guidelines compared to those who were married, controlling for all the other variables in the model. Compared to males, females had much higher odds of reporting non-adherence to the ADA dietary guidelines $(\mathrm{OR}=1.90 ; \mathrm{CI}=1.89-1.99)$, after controlling for all the other variables in the model.

As shown in Table 7, age, age at diagnosis, sex, race/ethnicity, marital status, education and income explained a significant amount of the variance in A1C values $[F$ $\left(13,9.8 \times 10^{6}\right)=8.3 \times 10^{4}, p<0.0001, R^{2}$ Adjusted $\left.=0.11\right]$. Educational level significantly predicted A1C values. For example, those with a high school education had a decrease of 
0.22 standard deviations below the mean of the $\mathrm{A} 1 \mathrm{C}$ when compared to their counterparts with less than a high school education $\left(\beta=-0.22, t\left(9.8 \times 10^{6}\right)=-201.5, p<0.0001\right)$.

\section{Discussion}

In the current study, sex, race/ethnicity, marital status, education, and income were all significantly associated with adherence to the ADA dietary guidelines. NonHispanic Whites had a reduced risk of reporting non-adherence to the ADA dietary guidelines compared to Hispanics. Those who were single were more likely to report non-adherence with ADA guidelines compared to those were married or in a relationship. These findings are similar to the findings of other studies in which race/ethnicity (Bohanny et al., 2013; Stephens, Rook, Franks, Khan, \&Iida, 2010; Trinacty et al., 2007) and marital status (Wong, Gucciardi, Li \& Grace, 2005) were among the sociodemographic characteristics that influenced T2D self-management and dietary adherence. This study was unique in that many self-report indicators were used to measure adherence with ADA dietary guidelines, specifically losing weight, reducing intake of fats and carbohydrates, and increasing intake of fruits and vegetables. In addition, the sociodemographic characteristics predicted the glycemic control among the various age groups, aligning with Chiu and Wray's (2010) research in which sociodemographic characteristics (age, sex, marital status, and education) were among the strongest predictors of glycemic control among middle-aged adults. It is interesting to note that while adherence to ADA dietary guidelines was significantly associated with A1C, it was not a significant predictor in the regression model. Additional exploration of the role of dietary adherence to ADA guidelines in predicting A1C is warranted since dietary adherence has been directly associated with A1C (Cosansu \& Erdogan, 2013). In 
future studies, it would be important to explore the predictive value of additional selfmanagement behaviors such as physical exercise, blood glucose monitoring and coping skills.

This study was limited due to the fact it was a secondary analysis of self-report data and used a cross-sectional design. Although sex, age, race/ethnicity, and marital status have been associated with glycemic control in previous studies (Ahn, Smith, Dickerson, \& Ory, 2012; Beverly, Miller, \& Wray, 2008; Rothamn et al., 2008), the effect sizes of these associations were very small. In addition, in this study the use of A1C was the sole indicator of glycemic control. Using another indicator indicative of glycemic control, such as fasting blood glucose or body mass index may improve the predictive ability of the model and, thus, explain the variations in glycemic control. For future studies, the addition of more self-management variables (e.g., caloric intake of diverse food types, exercise, medication use, coping) to the model may improve its ability to predict glycemic control. Dietary adherence could also be explored as a mediator variable between sociodemographic characteristics and glycemic control to improve the understanding of the relationship between sociodemographic characteristics and glycemic control. Health literacy is also thought to have a mediating effects in the relationship between self-management and glycemic control (Lee et al., 2016) and should be examined in future studies.

\section{Conclusion}

Given the associations of sociodemographic characteristics with ADA dietary adherence and $\mathrm{A} 1 \mathrm{C}$ levels, the assessment and subsequent treatment planning process for 
individuals with T2D should consider the age, race/ethnicity, cultural background, education level and economic status of the individual. The National Standards for Diabetes Self-Management Education and Support (Haas et al., 2013) recommends individualizing patient education for persons with diabetes. For example, knowing that single patients are less adherent to their diet requires the educator to focus on the cultural appropriateness of the educational materials and methods. In addition, minorities such as Hispanics may require more attention in designing dietary plans. For example, moderately low carbohydrate and vegetarian diets could be tailored for the person taking into consideration personal preferences and cultural differences to aid in managing diabetes and preventing diabetes-related complications (Ley, Hamdy, Mohan, \& Hu, 2014). Dietary management of diabetes is also greatly affected by economic status; for example, persons with low economic status are often not able to adhere to dietary management plans due to the costs of healthy food (Weaver, Lemonde, Payman, \& Goodman, 2014). In addition, more spousal support and higher level of education are associated with better dietary management and diabetes control (Formosa, \& Muscat, 2016; Weaver, Lemonde, Payman, \& Goodman, 2014).

This study supported that specific sociodemographic characteristics predicted glycemic control in adults with T2D. Race/ethnicity and marital status were determinant factors in predicting adherence with the ADA dietary guidelines. This information is helpful for health care providers as they educate patients of diverse ethnic and racial backgrounds.

The relationships of sociodemographic characteristics with dietary adherence and glycemic control will help in individualizing diabetes education. Diabetes educators and 
other health care providers should assess the patient's personal needs and characteristics prior to designing a patient's education plan (ADA, 2007). The assessment process should take into consideration a patient's sociodemographic characteristics such as age, race/ethnicity, cultural background, educational level, and economic status. 


\section{Tables}

Table 4. Descriptive Characteristics of Adults with T2D (> 17 Years of age) Obtained from NHANES (2007-2012) Survey Data $\left(N=17.14 \times 10^{6}\right) *$

$\begin{array}{ll}\mathrm{M}(\mathrm{SE}) & \text { Weighted count, } \\ & \text { estimated frequency }(\%)\end{array}$

Age

$45.14(0.004)$

$17.14 \times 10^{6}$

Age at diagnosis

$49.27(0.004)$

$16.96 \times 10^{6}$

A1c

$5.64(0.0003)$

$10.86 \times 0^{6}$

Sex

Male

$9.11 \times 10^{6}(47.3)$

Female

$8.03 \times 10^{6}(52.7)$

Race

Hispanic

$2.40 \times 10^{6}(14.0)$

Non-Hispanic White

$11.3 \times 10^{6}(66.1)$

Non-Hispanic Black

$2.00 \times 10^{6}(11.7)$

Other

$1.40 \times 10^{6}(8.2)$

\section{Marital Status}

Married /in a relationship

$9.93 \times 10^{6}(61.5)$

Divorced/Separated

$2.26 \times 10^{6}(14.0)$ 
Widowed

Single

Education

$<$ High school

$3.02 \times 10^{6}(18.7)$

High school

$3.55 \times 10^{6}(21.4)$

Some college

$5.22 \times 10^{6}(32.3)$

College or higher

$4.46 \times 10^{6}(27.6)$

Income

$<\$ 25,000$

$3.73 \times 10^{6}(22.6)$

$\geq \$ 25,000$

$12.79 \times 10^{6}(77.4)$

Did you try to lose weight in the

past year

Yes

$3.0 \times 10^{6}(31.9)$

No

$6.5 \times 10^{6}(68.1)$

\section{Adherence with ADA dietary}

\section{Guidelines}

Yes

$1.59 \times 10^{6}(59.0)$

No

$1.1 \times 10^{6}(41.0)$ 
Table 5. Associations between Demographic Characteristics and Dietary Adherence Among Those Who Tried to Lose Weight in The Past Year Obtained from NHANES (2007-2012) Survey Data $\left(N=2.69 \times 10^{6}\right) *$

Adherence with ADA Dietary Guidelines

\begin{tabular}{cccc}
\hline Yes & No & $\mathrm{X}^{2}$ & $p$ \\
$\mathrm{~N}(\%)$ & $\mathrm{N}(\%)$ & & \\
& & \\
\hline
\end{tabular}

Sex

Male

$8.1 \times 10^{5}(51.2) \quad 3.8 \times 10^{5}(34.5) \quad 7.3 \times 10^{4} \quad<0.0001$

Female

$7.7 \times 10^{5}(48.8) \quad 7.2 \times 10^{5}(65.5)$

Race

Hispanic

$2.4 \times 10^{5}(14.9)$

$2.1 \times 10^{5}(19.1)$

$8.1 \times 10^{4}<0.0001$

Non-Hispanic

$1.0 \times 10^{6}(65.3) \quad 5.6 \times 10^{5}(50.4)$

White

Non-Hispanic

$2.0 \times 10^{5}(12.6) \quad 1.6 \times 10^{5}(14.3)$

Black

Others

$1.1 \times 10^{5}(7.2) \quad 1.8 \times 10^{5}(16.2)$

(Continued) 


\section{Marital Status}

$\begin{array}{lllll}\text { Married/In } & 1.0 \times 10^{6}(67.9) & 6.8 \times 10^{5}(67.2) & 4.6 \times 10^{4} & <0.0001 \\ \text { Relationship } & & & \end{array}$

Divorced/Separated $1.2 \times 10^{5}(8.3) \quad 8.0 \times 10^{4}(7.9)$

Widowed $\quad 1.7 \times 10^{5}(11.6) \quad 5.5 \times 10^{4}(5.4)$

Single $\quad 1.8 \times 10^{5}(12.2) \quad 1.9 \times 10^{5}(19.5)$

\section{Education}

$\begin{array}{llll}<\text { High School } & 3.8 \times 10^{5}(25.4) & 1.9 \times 10^{5}(18.7) & 7.9 \times 10^{4}<0.0001 \\ \text { High School } & 2.9 \times 10^{5}(19.3) & 2.1 \times 10^{5}(20.8)\end{array}$

Some College $\quad 3.6 \times 10^{5}(24.2) \quad 4.0 \times 10^{5}(39.1)$

College Degree or $\quad 4.6 \times 10^{5}(31.1) \quad 2.3 \times 10^{5}(21.3)$

Higher 


\section{Income Level}

\begin{tabular}{|c|c|c|c|}
\hline$<\$ 25,000$ & $4.7 \times 10^{5}(30.9)$ & $2.8 \times 10^{5}(26.5)$ & $6.0 \times 10^{3}$ \\
\hline$\geq \$ 25,000$ & $1.0 \times 10^{6}(69.1)$ & $7.8 \times 10^{5}(73.5)$ & \\
\hline
\end{tabular}

*Note: the number of valid cases for analysis are varied across the variables. 
Table 6. T-Test and One-Way ANOVA results Applied to the AlC Related to Sex, Race, Education, Marital Status, Income, and Dietary Adherence Obtained from NHANES (2007-2012) Survey Data $\left(N=17.14 \times 10^{6}\right) *$

\begin{tabular}{|c|c|c|c|c|c|}
\hline Characteristics & $\begin{array}{l}\text { Mean (95\% } \\
\text { Confidence } \\
\text { Interval }[\mathrm{CI}])\end{array}$ & $\mathrm{DF}^{* *}$ & $\begin{array}{l}\text { F/t-test } \\
\text { results }\end{array}$ & P-Value & Cohen's $d$ \\
\hline Sex & & $10.58 \times 10^{6}$ & -107.272 & $<0.0001$ & 0.07 \\
\hline Male & $5.60(5.60-5.60)$ & & & & \\
\hline Female & $5.67(5.67-5.67)$ & & & & \\
\hline Race & & $\left(3,10.86 \times 10^{6}\right)$ & 13061.30 & $<0.0001$ & 0.004 \\
\hline Hispanic & $5.68(5.67-5.68)$ & & & & \\
\hline
\end{tabular}

Non-Hispanic White $\quad 5.60(5.60-5.60)$

Non-Hispanic Black $\quad 5.79(5.78-5.79)$

Other Race $\quad 5.61(5.61-5.61)$

$\begin{array}{lllll}\text { Marital Status } & \left(3,10.26 \times 10^{6}\right) & 801.45 & <0.0001 & 0.0002\end{array}$

Married/in a $\quad 5.64(5.64-5.64)$

relationship

Divorced/Separated $\quad 5.61(5.61-5.61)$ 
Widowed

Single $\quad 5.62(5.61-5.62)$

\section{Education}

$<$ High school

High School

Some college

College degree

Income

$<25,000$

$>25,000$

Did you try to lose

weight in the past

year?

Yes

No

$5.68(5.68-6.69)$

$5.63(5.62-5.63)$

$5.65(5.65-5.66)$

$5.70(5.70-5.70)$

$5.61(5.61-5.61)$

$5.66(5.65-5.66)$

$5.63(5.63-5.63)$ $\left(3,10.26 \times 10^{6}\right) \quad 19041.12<0.0001 \quad 0.006$

$5.76(5.76-5.77)$

$5.52(5.52-5.52)$

$\begin{array}{llll}3.8 \times 10^{6} & 106.11<0.0001 & 0.11\end{array}$

$\begin{array}{llll}8.8 \times 10^{6} & 32.6 & <0.0001 & 0.02\end{array}$ 
with ADA Guidelines

$\begin{array}{ll}\text { Yes } & 5.78(5.78-5.79) \\ \text { No } & 5.55(5.55-5.55)\end{array}$

*The number of valid cases for analysis is varied across the variables.

** DF: Degrees of Freedom 
Table 7. A Multiple Linear Regression Model of the AlC Obtained from NHANES (20072012) Survey Data $\left(N=17.14 \times 10^{6}\right) *$

Unstandardized

Coefficients Standardized Coefficients

Model B Std. Error Beta $t \quad p$

(Constant)

$5.8 \quad 0.002$

$2341.9<0.0001$

Age at Diagnosis (per one-year $\quad 7.8 \times^{10-5} \quad 0 \quad-0.006 \quad-19.8 \quad<0.0001$ increase)

$\begin{array}{llllll}\text { Age (per one-year increase) } & -0.001 & 0.0001 & -0.01 & -24.9 & <0.0001\end{array}$

Sex

Male

$\begin{array}{lllll}0.041 & 0.001 & 0.02 & 60.1 & <0.0001\end{array}$

Female

Race

Non-Hispanic White

Hispanic

$\begin{array}{lllll}0.08 & 0.001 & 0.02 & 69.5 & <0.0001\end{array}$

(Continued) 
Non-Hispanic Black

Other Race

\section{Marital Status}

Married/in a relationship

Divorced/Separated

Widowed

Single

\section{Education}

$<$ High school

High School

Some college

College degree

\section{Income}

$\leq 25,000$

$>25,000$

$0.17 \quad 0.001$

$\begin{array}{lll}-0.03 & 0.001 & -0.009\end{array}$

$-26.1$

$<0.0001$

$\begin{array}{lllll}-0.037 & 0.001 & -0.012 & -35.7 & <0.0001\end{array}$

$\begin{array}{lllll}0.02 & 0.002 & 0.005 & 15.0 & <0.0001\end{array}$

$\begin{array}{lllll}-0.02 & .001 & .008 & -23.3 & <0.0001\end{array}$

$\begin{array}{lllll}-0.22 & .001 & .09 & -201.5 & <0.0001\end{array}$

$\begin{array}{lllll}0-.13 & 0.001 & -0.06 & -118.8 & <0.0001\end{array}$

$\begin{array}{lllll}-0.06 & 0.001 & -0.03 & -55.714 & <0.0001\end{array}$

$\begin{array}{lllll}-0.07 & 0.001 & -0.03 & -78.2 & <0.0001\end{array}$

(Continued) 
f-test for the whole model

Significance level (overall)

Adjusted $\mathrm{R}^{2}$
$8.3 \times 10^{4}$

$<0.0001$

0.11

*The number of valid cases for analysis is varied across the variables. 
Table 8. Logistic Regression Results Modeling the Odds of Dietary Non-Adherence Among Those Who Tried to Lose Weight in The Past Year Obtained from NHANES (2007-2012) Survey Data $\left(N=2.69 \times 10^{6}\right) *$

\section{Variables}

\section{Dietary Non-Adherence}

\begin{tabular}{lccc}
\hline Unadjusted & $95 \%$ & Adjusted & \\
Odds Ratio & $\mathrm{CI}^{* *}$ & Odds & $95 \% \mathrm{CI}^{* *}$ \\
& & Ratio
\end{tabular}

Age - one-year

$0.98 \quad .098-.098$

0.99

0.99-0.99

increase

Age at diagnosis-

$1.02 \quad 1.02-1.02 \quad 1.02$

$1.02-1.02$

one-year increase

Sex

\begin{tabular}{crrrr} 
Male & ref & \multicolumn{3}{c}{ ref } \\
Female & 1.99 & $1.98-2.00$ & 1.90 & $1.89-1.91$
\end{tabular}

Race

Hispanic ref ref




\begin{tabular}{ccccc}
\hline Non-Hispanic White & 0.61 & $0.60-0.61$ & 0.46 & $0.45-0.46$ \\
Non-Hispanic Black & 0.89 & $0.88-0.90$ & 0.77 & $0.76-0.78$ \\
Others & 1.77 & $1.75-1.78$ & 1.80 & $1.78-1.82$
\end{tabular}

\section{Marital Status}

Married/In ref ref

Relationship

$\begin{array}{ccccc}\text { Divorced/Separated } & 0.97 & 0.95-0.97 & 0.81 & 0.80-.82 \\ \text { Widowed } & 0.47 & 0.47-.048 & 0.57 & 0.56-0.57 \\ \text { Single } & 1.60 & 1.60-162 & 1.35 & 1.34-1.36\end{array}$

\section{Education}

\begin{tabular}{ccccc}
$\begin{array}{c}\text { High School } \\
\text { High School }\end{array}$ & ref & \multicolumn{2}{c}{ ref } & \\
Degree & 1.46 & $1.45-1.47$ & 2.03 & $2.01-2.05$ \\
Some College & 2.20 & $2.18-2.20$ & 2.07 & $2.05-2.09$ \\
& & & & \\
College Degree or & 0.93 & $0.92-0.93$ & 0.79 & $0.78-.80$
\end{tabular}

Higher

(Continued) 


\section{Income Level}

\begin{tabular}{|c|c|c|c|}
\hline$<\$ 25,000$ & ref & & ref \\
\hline$\geq \$ 25,000$ & 1.24 & $1.23-1.25$ & 1.35 \\
\hline
\end{tabular}

*The number of valid cases for analysis is varied across the variables.

$* * \mathrm{CI}=$ Confidence Interval

Table 9. The Distribution of Adults with T2D Who Tried to Lose

Weight in Past Year in Relation to ADA Guidelines $(N=638)$

$$
\mathrm{n}(\%)
$$

1. Ate less to lose weight

$159(11.3)$

2. Switched to foods lower in calories

92(6.6)

3. Ate less fat to lose weight

$100(7.1)$

4. Ate diet foods or products

29(2.1)

5. Followed a special diet

24(1.7)

6. Ate fewer crabs

61(4.4)

7. Ate more fruits, vegetables, or salads

78(5.6)

8. Changed eating habits

47(3.4)

9. Ate less sugar, candy, or sweets

48(3.4) 


\section{CHAPTER IV}

\section{SELF-MANAGEMENT AS A MEDIATOR OF THE RELATIONSHIP BETWEEN}

\section{SOCIAL SUPPORT AND HEALTH OUTCOMES OF AFRICAN AMERICAN}

\section{ADULTS WITH TYPE 2 DIABETES}

\section{Introduction and Background}

It was estimated that $12.2 \%$ (30.2 million) of the United States adults had diabetes in 2015 (Centers for Disease Control and Prevention [CDC], 2017). The prevalence of diabetes among Asians, non-Hispanic blacks, and Hispanics are higher than their nonHispanic Whites counterparts (CDC, 2017). African American adults with type 2 diabetes (T2D) experience higher rates of diabetes-related complications than other ethnic groups (CDC, 2017). Heredity, economic status, and limited access to health care services are possible factors that may increase the rates of complications among African Americans with T2D (Chlebowy \& Garvin, 2006).

Diabetes-related complications affect various body systems, causing diseases and conditions that include cardiovascular diseases, stroke, kidney failure, blindness, and amputations (CDC, 2017). In addition, the psychological wellbeing of patients with T2D is affected adversely; depression is one complication commonly associated with T2D (CDC, 2014). Studies showed that persons diagnosed with T2D are at an increased risk of developing depression compared to persons without T2D (Nouwen et al., 2010; Penckofer, Doyle, Byrn, \& Lustman, 2014) African Americans with T2D are often unlikely 
to discuss their depressive symptoms with their health care professionals, to be seen by a psychiatrist, or to be prescribed antidepressants (Wagner et al., 2009).

Depression is associated with diabetes-related distress (Fisher et al., 2010). Diabetes-related distress is conceptualized as the negative emotional reactions to the diagnosis of diabetes and diabetes-related self-management demands, and complications (Gonzalez, Fisher, \& Polonsky, 2011). In addition, the negative psychological impact of T2D includes the symptoms of anxiety and stress (Fisher et al., 2008; Lloyd, Smith, \& Weinger, 2005). Patients diagnosed with diabetes are at a higher risk of having anxiety symptoms than people without diabetes (Smith et al., 2013). Conversely, persons with higher levels of anxiety are at an increased risk for having T2D (Engum, 2007).

Depression, anxiety, and stress are occurring at higher rates among African Americans (Soto, Dawson-Andoh, \& BeLue, 2011). Functional social support is thought to have a buffering effect on these disorders (Shallcross et al., 2015). However, few studies (Collins-McNeil, 2006; Kim et al., 2009) explored the relationships of these disorders with T2D among African Americans. These limitations could be attributed to small sample sizes; for example, the number of participants in Thomas, Jones, Scarinci, and Brantley (2007) and Collins-McNeil (2006) studies were 58 and 57, respectively. Another limitation is the women-to-men ratio; for example, participants in the Thomas et al. study were mostly (65\%) women. Furthermore, Penckofer, Doyle, Byrn, and Lustman (2014) and Kim et al. (2009) conducted studies only with women.

A significant association was found between diabetes-related distress and diabetes self-management that consequently affected glycemic control (Fisher et al., 2008, 2010). Thus, it is essential to delineate the predisposing variables associated with the increased 
risk of these complications and to understand how they are related to patients' outcomes to prevent and eliminate the existing disparity affecting African American adults with T2D.

Studies showed that diabetes-related complications are prevented by selfmanagement that constitute health-related behavior change (Berard et al., 2013; Chlebowy \& Garvin, 2006; Komar-Samardzija, Braun, Keithley, \& Quinn, 2012), which enables persons with T2D to control their disease (Haas et al., 2013).

Diabetes self-management is affected by the availability of social support dimensions (function, structure, and quality) (Strom, \& Egede, 2012; Komar-Samardzija, et al., 2012; Watkins et al., 2013). Functional social support is positively associated with better glycemic control (Cosansu \& Erdogan, 2013). Functional social support is defined by Langford, Bowsher, Maloney, and Lillis (1997) as instrumental, informational, emotional, and appraisal support. Functional social support can improve positive behavior change and self-management that leads to improved biobehavioral and psychological outcomes (Egede \& Osborn, 2010; Gallegos-Carrillo, García-Peña, DuránMuñoz, Flores, \& Salmeron, 2009; Murano et al., 2014).

Psychological outcomes that include depression, anxiety, and stress are positively impacted by high quality social support in persons with T2D (Hessler, Fisher, Naranjo, \& Masharani, 2011; Yang, Li, \& Zheng, 2009); In addition, a positive correlation of social support dimensions with glycemic control has been found in this population (Smalls, Gregory, Zoller, \& Egede, 2015; Walker, Gebregziabher, Martin-Harris, \& Egede, 2014).

The strength and the direction of the dimensions of social support (function, structure, and quality) with the outcomes of T2D should be studied (Osborn and Egede, 
2010). In addition, there is no specific measure of social support designed specifically for African Americans with T2D (Collins-McNeil, 2006). Furthermore, using different measures to assess various dimensions of social support enhances the ability to capture the multidimensionality of the social support concept (Al-Dwaikat \& Hall, 2017; Gallegos-Carrillo, García-Peña, Durán-Muñoz, Flores, \& Salmeron, 2009). In addition, it is important to note that the effect of self-management as a mediator variable in the relationship between social support and health outcomes was explored in a few studies (Cosansu \& Erdogan, 2013; Nicklett \& Liang, 2010; Strom \& Egede, 2012; Vest et al., 2013). Thus, it is warranted to explore how self-management mediates the relationship between different dimensions of social support and diabetes biomarkers and psychosocial outcomes in African American adults with T2D. These findings would enable health care professionals to be more familiar with the factors that are related to diabetes-related outcomes in African Americans with.T2D.

\section{Theoretical Framework}

Pender's Health Promotion Model (HPM) was used as a theoretical framework for this study. The primary purpose of the model is to assist nurses to better understand the determinant variables of health behavior that will form a basis for behavior change leading to a healthier lifestyle (Pender, 2011, p. 3). The relationships of social support dimensions with self-management behaviors, diabetes biomarkers, and psychosocial outcomes of African American adults with T2D will be conceptualized within the three major components of the HPM (Figure 1).

This model shows that a possible direct relationship of sociodemographic characteristics on health outcomes should be taken into consideration when studying the 
impact of social support dimensions on these outcomes (Pender, 2011; Pender et al., 2002). In addition, a direct relationship is expected between social support dimensions with health outcomes. Furthermore, self-management behaviors are expected to mediate the relationship between social and health outcomes of T2D using this model (Figure 1).

\section{Purpose and Specific Aims}

The purpose of this cross-sectional exploratory study was to examine the role of self-management (diet, medication, exercise, blood glucose testing, and foot care) as a mediator of the impact of the three dimensions of social support (function, structure, and quality) on diabetes biomarkers (glycated hemoglobin [A1C] and Body Mass Index $[\mathrm{BMI}]$ ) and psychosocial health outcomes (depression, anxiety, and stress) in African American adults with T2D.The specific aims were to: (1) examine the associations of social support dimensions with self-management behaviors of African American adults with T2D adjusting for sociodemographic characteristics; (2) examine the associations of social support dimensions with diabetes biomarkers and psychosocial outcomes among African American adults diagnosed with T2D adjusting for sociodemographic characteristics; and (3) examine whether the associations of social support dimensions with diabetes biomarkers and psychosocial outcomes are mediated by self-management behaviors of African American adults with T2D adjusting for sociodemographic characteristics.

\section{Research Design and Methods}

\section{Design and Setting}

This study was conducted using a cross-sectional design to explore the relationships of social support dimensions with biomarkers and psychosocial outcomes in 
African American adults with T2D. African American adults diagnosed with T2D were interviewed for responses to a series of standardized instruments that assess: (1) demographics (sex, age, age at diagnosis, education, and income); (2)functional social support, structure of social support, and quality of social support; and (3) selfmanagement behaviors, depression, anxiety, and stress. Diabetes biomarkers (A1C and BMI), and depression, anxiety, and stress were the major outcome variables. The participants were recruited from an outpatient clinic in a midsize southern city in the United States.

\section{Sample}

A convenience sample of 102 clients was recruited from an outpatient clinic. Sample size was calculated on power analysis calculations. The clients were included in the study if they were: (1) African American; (2) aged 18 years and older; (3) diagnosed with T2D; (4) able to speak, read, and write in English; and (5) able to understand study procedures. The clients were excluded if they are treated for T2D in places other than the targeted clinic. Only two participants declined to continue the study after signing informed consents.

\section{Measures}

Demographic characteristics and medical history. The following demographic characteristics were assessed via self-report: (a) age, (b) age at diagnosis, (c) sex, (d) marital status, (e) education, (f) employment status, (g) type of health insurance, and (h) income. Medical history data were obtained regarding (a) history of smoking and alcohol consumption, (b) other morbidities, (c) medications, and (d) diabetes education history. These data were obtained at the time of the interviews with the participants. 
Social support (functional support). Social support was measured using the Medical Outcomes Study Social Support Survey (MOS-SSS), (Sherbourne \& Stewart, 1991). The MOS-SSS is a brief, comprehensive measure of available functional support. The MOS-SSS is composed of 19 items that assess emotional support, informational support, tangible support, positive social interaction, and affectionate support (Sherbourne, \& Stewart, 1991). The respondents were asked to indicate the available amount of support by selecting one of the following choices: (1) none of the time, (2) a little of the time, (3) some of the time, (4) most of the time, and (5) all of the time. An item was added to the measure asking for the number of support persons, such as relatives and friends who were available to the respondent. Sherbourne and Stewart (1991) suggested that a score for each subscale could be calculated by averaging the scores of each item in the subscale and then transforming the score to range from 0 to 100 such that higher scores indicate more available support. The overall Cronbach's $\alpha$ was .97 , the test-retest reliability correlation was .78 for the overall support measure; subscales' correlations ranged between .72 and .76 . All of the items showed strong correlations with their hypothesized subscales ( $\geq$.72) (Sherbourne, \& Stewart, 1991). In this study the Cronbach's $\alpha$ for the total scale was .97. The MOS-SSS showed strong evidence of reliability and validity as a measure of social support.

Social Support Questionnaire shortened version (SSQ6). The SSQ6 was developed by Sarason, Sarason, Shearin and Pierce (1987) from the 27-item social support questionnaire developed by Sarason et al. (1983). The SSQ6 was developed to measure perceived social support in terms of the number of support persons and the satisfaction with the support derived from these persons. The SSQ6 is composed of 12 
items, six items for each category. The responses for the number $(\mathrm{N})$ items range from "no one" to "9 persons" for each item. Six responses were used for satisfaction (S), which range from "very satisfied" to "very dissatisfied." The score of the SSQ6 is calculated by taking the average of the number of support persons to get the SSQN score, which ranges from 0 to 9 , and the average of the satisfaction score, which ranges from 1 to 6. The Cronbach's $\alpha$ for the SSQ6 were .90 and .93 for $\mathrm{N}$ and $\mathrm{S}$ items, in this study the Cronbach's $\alpha$ was .93 for the SSQ6N subscale and .94 for the SSQ6S subscale.

The Autonomy and Relatedness Inventory (ARI). The primary purpose of the $\mathrm{ARI}$ is to measure the quality of the relationship between any intimate dyad. Intimate is the most significant person to the respondent (e.g., family member, friend, or any significant other; (Hall \& Kiernan, 1992). The relevant items were selected from Schaefer and Edgerton's (1979) Marital Autonomy and Relatedness Inventory and Hall (1983) added 8 items to develop the 32-items ARI (Hall \& Kiernan, 1992). Prior to responding to the ARI items, the respondent is asked to identify the relationship of his/her intimate person. The 32 items of the ARI are categorized into eight subscales: Acceptance, Relatedness, Support, Listening, Autonomy, Control, Hostile Control, and Detachment/Rejection, with four items for each subscale.

The responses for each item in the ARI range from 1 "not at all like the intimate" to 5 "very much like the intimate" describing the behavior of the intimate on a 5-point Likert scale. The total score is calculated by summing the ratings of all items, after reversing the negative items, then 32 is subtracted from the sum to create a cumulative score that ranges from 0 to 128 . Subscale scores are calculated by summing their relative items and subtracting four. The Cronbach's alphas for the subscales ranged from .53 to 
.76 in a sample of 213 women (Hall \& Kiernan, 1992). In samples of 214 and 100 women, Cronbach's alphas for the total scale were .94 and .92 respectively (Hall, Schaefer, \& Greenberg, 1987; Linares, Hall, \& Ashford, 2015). The Cronbach's $\alpha$ for the ARI total scale in this study was .92 . The ARI items were found to be factored into two dimensions, Support/Positive Regard and Dominance/Control (negative), which were moderately correlated (Hall \& Kiernan, 1992). For the purposes of this study the associations between the negative and positive ARI subscales' scores with other study variables were examined.

\section{The Summary of Diabetes Self-Care Activities Measure (SDSCA). The} SDSCA was developed by Toobert, Hampson, \& Glasgow (2000). The SDSCA was developed to measure the frequency of diabetes self-management behaviors over the past 7 days such as diet, exercise, and blood glucose monitoring. The SDSCA is composed of 11 items, the first 10 items are grouped into 5 subscales with 2 items for each subscale, and these subscales are: General Diet, Specific Diet, Exercise, Blood Glucose Testing, and Foot Care. The last item concerns smoking. Toobert et al. (2000) suggested that some subscales could be removed and others could be added as needed. For the purposes of this study, an additional subscale (Medications) was added, and the smoking item was removed, smoking history was assessed in demographic questionnaire separately. The responses for the selected items of the SDSCA range from " 0 " day to " 7 " days a week. The score of the SDSCA is calculated by taking the average of responses for the pair of items in each subscale, and then averaging the scores of the subscales to calculate the total score. 
The Cronbach's $\alpha$ for the total SDSCA scale was .63 in a sample of 261 persons with diabetes, in this study the Cronbach's $\alpha$ for the SDSCA scale was .75 .

Diabetes biomarkers. The principal investigator (PI) obtained A1C and BMI data using patients 'medical records. BMI values were calculated by dividing the weight (kilograms) of the participants by their height (meters squared). Blood samples were drawn from the participants' antecubital veins by trained professionals according to a standardized protocol. A1C, a diabetes test that reflects plasma glucose for the previous 120 days, has been used to monitor diabetes for many years (CDC, 2014). These two measures are used consistently in the literature to measure the effectiveness of long-term control over diabetes (ADA, 2015; Chlebowy et al., 2014; Hessler et al., 2011).

Depression, anxiety, and stress. Depression, anxiety, and stress symptoms were measured using the Depression, Anxiety, and Stress Scale-21 (DASS-21) developed by Lovibond and Lovibond (1995). The DASS-21 is a 21-item brief scale of the DASS-42 full scale (Lovibond \& Lovibond, 1995) that assesses the negative emotional state of depression, anxiety, and stress of individuals during the last week. The DASS-21 is composed of seven items for each subscale (anxiety, depression, and stress). The responses to these items range from 0 (did not apply to me at all-never) to 3 (applied to me very much, or most of the time - almost always). The total score for each subscale is calculated by summing the scores for each item and then multiplying it by 2 to make it comparable to the full scale. The resulting totals are then classified into normal, mild, moderate, severe, or extremely severe (Lovibond \& Lovibond, 1995). The concurrent validity of the DASS-21 was supported by computing the correlations of the DASS-21 with other measures of depression, anxiety, and stress (Antony, Bieling, Cox, Enns, \& 
Swinson, 1998). The Cronbach's $\alpha$ for the DASS-21 subscales were .94 for depression, .87 for anxiety, and .91 for stress (Antony, Bieling, Cox, Enns, \& Swinson, 1998). The Cronbach's Alphas for depression, anxiety, and stress subscales in this study were 0.88 , 0.81 , and 0.82 respectively.

\section{Procedure}

Prior to the recruitment of the participants, Institutional Review Board approval was obtained from the University of Louisville. The staff and physicians at the recruitment location were introduced to the aims and procedures of the study. The PI recruited participants at the time of their clinic visits. Participants were approached and screened for eligibility; if eligible, information about the study nature and purpose was provided. Written informed consents were obtained from the eligible interested participants. Participants were assured of their voluntary participation in the study and their right to withdraw any time during the course of the study. In addition, they were informed that they were able to contact the PI any time to request further explanations and clarifications. The collected data were stored in a locked cabinet at the School of Nursing. The PI reviewed clients' records to obtain biomarkers (A1C and BMI). Each participant was given a 10-dollar gift card in appreciation of their involvement in the study.

\section{Data Analysis}

All statistical analyses were conducted using the statistical package SPSS version 24 (IBM, Armonk, NY). For the descriptive and bivariate analysis an alpha level of less than 0.05 was employed for the results to be significant. To avoid the problem of inflated Type I error due to use of multiple comparisons Bonferroni Correction method; the 
corrected alpha was calculated to be 0.005 (Bender \& Lange, 2001) was used. All continuous outcome variables were tested for normality using the Kolmogorov-Smirnov test; no problems with normality were noticed. Participants' responses for each predictor variable (measure) was evaluated; if the missing data per measure were $40 \%$ or more of the items making up that measure then participant's responses for that measure were deleted listwise (Raymond \& Roberts, 1987). Missing data that were less than $40 \%$ of the items making up a measure were imputed by the participant's mean response of the present items for each specific measure (Raymond, 1986). Data imputation by mean responses were done only for 12 participants' missing data. Descriptive statistics were run to describe study participants' sociodemographic characteristics and measures' total scores. Means, medians, standard deviations, and ranges were used for continuous variables, while percentages and frequencies were used for categorical variables.

\section{Outcome Analyses}

Nonparametric bivariate analyses were conducted to determine associations between each of sociodemographic characteristics and self-management behaviors total score, A1C, BMI, depression, anxiety, and stress scores. Nonparametric tests were used because of the unequal distribution of the sample across the categories of the sociodemographic characteristics (see Table 10). First, Mann-Whitney U and KruskalWallis tests were employed to determine if there is an association between each of the following: self-management behaviors total score, A1C, BMI, depression, anxiety, and stress scores and each sociodemographic characteristic. Second, the relationships between social support dimensions (MOS-SSS score, SSQN score, SSQS score, ARI negative score, ARI positive score, and ARI total score) and all of the outcome variables 
(self-management behaviors total score, A1C, BMI, depression, anxiety, and stress) were examined. Pearson's product-moment correlation coefficients were used to identify the direction and strength of the relationship between MOS-SSS scores, SSQN scores, SSQS scores, ARI negative scores, ARI positive scores, and the ARI total scores and each of the outcome variables.

To examine to what extent self-management mediates the relationship between social support dimensions and health outcomes of African Americans with T2D, the Baron and Kenny (1986) mediation analysis was conducted. To assess for mediation, three groups multiple regressions were conducted. Backward elimination regression was employed to examine whether any of the sociodemographic characteristics should be controlled for in all mediation analyses.

Three groups of multiple regressions were used to test for the mediational effect of the self-management in the relationship between social support dimensions and health outcome variables. First group of multiple regressions was conducted to assess whether social support dimensions predicted health outcomes. The second group of multiple regressions was conducted to assess whether social support dimensions predicting selfmanagement. The third group of multiple regressions was conducted to assess whether social support dimensions and self-management predicting health outcomes.

In order for mediation to be met, four conditions must be met. First, social support dimensions must be related to health outcomes (regression group 1). Second, social support dimensions must be related to self-management (regression group 2). Third, in the final group of regressions, self-management should remain a significant predictor of health outcomes. Fourth, in the final regression, social support dimensions should no 
longer significantly predict health outcomes and the parameter estimates must decrease in size. If all four conditions are met, full mediation is supported. If after controlling for self-management, social support dimensions' decrease in effect, but still significant, then partial mediation is supported. Bootstrap estimates were obtained for the indirect effects using SPSS Macro for Simple Mediation to test the significance of the mediation effects (Preacher, \& Hayes, 2004; Sobel, 1982). Prior to conducting multiple regressions, linearity and normality of the dependent variables for each level of the independent variables and homoscedasticity assumptions were all checked. Multicollinearity statistics (tolerance and variance inflation factors) were obtained and assessed; all assumptions were met. Education, marital status and treatment modality, was re-coded to create dichotomized dummy coded variable. Then, simultaneous multiple regressions were conducted.

\section{Results}

The total number of participants was 102 African American adults who were diagnosed with T2D. The average age of the participants was 57.4 years $(S D=11.3)$. The majority of the participants were female $(71.6 \%)$, single (52\%), unemployed (71.7\%) and low income (73.5\%) (Table 10). The average A1C and BMI for the participants were $8.1 \%(S D=2.2)$ and $35.3(S D=9.2)$ respectively.

The mean depression and anxiety scores for the sample were mild to moderate (Table 11), whereas, the mean stress score was normal according to Lovibond \& Lovibond (1995). The participants' average self-management score was 4.2 days $(S D=$ 1.4); the highest mean score was 5.7 days $(S D=2.3)$ for the Medication subscale and lowest mean score was 2.7 days $(S D=2.0)$ for the Physical Activity subscale (Table 12$)$. 
The functional support mean score for the participants was $66.9(S D=29.3)$ indicating higher availability of social support according to (Sherbourne \&Stewart, 1991). The average total score of the quality of the primary intimate relationship for the participants was $92.9(S D=21.7)$ indicating better quality of the available social support (Hall \& Kiernan, 1992).

Pearson's product-moment correlations between main study variables and sociodemographic characteristics were examined (Table 13). Self-management was correlated with functional support $(r=0.25, p<.05)$, satisfaction with support $(r=0.27, p$ $<.01)$, and positive quality of the primary intimate relationship $(r=0.21, p<.05)$. Functional support, the quality of the primary intimate relationship total score, and number of support persons were negatively correlated with depression.

Nonparametric bivariate analyses showed that there was a statistically significant difference in the participants' most recent A1C by the treatment modality $(H(3)=10.39$, $p=0.016$ ), with a mean rank of 8.5 for none use of medications, 32.9 for oral hypoglycemic agents' treatment, 50.4 for insulin only, and 43.1 for insulin with oral hypoglycemic agents' treatment. Pairwise comparisons showed that there were a statistical significant differences in most recent $\mathrm{A} 1 \mathrm{C}$ between those who were not treated with medications and those who were treated with insulin $(p=0.028)$, and those who were not treated with medications and those who were treated with insulin and oral hypoglycemic agents together $(p=0.012)$, and those who were treated with oral hypoglycemic agents only and those who were insulin only $(p=0.024)$. Bonferroni correction method was used. Mann-Whitney tests indicated that the quality of the primary intimate relationship was greater for females $(\mathrm{Mdn}=103)$ than for males $(\mathrm{Mdn}=$ 
$81), \mathrm{U}=1397.5, p=0.01$, and the positive quality of the primary intimate relationship was greater for females $(\mathrm{Mdn}=64)$ than for males $(\mathrm{Mdn}=47), \mathrm{U}=1416, p=0.008$.

In addition, there was a statistically significant difference in the participants' most recent BMI by participants' level of education $(H(3)=8.39, p=0.039)$, with a mean rank of 39.76 for less than high school, 47.43 for high school diploma, 41.17 for vocational or some college, and 49.72 for college degree or higher.

The results of the first group of multiple regressions (Table 14) showed that none of the predictor variables were successful in predicting the A1C values in the study sample. However, satisfaction with support and education explained a significant amount of the variance in the BMI values $\left(F(2,95)=5.3, p=0.007, R^{2}{ }_{\text {Adjusted }}=0.08\right)$. In addition, functional support and negative quality of the primary intimate relationship explained a significant amount of the variance in depression controlling for sex $(F(3,98)$ $=8.3, p<0.0001, R_{\text {Adjusted }}^{2}=0.18$ ). Negative quality of the primary intimate relationship explained a significant amount of the variance in anxiety controlling for marital status ( $F$ $(2,97)=9.6, p<0.0001, R^{2}$ Adjusted $\left.=0.15\right)$. Functional support and negative quality of the primary intimate relationship explained a significant amount of the variance in stress ( $F$ $\left.(3,97)=5.11, p=0.002, R^{2}{ }_{\text {Adjusted }}=0.11\right)$.

The second group of multiple regressions showed that functional support and satisfaction with support explained a significant amount of the variance in selfmanagement $\left(F(2,99)=6.0, p, 0.003, R^{2}{ }_{\text {Adjusted }}=0.09\right)$. The results of the final group of regression (Table 15) showed self-management was not a successful predictor of either BMI, depression, anxiety, or stress. In addition, satisfaction with support, functional support, and negative quality of the primary intimate relationship were still significantly 
predicting BMI, depression, anxiety, and stress. After applying Baron and Kenny (1986) method of assessing mediational effect and further testing of bootstrap estimates to test the significance of the mediation effects (Preacher, \& Hayes, 2004; Sobel, 1982), selfmanagement failed to mediate the relationship between social support dimensions and health outcomes. The significant relationships (based on regression analyses) between social support dimensions and health outcomes were depicted in figure 1.

The results of this study indicated that African American adults with T2D had high A1C $(\mathrm{M}=8.1 \%)$ and BMI $(\mathrm{M}=35.3)$ values. In addition, the participants showed mild to moderate levels of depression, anxiety; however, they reported that they had higher levels of functional social support and quality of the primary intimate relationship. Furthermore, they reported higher scores on self-management. None of social support dimensions were correlated with A1C; however, functional support, satisfaction with support, and negative quality of the primary intimate relationship were found to be correlated with depression and anxiety. Regression analysis showed that functional support and satisfaction with support predicted self-management. In addition, functional support with negative quality of the primary intimate relationship predicted depression and anxiety. However, self-management was not a successful mediator in the relationship between social support dimensions and health outcomes.

\section{Discussion}

The results of this study showed that self-management was not a successful mediator in the relationship between social support and diabetes-related health outcomes. One of the reasons for these results could be the discrepancy between the study participants' high scores on self-management and poor control over their health status as 
manifested by their high $\mathrm{A} 1 \mathrm{C}$ and $\mathrm{BMI}$ values. The average self-management total score was 4.2 days out of 7 days which indicates that study participants reported that they highly adhered to their diabetes treatment regimens during the last 7 days prior to the interview; however, the average $\mathrm{A} 1 \mathrm{C}$ and $\mathrm{BMI}$ was $8.1 \%$ and 35.3 respectively. This discrepancy raises the possible effects of social desirability on participants' responses to the self-management questionnaire. In turn, this may affect the association between selfmanagement and diabetes biomarkers (Table 15). Another possible indicator of poor selfmanagement was the high percentage (80\%) of participants having at least one chronic condition in addition to T2D.

Having other comorbidities, low income, the presence of diabetes-related complications, and lack of financial support may also hinder self-management ability (Bayliss, Ellis, \& Steiner, 2007). Diabetes self-management is complex, especially for older adults (Suhl \& Bonsignore, 2006) and African Americans (Murrock, Taylor, \& Marino, 2013). Murrock and colleagues' (2013) found that African American women diagnosed with $\mathrm{T} 2 \mathrm{D}$ had challenges in self-management of their dietary regimens. These challenges were attributed to difficulties in changing dietary behavior, lack of information, and lack of support.

Lack of functional social support along with other barriers, such as physical inactivity and depression, were among the challenges that older adults may face in managing T2D (Suhl \& Bonsignore, 2006). Middle-aged adults were also a disadvantaged group when self-management and T2D outcomes were measured (Ahn, Smith, Dickerson, \& Ory, 2012; Chiu \& Wray, 2010). Thus, it is recommended to use one of the social desirability scales to improve the validity of the results in health 
research (Van de Mortel, 2008). People tend to select more socially appropriate answers when responding to questions of social value which may distort the results of healthrelated studies (Adams et al., 2005; Van de Mortel, 2008).

Social desirable responses also had an effect on the A1C relationships with other study variables. Even though study results showed that A1C levels differ significantly by treatment modality and $\mathrm{A} 1 \mathrm{C}$ had a negative association with age at diagnosis $(r=0-.21, p$ $<0.05)$, none of the study variables were successful in predicting A1C. This in turn affects the ability of self-management to mediate the relationship between social support and glycemic control. Other variables such as self-efficacy were thought to mediate this relationship; the relationship between functional social support and health-related outcomes is affected by a number of variables. For example, Cosansu and Erdogan (2014) and Nakahara et al. (2006) found that the relationship between functional social support and glycemic control was mediated by self-efficacy. Gao et al. (2013) found that functional social support had a direct positive relationship with glycemic control. On the other hand, they found that higher levels of functional social support and higher selfefficacy were associated with improved self-care that is directly related to glycemic control.

Self-efficacy could be studied as mediator in the relationship between social support and glycemic control. Self-efficacy should be taken into consideration when studying the effects of social support dimensions on self-management and thus glycemic control in African American adults (Komar-Samardzija, Braun, Keithley, \& Quinn, 2012). Anxiety was found to be significantly negatively correlated with self-efficacy to perform self-care behaviors and positively correlated with diabetes-related complications 
(Wu et al., 2013). On the other hand, the intensive treatment of T2D can lead to increased psychological burden and higher rates of anxiety and decreased self-efficacy that impedes self-care (Thoolen, De Ridder, Bensing, J Gorter, \& Rutten, 2006). Thus, the relationship between social and glycemic control and psychosocial outcomes could be mediated by self-efficacy and self-management together.

Although A1C remains the gold standard in assessing glycemic control (ADA, 2015), it should be evaluated as an indicator of glycemic control in racial disparities population such African Americans due to several factors including the differences in red blood cell survival (Herman et al., 2007). Other indicators of glycemic control could be used beside A1C and BMI (e.g., fasting blood glucose) which may show different associations with study variables.

An open ended question to assess social support dimensions could be added to explore the lived experience of social support and its effects on self-management as experienced by the African American adults with T2D. The discovery of the essence of social support and its relationship with self-management that are specifically relevant to African American adults with T2D, and exploring the uniqueness of social support to them would enrich the results of such a study. Yet, the descriptive phenomenology has been prescribed as a method that will produce studies characterized by being full of experiences, meaningful descriptions, and emotions (Richards \& Morse, 2013). This will promote a better understanding of the phenomenon of interest.

\section{Limitations}

The generalizability of the study finding was limited due to several reasons. First, the use of convenience sampling procedure in recruiting study participants; convenience 
sampling resulted in overrepresentation or underrepresentation of participants with certain characteristics. For example, the majority of the sample were unemployed females who were using a government health insurance services. Second, the use of self-report measures to assess for social support and self-management behaviors. Future studies are recommended to explore the social support available for the patients with diabetes using qualitative approaches such as open-ended questions and focus groups. Future studies could also include the primary support persons in the assessment of social support to add more insight to the findings.

Third, social desirability was a prominent limitation that led to inability to demonstrate that self-management was a successful mediator in the relationship between social support and health outcomes of persons with T2D. Using a social desirability as a covariate is recommended to support the findings. Finally, the use of multiple comparisons that could lead to the inflation of Type I error. It is recommended to also use larger sample sizes in future studies. In this study two measures of social support quality (SSQ6 and the ARI) which may burden the participants. Future studies are recommended to use either of these measures.

\section{Conclusion}

The purpose of this study was evaluate the role of self-management in mediating the relationship between various dimensions of social support and the health outcomes of African American adults with T2D. The results of this study were successful in demonstrating that there were direct relationships between various dimensions of social support and biological and psychological health outcomes of African American adults with T2D. Due to several limitations, the results of this study failed to show that self- 
management was a successful mediator in the relationship between social support dimensions and health outcomes. Despite that, the results of this study contribute to the existing literature by shedding the light on the unique relationships of social support dimensions with health outcomes of persons with T2D. This study helps to explain the relationship of functional social support and the negative quality of the primary intimate relationship with psychological outcomes of persons with T2D. In addition, this study showed that sociodemographic characteristics of the participants played an important role in explaining the relationship of social support dimensions with health outcomes of person with T2D. The impact of self-efficacy on self-management in persons diagnosed with T2D should be taken onto consideration. Thus, further exploration of the role of self-management as mediator in the relationship of social support dimensions with health outcomes is recommended. 


\section{Tables}

Table 10. Descriptive Characteristics of Study Participants $(n=102) *$

$\mathrm{M}(\mathrm{SE}) \quad$ Frequency (\%)

\begin{tabular}{ll}
\hline Age & $57.4(1.1)$
\end{tabular}

Age at diagnosis

$44(1.3)$

Sex

Male

Female

Marital Status

Married

$14(14)$

Divorced

Widowed

Single

$52(52)$

\section{Employment Status}

Full time

Part time

Unemployed

71 (71.7)

Education

$<$ High school

High school

35 (35.7)

Some college

$22(22.4)$

Continued 


\section{Income}

0 to $\$ 20,000$

$73(73.5)$

20,001 to $\$ 40,000$

17 (18.3)

40,001 to $\$ 46,000$

Insurance

None

Medicaid/Medicare

$63(74.1)$

Kynect

$16(18.8)$

Treatment Modality

None

Oral Hypoglycemic Agents Only

Insulin Only

$10(12.70$

Insulin with Oral Hypoglycemic

$22(27.8)$

Agents

\section{Comorbidity}

No

$20(20)$

Yes

$80(80)$

\section{Current Smoking}

No

$74(72.5)$

Yes

27 (26.5) 


\section{Alcohol Consumption}

Never

Monthly or less

2-4 times a month

2-3 times a week

4 or more time a week

*Note: the number of valid cases for analysis are varied across the variables.
$54(54)$

$29(29)$

$10(10)$

$4(4)$

$3(3)$ 
Table 11. Descriptive Characteristics of Study Participants' Social Support Scores and Outcome Variables $(n=102)$

\begin{tabular}{|c|c|c|c|c|}
\hline \multicolumn{5}{|c|}{ Range } \\
\hline Outcome Variable & Observed & Observed & Mean & Standard \\
\hline & Minimum & Maximum & & Deviation \\
\hline A1C* & 5.1 & 14.4 & 8.1 & 2.2 \\
\hline BMI & 17.4 & 62 & 35.3 & 9.2 \\
\hline Depression & 0 & 40 & 9.8 & 8.3 \\
\hline Anxiety & 0 & 40 & 10.0 & 7.6 \\
\hline Stress & 0 & 34 & 11.4 & 7.4 \\
\hline Self-Management** & 0.5 & 6.7 & 4.2 & 1.4 \\
\hline \multicolumn{5}{|c|}{ Social Support Measures } \\
\hline MOS-SSS & 3.3 & 100 & 66.9 & 29.3 \\
\hline SSQ6N & 0 & 9 & 2.3 & 1.7 \\
\hline SSQ6S & 1 & 6 & 5.0 & 1.2 \\
\hline ARI Negative & 1 & 80 & 55.9 & 18.7 \\
\hline ARI Positive & 8 & 48 & 37.0 & 8.6 \\
\hline ARI Total & 41 & 128 & 92.9 & 21.7 \\
\hline
\end{tabular}

\footnotetext{
*A1C: Glycated Hemoglobin Percentage of total hemoglobin

**Self-management scores represent number of days out of the last 7 days prior to interview
} 
Table 12. Descriptive Characteristics of Study Participants' Self-Management Scores $(n=102)$

\begin{tabular}{lcccc}
\hline & Minimum & Maximum & Mean & Std. Deviation \\
Total Score & 0.5 & 6.7 & 4.2 & 1.4 \\
Diet & 0.25 & 7 & 3.7 & 1.3 \\
Physical Activity & 0 & 7 & 2.7 & 2.0 \\
Blood Sugar Testing & 0 & 7 & 4.4 & 2.4 \\
Foot Care & 0 & 7 & 4.1 & 2.4 \\
Medication & 0 & 7 & 5.7 & 2.3 \\
Note: Self-management scores represent number of days out of the last 7 days prior to
\end{tabular}


Table 13. Pearson Product-Moment Correlations of Study Variables

\begin{tabular}{|c|c|c|c|c|c|c|c|c|c|c|c|c|}
\hline & $\begin{array}{c}\text { MOS- } \\
\text { SSS }\end{array}$ & SSQ6N & SSQ6S & $\begin{array}{c}\text { ARI Total } \\
\text { Score } \\
\end{array}$ & $\begin{array}{c}\text { ARI } \\
\text { Positive } \\
\end{array}$ & $\begin{array}{c}\text { ARI } \\
\text { Negative } \\
\text { Score }\end{array}$ & $\begin{array}{c}\text { Self- } \\
\text { management }\end{array}$ & Depression & Anxiety & Stress & $\mathrm{A} 1 \mathrm{C}$ & BMI \\
\hline MOS-SSS & 1 & $.354^{* *}$ & $.259^{* *}$ & $.472^{* *}$ & $.564^{* *}$ & -.037 & $.253^{*}$ & $-.343^{* *}$ & -.120 & $-.271^{* *}$ & .041 & -.095 \\
\hline SSQ6N & & 1 & .108 & $.263^{* *}$ & $.292^{* * *}$ & .028 & -.003 & $-.234^{*}$ & -.088 & -.125 & .167 & -.008 \\
\hline SSQ6S & & & 1 & $.208^{*}$ & $.243^{*}$ & -.005 & $.269^{* * *}$ & -.150 & .021 & -.046 & .059 & $-.206^{*}$ \\
\hline ARI Total & & & & 1 & $.920^{* *}$ & $.520^{* *}$ & .177 & $-.269^{* *}$ & -.186 & -.183 & .114 & -.086 \\
\hline ARI Positive & & & & & 1 & .143 & $.206^{*}$ & $-.237^{*}$ & -.072 & -.130 & .135 & -.031 \\
\hline ARI & & & & & & 1 & .002 & .163 & $.313^{* *}$ & .178 & .007 & .148 \\
\hline Negative & & & & & & & & & & & & \\
\hline $\begin{array}{c}\text { Self- } \\
\text { management }\end{array}$ & & & & & & & 1 & -.079 & .090 & -.019 & -.017 & -.038 \\
\hline Depression & & & & & & & & 1 & $.680^{* *}$ & $.797^{* *}$ & .013 & .194 \\
\hline Anxiety & & & & & & & & & 1 & $.774^{* * *}$ & .037 & .158 \\
\hline Stress & & & & & & & & & & 1 & -.078 & .127 \\
\hline $\mathrm{A} 1 \mathrm{C}$ & & & & & & & & & & & 1 & .111 \\
\hline BMI & & & & & & & & & & & & 1 \\
\hline
\end{tabular}

*. Correlation is significant at the 0.05 level (2-tailed).

**. Correlation is significant at the 0.01 level (2-tailed). 
Table 14. Regression Results for Self-Management, BMI, Depression, Anxiety, and $\operatorname{Stress}(n=102)$

\begin{tabular}{llllll}
\hline Dependent & Predictor & $\beta$ & SE & $t$ & $p$
\end{tabular}

Variable

Model Summary $\quad F(2,99)=6.0, p=0.003, R^{2}$ Adjusted $=0.09$

$\begin{array}{lllll}\text { Self- } & \text { Constant } & 0.57 & 4.1 & <0.0001\end{array}$

management

$\begin{array}{lllll}\text { Functional support } & 0.20 & 0.01 & 2.0 & <0.04\end{array}$

Satisfaction with support $\quad \begin{array}{llll}0.22 & 0.11 & 2.2 & <0.03\end{array}$

Model Summary $\quad F(5,96)=0.9, p=0.5, R_{\text {Adjusted }}^{2}=0.04$

\begin{tabular}{|c|c|c|c|c|c|}
\hline $\mathrm{A} 1 \mathrm{C}$ & Constant & & 1.31 & 5.5 & $<0.0001$ \\
\hline & Functional support & -0.10 & 0.01 & -0.9 & 0.39 \\
\hline & Number of support & 0.16 & 0.13 & 1.5 & 0.14 \\
\hline & persons & & & & \\
\hline & Satisfaction with support & 0.03 & 0.17 & 0.33 & 0.74 \\
\hline & Negative quality of the & & & & \\
\hline & primary intimate & 0.003 & 0.03 & 0.35 & 0.72 \\
\hline & relationship & & & & \\
\hline & Positive quality of the & .147 & .014 & 1.2 & .242 \\
\hline & primary intimate & & & & \\
\hline & relationship & & & & \\
\hline
\end{tabular}

(Continued) 


\begin{tabular}{|c|c|c|c|c|c|}
\hline Model Summary & \multicolumn{4}{|c|}{$F(2,95)=5.3, p=0.007, R_{\text {Adjusted }}^{2}=0.08$} & \\
\hline \multirow[t]{3}{*}{ BMI } & \multicolumn{2}{|l|}{ Constant } & 3.69 & 12.2 & $<0.0001$ \\
\hline & Satisfaction with support & -0.23 & 0.69 & -2.4 & $<0.02$ \\
\hline & Education & -0.24 & 1.83 & -2.4 & $<0.02$ \\
\hline \multicolumn{6}{|c|}{$F(3,98)=8.3, p<0.0001, R_{\text {Adjusted }}^{2}=0.18$} \\
\hline \multirow[t]{6}{*}{ Depression } & \multicolumn{2}{|l|}{ Constant } & 4.4 & 3.8 & $<0.0001$ \\
\hline & Sex & 0.24 & 1.7 & 2.6 & $<0.01$ \\
\hline & Functional support & -0.38 & 0.03 & -4.3 & $<0.0001$ \\
\hline & \multicolumn{5}{|l|}{ Negative quality of the } \\
\hline & primary intimate & 0.20 & 0.10 & 2.2 & $<0.03$ \\
\hline & \multicolumn{5}{|l|}{ relationship } \\
\hline \multicolumn{6}{|c|}{$F(2,97)=9.6, p<0.0001, R_{\text {Adjusted }}^{2}=0.15$} \\
\hline \multirow[t]{5}{*}{ Anxiety } & \multicolumn{3}{|l|}{ Constant } & 1.4 & 0.15 \\
\hline & Marital Status & 0.25 & 1.4 & 2.7 & $<0.007$ \\
\hline & \multicolumn{5}{|l|}{ Negative quality of the } \\
\hline & primary intimate & 0.30 & 0.1 & 3.2 & $<0.002$ \\
\hline & \multicolumn{5}{|l|}{ relationship } \\
\hline
\end{tabular}


Model Summary $\quad F(3,97)=5.11, p=0.002, R^{2}{ }_{\text {Adjusted }}=0.11$

\begin{tabular}{|c|c|c|c|c|c|}
\hline Stress & Constant & & 5.2 & 5.6 & $<0.0001$ \\
\hline & Age & -.18 & 0.06 & -1.9 & 0.06 \\
\hline & Functional support & -.26 & 0.02 & -2.7 & $<0.008$ \\
\hline & Negative quality of & & & & \\
\hline & primary intimate & .21 & 0.08 & 2.2 & $<0.03$ \\
\hline
\end{tabular}


Table 15. Regression Results for BMI, Depression, Anxiety, and Stress $(n=102)$

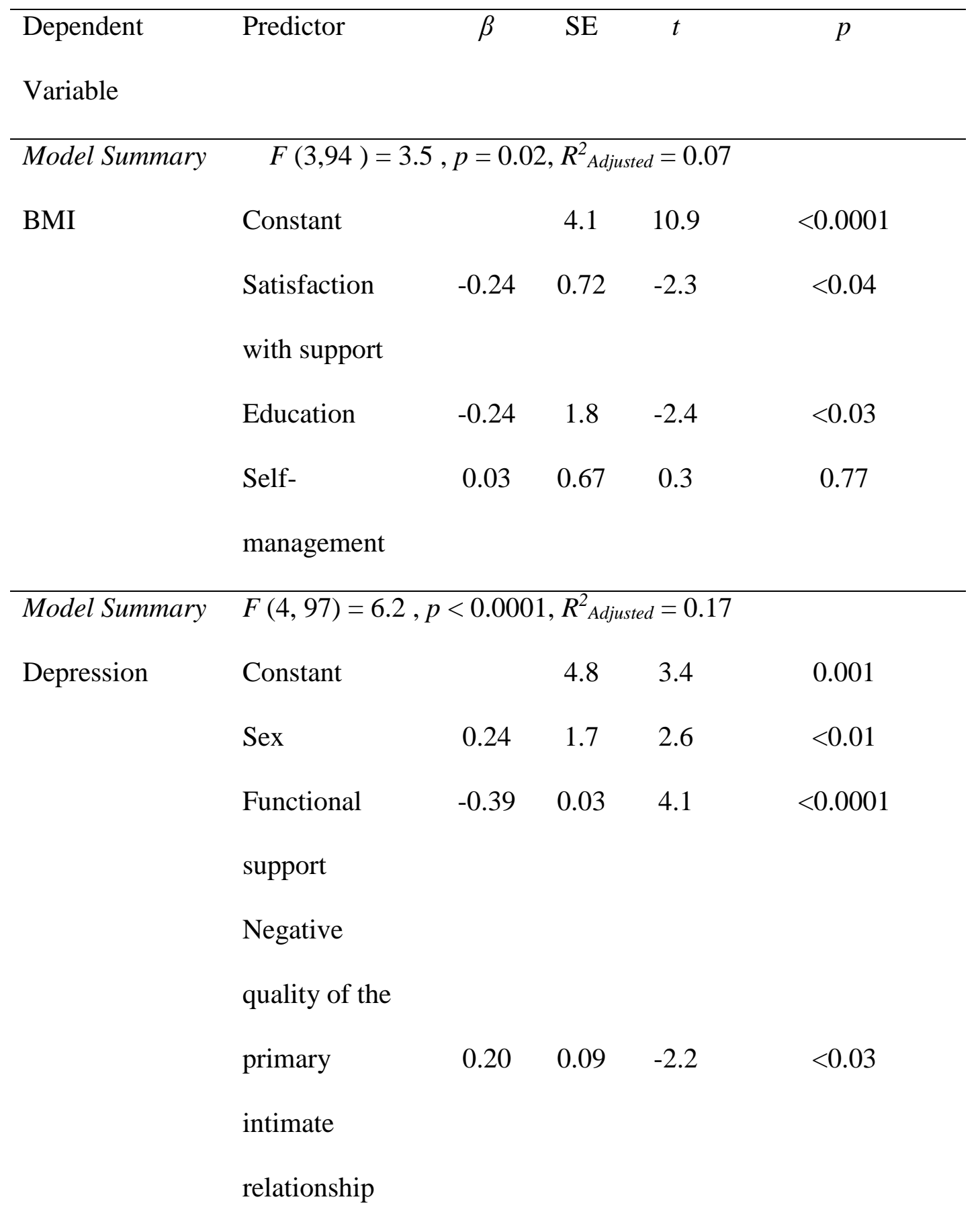




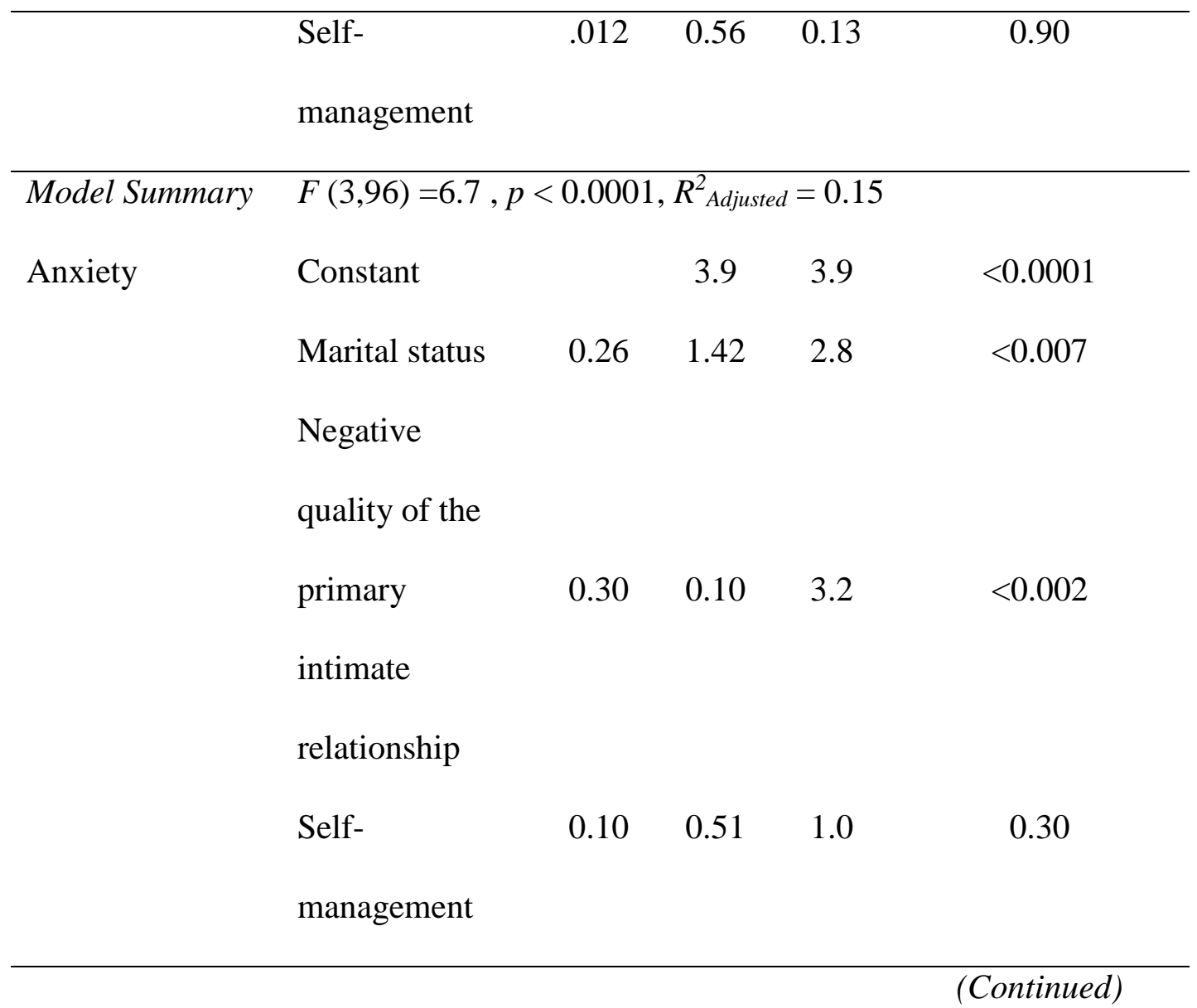




\begin{tabular}{|c|c|c|c|c|c|}
\hline Model Summary & $F(4,96)=4$ & $=0.005$ & $R^{2}$ Adjust & $=0.10$ & \\
\hline Stress & Constant & & 5.4 & 5.2 & $<0.0001$ \\
\hline & Age & -0.18 & 0.06 & -1.9 & 0.05 \\
\hline & Negative & & & & \\
\hline & quality of th & & & & \\
\hline & primary & 0.21 & 0.08 & -2.2 & $<0.03$ \\
\hline & intimate & & & & \\
\hline & relationship & & & & \\
\hline & Functional & -0.27 & 0.03 & -2.8 & $<0.008$ \\
\hline & support & & & & \\
\hline & Self- & 0.07 & 0.52 & 0.67 & 0.51 \\
\hline
\end{tabular}




\section{Figures}

Figure 6. The Mediational Relationship of Self-management between Social Support dimansions and Health Outcomes of African Amerivans with T2D Based on Regressions Analyses
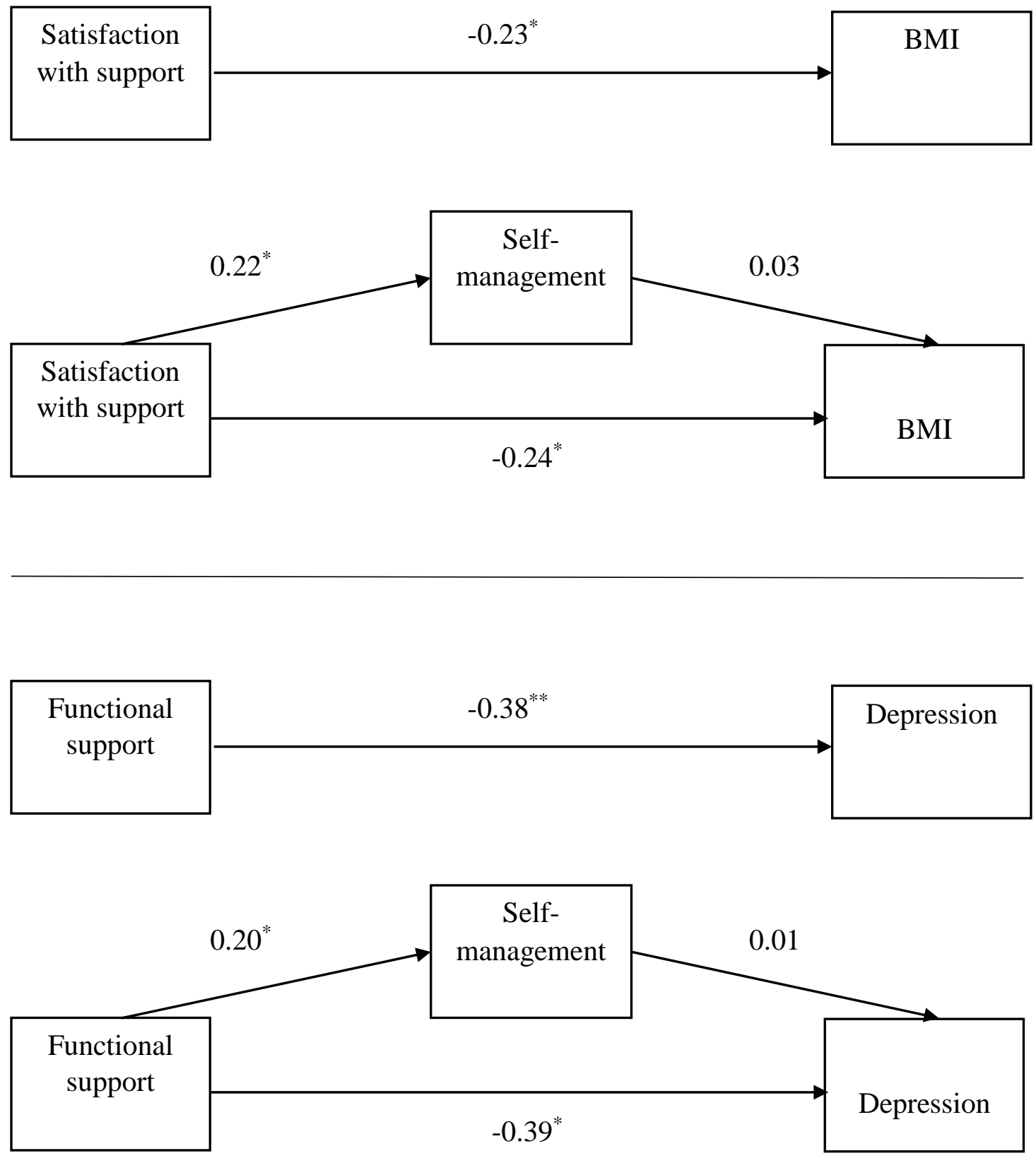

*Standardized Coefficients $(p<0.05)$

**Standardized Coefficients $(p<0.01)$

$* * *$ Standardized Coefficients $(p<0.001)$ 

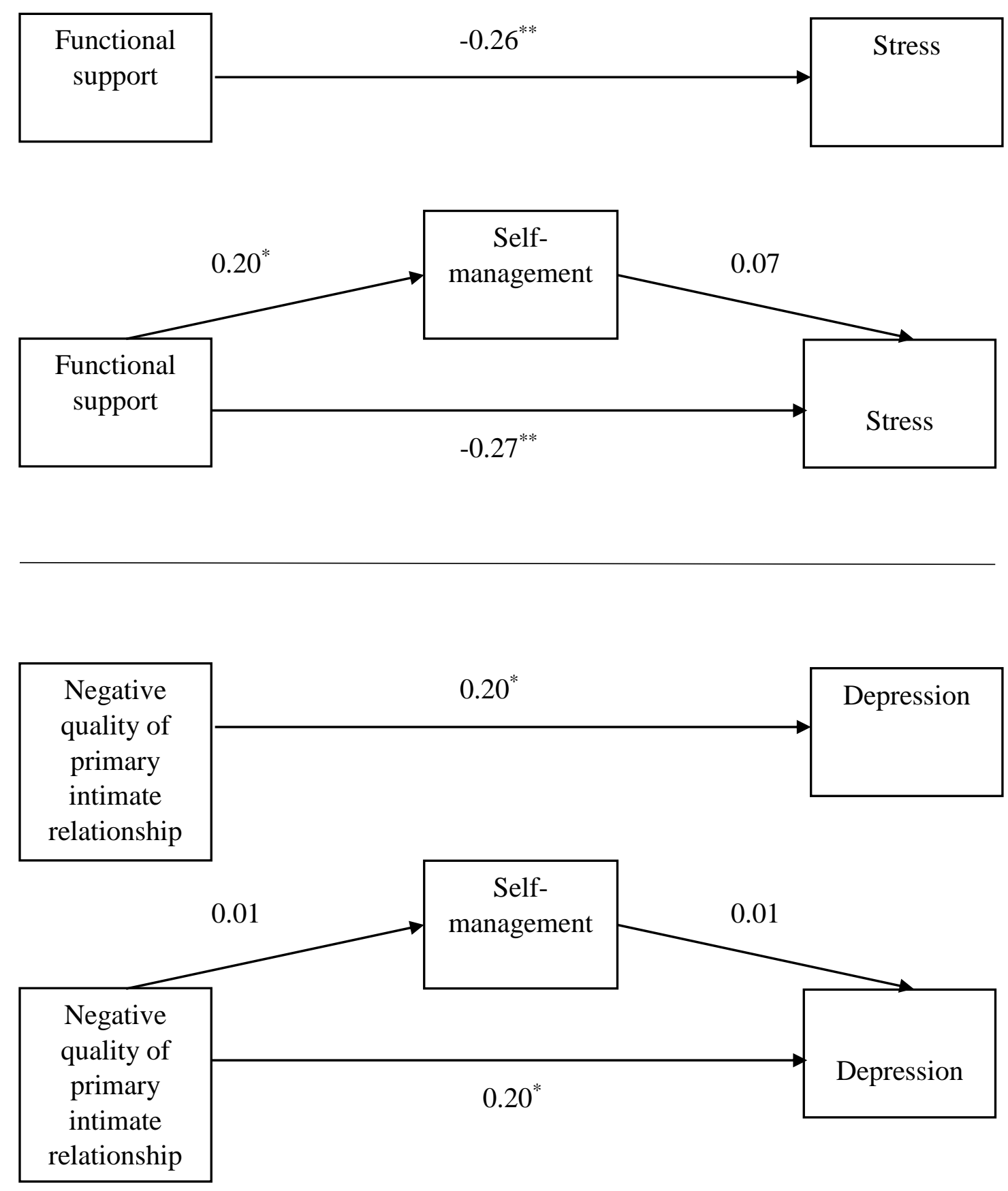

*Standardized Coefficients $(p<0.05)$

$* *$ Standardized Coefficients $(p<0.01)$

$* * *$ Standardized Coefficients $(p<0.001)$ 

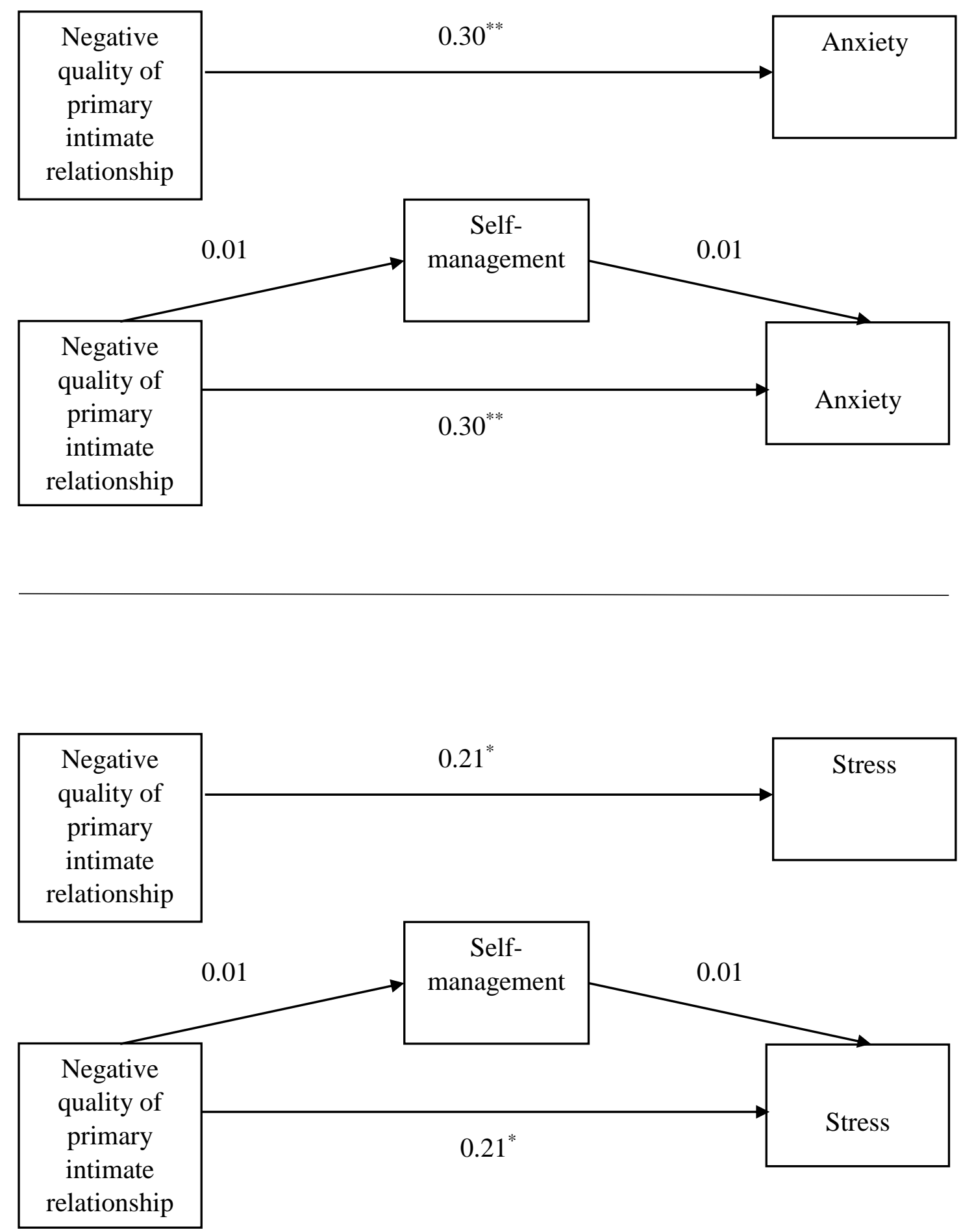

* Standardized Coefficients $(p<0.05)$

$* *$ Standardized Coefficients $(p<0.01)$

$* * *$ Standardized Coefficients $(p<0.001)$ 


\section{CHAPTER V}

\section{SYNTHESIS AND CONCLUSIONS}

The purposes of this dissertation were to: (1) systemically review the literature on social support relationships with health outcomes and critically review the measurement of social support in persons diagnosed with T2D; (2) examine the relationships of sociodemographic characteristics with dietary adherence and glycemic control in patients diagnosed with T2D; and (3) examine the relationships of social support dimensions with health outcomes in African American adults diagnosed with T2D.

\section{Synthesis of Findings and Implications}

Diabetes is one of the chronic diseases that affects the lives of many American people. Diabetes was listed as the seventh leading cause of death in the United States in 2015 (CDC, 2017). One and half million American adults were diagnosed with diabetes in 2015; more than $50 \%$ of them were aged between 45 to 64 years at the time of diagnosis (CDC, 2017). Adjusting for age, African American adults had higher rates of diagnosis with diabetes when compared to their non-Hispanic Whites counterparts (CDC, 2017). Physical and psychological wellbeing of persons diagnosed with diabetes are adversely affected by diabetes-related complications (CDC, 2017; Nouwen et al., 2010). Self-management which requires a group of skills and behavior change is thought to be a cornerstone of diabetes care (Berard et al., 2013; Powers et al., 2017). 
Social support enhances positive behavior modification and improves selfmanagement skills which are linked with improved health outcomes in persons diagnosed with T2D (Collins-McNeil et al., 2009; Egede \& Osborn, 2010).

In order to study the mediating effects of self-management on the relationship between social support and health outcomes, a critical review of the measurement of social support in the literature was performed to capture the essence of the concept and how it is measured. Following the review, an analysis of existing data was performed to study the impact of sociodemographic characteristics on T2D outcomes. After conducting this review, the main study followed.

In Chapter Two, the literature review showed that social support characterized by the existence of social networks that exhibit supportive behaviors, tangible or intangible, improves positive behavior change and disease self-management; this improves the health outcomes of persons with T2D. These social networks are comprised of members who could be families, healthcare professionals, or internet support groups. Functional social support behaviors are classified into: instrumental, informational, emotional, and appraisal support (Langford, Bowsher, Maloney, \& Lillis, 1997). In addition to the function of support, the structure and the quality of support should be taken into consideration when studying social support in persons diagnosed with T2D (AL-Dwaikat \& Hall, 2017).

The impact of social support in persons with T2D can be classified as: (1) improving self-management (Cosansu \& Erdogan, 2013; Nicklett \& Liang, 2010); (2) improving behavior adjustment (Strom \& Egede, 2012), and (3) improving psychosocial outcomes (Finfgeld-Connett, 2005; Glasgow et al., 2012). Unfavorable outcomes are also 
expected; these negative consequences often include a feeling of being a burden, stigmatization, and negative critique by social network members (Bhattacharya, 2012; Mayberry and Osborn, 2012; \& Strom and Egede, 2012). Most of the studies reviewed (83\%) used measures that were designed to assess for positive support whereas only $17 \%$ of the studies used measures that assessed both positive and negative support. Forty-two percent of the studies used measures that assessed all aspects of functional support (tangible, emotional, informational, and instrumental), while the remainder of the studies (58\%) used measures that assessed for one or two types of functional support. Some of the measures assessed the quality or quantity of social support and others assessed the functional or structural properties of support. While some of the measures were used in specific populations, others could be used as broad measures in various populations (Gottlieb \& Bergen, 2010).

The critical review of the most frequently used measures of social support in persons diagnosed with T2D showed that the MOS-SSS, the SSQ6, and the MSPSS have strengths and weaknesses. The choice between these measures should be justified by the general purpose of each study and the specific dimension of support that will be examined. All of these measures were brief and will not contribute to study participant burden. Thus, these measures are recommended for use when the time is of concern (e.g., in persons diagnosed with chronic conditions). Furthermore, a combination of two measures is favored over using a single measure. The use of a combination of measures will enable the researcher to capture the multidimensionality of social support (GallegosCarrillo, García-Peña, Durán-Muñoz, Flores, \& Salmeron, 2009). 
A number of implications were recommended based on this review. First, a clear identification of social support dimensions to be measured should be determined prior to the start of the study. Second, a critical review of the psychometric properties of each measure should be performed while focusing on the study population. Finally, specific aims, as well as theoretical frameworks should guide the studies that intend to measure social support.

In Chapter Three, a study of the relationships of sociodemographic characteristics with dietary adherence and glycemic control using NHANES data was conducted. The results of this study revealed that sex, race/ethnicity, marital status, education, and income were significantly related to adherence with ADA guidelines. Furthermore, these sociodemographic characteristics were significantly related to A1C. The effect sizes of these associations in this study were very small. The results of this study could be limited due to the use of A1C as a single measure of glycemic control. It is recommended to use another measure such as BMI. In addition, the results of this study were limited because they were based on a secondary analysis of self-report data.

In Chapter Four, a cross-sectional study was conducted to examine the role of self-management as a mediator in the relationship between social support and health outcomes of African American adults diagnosed with T2D. This study concluded that there were direct relationships between different dimensions of social support and health outcomes of African American adults with T2D. However, the results of this study failed to show that self-management was a mediator in the relationship between social support dimensions and health outcomes. This study had several limitations (e.g., convenience sampling, the use of self-report measures to assess for social support and self- 
management behaviors, social desirability, Type I error inflation due to multiple comparisons, and the use of two measures to assess the quality of social support).

Despite these limitations, the results of this study are promising because they shed light on the distinctive relationships of social support dimensions with health outcomes of persons with T2D. In addition, this study emphasized the important role of sociodemographic characteristics in explaining the relationship between social support dimensions and health outcomes.

\section{Recommendations for Future Research and Practice}

A group of recommendations are postulated based on the results of the review and the two subsequent studies. The review of the literature study suggested that the measurement of social support should be carefully considered. The selection of the bestfit social support measures should be supported by a thorough evaluation of their psychometric properties and attention to the dimensions of social support intended to be measured. Also, it is recommended to use more than one measure of social support to increase the likelihood of identifying the most important dimensions essential to improving health outcomes in persons with T2D.

The second study recommended to add more variables (e.g., diet, exercise, medication use) to the model that may improve its ability to predict glycemic control. In addition, dietary adherence is recommended to be studied as a mediator variable in the relationship between sociodemographic characteristics and glycemic control; this may improve the understanding of the relationships between sociodemographic characteristics and glycemic control in persons with T2D. 
The above mentioned recommendations were considered in conducting the third study of this dissertation. This study's results recommended future studies to explore of the role of self-management as a mediator in the relationship of social support dimensions with health outcomes using random sampling with larger numbers of participants and their support persons. In addition, it is recommended to use social desirability scales to eliminate the problem of social desirability and use mixed methods to assess for social support dimensions. 


\section{REFERENCES}

Adams, S. A., Matthews, C. E., Ebbeling, C. B., Moore, C. G., Cunningham, J. E., Fulton, J., \& Hebert, J. R. (2005). The effect of social desirability and social approval on self-reports of physical activity. American Journal of Epidemiology, 161(4), 389398.

Adarmouch, L., Sebbani, M., Elyacoubi, A., \& Amine, M. (2016). Psychometric Properties of a Moroccan Version of the Summary of Diabetes Self-Care Activities Measure. Journal of Diabetes Research, (2016). Retrieved from http://dx.doi.org/10.1155/2016/5479216.

Ahia, C. L., Holt, E. W., \& Krousel-Wood, M. (2014). Diabetes care and its association with glycosylated hemoglobin level. The American Journal of the Medical Sciences, 347(3), 245-247.

Ahn, S., Smith, M. L., Dickerson, J. B., \& Ory, M. G. (2012). Health and health care utilization among obese and diabetic baby boomers and older adults. American Journal of Health Promotion, 27(2), 123-132.

Al-Dwaikat, T. N., \& Hall, L. A. (2017). Systematic Review and Critical Analysis of Measures of Social Support Used in Studies of Persons with Type 2 Diabetes. Journal of Nursing Measurement, 25(2), 74E-107E. 
Ali, S., Stone, M. A., Peters, J. L., Davies, M. J., \& Khunti, K. (2006). The prevalence of co-morbid depression in adults with type 2 diabetes: A systematic review and meta-analysis. Diabetic Medicine, 23(11), 1165-1173.

Almawi, W. Y., Tamim, H., Al-Sayed, N., Arekat, M. R., Al-Khateeb, G. M., Baqer, A., ... \& Kamel, C. (2008). Association of comorbid depression, anxiety, and stress American Diabetes Association (2016). 10. Older Adults. Diabetes Care.39(Supplement 1): S81-S85.

American Diabetes Association (2016). 3. Foundations of Care and Comprehensive Medical Evaluation. Diabetes Care. 39(Supplement 1): S23-S35.

American Diabetes Association. (2015). 2. Classification and diagnosis of diabetes. Diabetes Care, 38(Supplement 1), S8-S16.

American Psychiatric Association. (2013). Diagnostic and statistical manual of mental disorders. Arlington: American Psychiatric Publishing.

An, G. J., \& Kim, M. J. (2012). Powerlessness, social support, and glycemic control in Korean adults with type 2 diabetes. Contemporary Nurse, 42(2), 272-279.

Anderson, D., Bilodeau, B., Deshaies, G., Gilbert, M., \& Jobin, J. (2005). French-Canadian validation of the MOS Social Support Survey. The Canadian Journal of Cardiology, 21(10), 867-873.

Antony, M.M., Bieling, P.J., Cox, B.J., Enns, M.W. \& Swinson, R.P. (1998). Psychometric properties of the 42-item and 21-item versions of the Depression Anxiety Stress 
Scales (DASS) in clinical groups and a community sample. Psychological Assessment, 10, 176-181.

Arigo, D., Smyth, J. M., Haggerty, K., \& Raggio, G. A. (2015). The social context of the relationship between glycemic control and depressive symptoms in type 2 diabetes. Chronic Illness, 11(1), 33-43.

Arora, N. K., \& McHorney, C. A. (2000). Patient preferences for medical decision making: who really wants to participate? Medical Care, 38(3), 335-341.

Aylaz, R., Karadağ, E., Işik, K., \& Yildirim, M. (2015). Relationship between social support and fatigue in patients with type 2 diabetes mellitus in the east of Turkey. Japan Journal of Nursing Science, 12(4), 367-376.

Bai, Y. L., Chiou, C. P., \& Chang, Y. Y. (2009). Self-care behaviour and related factors in older people with Type 2 diabetes. Journal of Clinical Nursing, 18(23), 3308-3315.

Baron, R. M., \& Kenny, D. A. (1986). The moderator-mediator variable distinction in social psychological research: Conceptual, strategic, and statistical considerations. Journal of Personality and Social Psychology, 51(6), 1173-1182.

Barrera, M., Glasgow, R. E., McKay, H. G., Boles, S. M., \& Feil, E. G. (2002). Do Internetbased support interventions change perceptions of social support? An experimental trial of approaches for supporting diabetes self-management. American Journal of Community Psychology, 30(5), 637-654. 
Barrera, M., Toobert, D. J., Angell, K. L., Glasgow, R. E., \& MacKinnon, D. P. (2006). Social support and social-ecological resources as mediators of lifestyle intervention effects for type 2 diabetes. Journal of Health Psychology, 11(3), 483-495.

Baumann, L. C., Frederick, N., Betty, N., Jospehine, E., \& Agatha, N. (2015). A demonstration of peer support for Ugandan adults with type 2 diabetes. International Journal of Behavioral Medicine, 22(3), 374-383.

Bayliss, E. A., Ellis, J. L., \& Steiner, J. F. (2007). Barriers to self-management and qualityof-life outcomes in seniors with multimorbidities. The Annals of Family Medicine, $5(5), 395-402$.

Bearman, K. J., \& La Greca, A. M. (2002). Assessing friend support of adolescents' diabetes care: the diabetes social support questionnaire-friends version. Journal of Pediatric Psychology, 27(5), 417-428.

Beck, A.T., Ward, C. H., Mendelson, M., Mock, J., \& Erbaugh, J. (1961). An inventory for measuring depression. Archives of General Psychiatry, 4, 561-571.

Bender, R., \& Lange, S. (2001). Adjusting for multiple testing—when and how?. Journal of Clinical Epidemiology, 54(4), 343-349.

Berard, L. D., Blumer, I., Houlden, R., Miller, D., \& Woo, V. (2013). Monitoring glycemic control. Canadian Journal of Diabetes, 37, S35-S39.

Beverly, E. A., Miller, C. K., \& Wray, L. A. (2008). Spousal support and food-related behavior change in middle-aged and older adults living with type 2 diabetes. Health Education \& Behavior, 35(5), 707-720. 
Beverly, E. A., Wray, L. A., Chiu, C. J., \& LaCoe, C. L. (2014). Older Adults Perceived Challenges with Health Care Providers Treating Their Type 2 Diabetes and Comorbid Conditions. Clinical Diabetes, 32(1), 12-17.

Bhattacharya, G. (2012). Psychosocial impacts of type 2 diabetes self-management in a rural African-American population. Journal of Immigrant and Minority Health, 14(6), 1071-1081.

Bohanny, W., Wu, S. F. V., Liu, C. Y., Yeh, S. H., Tsay, S. L., \& Wang, T. J. (2013). Health literacy, self-efficacy, and self-care behaviors in patients with type 2 diabetes mellitus. Journal of the American Association of Nurse Practitioners, 25(9), 495-502.

Brawley, L. R., Rejeski, W. J., \& King, A. C. (2003). Promoting physical activity for older adults: the challenges for changing behavior. American Journal of Preventive Medicine, 25(3), 172-183.

Broadhead W.E., Gehlbach S.H., de Gruy F.V. \& Kaplan B.H. (1988) The Duke-UNC Functional Social Support Questionnaire. Measurement of social support in family medicine patients. Medical Care 26(7), 709-723.

Brody, G. H., Flor, D. L., Hollett-Wright, N., \& McCoy, J. K. (1998). Children's development of alcohol use norms: Contributions of parent and sibling norms, children's temperaments, and parent-child discussions. Journal of Family Psychology, 12(2), 209.

Brody, G. H., Kogan, S. M., Murry, V. M., Chen, Y. F., \& Brown, A. C. (2008). Psychological functioning, support for self-management, and glycemic control 
among rural African American adults with diabetes mellitus type 2. Health Psychology, 27(1S), S83-S90.

Bruwer, B., Emsley, R., Kidd, M., Lochner, C., \& Seedat, S. (2008). Psychometric properties of the Multidimensional Scale of Perceived Social Support in youth. Comprehensive Psychiatry, 49(2), 195-201.

Calvin, D., Quinn, L., Dancy, B., Park, C., Fleming, S. G., Smith, E., \& Fogelfeld, L. (2011). African Americans' perception of risk for diabetes complications. The Diabetes Educator, 37(5), 689-698.

Canty-Mitchell, J., \& Zimet, G. D. (2000). Psychometric properties of the Multidimensional Scale of Perceived Social Support in urban adolescents. American Journal of Community Psychology, 28(3), 391-400.

Casagrande, S. S., Fradkin, J. E., Saydah, S. H., Rust, K. F., \& Cowie, C. C. (2013). The prevalence of meeting A1C, blood pressure, and LDL goals among people with diabetes, 1988-2010. Diabetes Care, 36(8), 2271-2279.

Centers for Disease Control and Prevention (2012). National Center for Health Statistics (NCHS). National Health and Nutrition Examination Survey Questionnaire. Hyattsville, MD: U.S. Department of Health and Human Services, Centers for Disease Control and Prevention.

Centers for Disease Control and Prevention. (2014). National diabetes statistics report: Estimates of diabetes and its burden in the United States, 2014. Atlanta, GA: US Department of Health and Human Services. 
Centers for Disease Control and Prevention. (2016). Summary Health Statistics: National Health Interview Survey: 2014. Atlanta, GA: US Department of Health and Human Services.

Centers for Disease Control and Prevention. (2017). National diabetes statistics report: estimates of diabetes and its burden in the United States, 2017. Atlanta, GA: US Department of Health and Human Services.

Chew, B. H., Khoo, E. M., \& Chia, Y. C. (2015). Social support and glycemic control in adult patients with type 2 diabetes mellitus. Asia-Pacific Journal of Public Health, 27(2), NP166-NP173.

Chiu, C. J., \& Wray, L. A. (2010). Factors predicting glycemic control in middle-aged and older adults with type 2 diabetes. Preventing Chronic Disease, 7(1), 1-11.

Chiu, C. J., \& Wray, L. A. (2011). Gender differences in functional limitations in adults living with type 2 diabetes: biobehavioral and psychosocial mediators. Annals of Behavioral Medicine, 41(1), 71-82.

Chlebowy, D. O., \& Garvin, B. J. (2006). Social support, self-efficacy, and outcome expectations Impact on self-care behaviors and glycemic control in Caucasian and African American adults with type 2 diabetes. The Diabetes Educator, 32(5), 777786.

Chlebowy, D. O., Kubiak, N., Myers, J., \& Jorayeva, A. (2016). The Relationships of Demographic Characteristics with Diabetes Biomarkers and Physical Activity Adherence in African American Adults. Journal of racial and Ethnic Health Disparities, 3(2), 240-244. 
Clay, O. J., Roth, D. L., Wadley, V. G., \& Haley, W. E. (2008). Changes in social support and their impact on psychosocial outcome over a 5-year period for African American and White dementia caregivers. International Journal of Geriatric Psychiatry, 23(8), 857-862.

Clay, O. J., Roth, D. L., Wadley, V. G., \& Haley, W. E. (2008). Changes in social support and their impact on psychosocial outcome over a 5-year period for African American and White dementia caregivers. International Journal of Geriatric Psychiatry, 23(8), 857-862.

Cohen, S., Mermelstein, R., Kamarack, T. \& Hoberman, H. (1985) Measuring the functional components of social support. In I. G. Sarason and B. R. Sarason (Eds.), Social support: Theory, research and applications (pp. 73-94) Dordrecht, Netherlands: Martinus Nijhoff Publishers.

Collins-McNeil, J. (2006). Psychosocial characteristics and cardiovascular risk in African Americans with diabetes. Archives of Psychiatric Nursing, 20(5), 226-233.

Collins-McNeil, J. C., Holston, E. C., Edwards, C. L., Benbow, D., \& Ford, Y. (2009). Physical activity, depressive symptoms, and social support among AfricanAmerican women with type 2 diabetes. Canadian Journal of Nursing Research, 41(3), 24-43.

Cosansu, G., \& Erdogan, S. (2013). Influence of psychosocial factors on self-care behaviors and glycemic control in Turkish patients with type 2 diabetes mellitus. Journal of Transcultural Nursing, 25(1) 51-59. 
Costa, V., Pereira, M. G., \& Pedras, S. (2012). Partner support, social-cognitive variables and their role in adherence to self-monitoring of blood glucose in type 2 diabetes. European Diabetes Nursing, 9(3), 81-86.

Coste, J., Guillemin, F., Pouchot, J., \& Fermanian, J. (1997). Methodological approaches to shortening composite measurement scales. Journal of Clinical Epidemiology, 50(3), 247-252.

De Melo, M., De Sa, E., \& Gucciardi, E. (2013). Exploring differences in Canadian adult men and women with Diabetes management: results from the Canadian Community Health Survey. BMC public health, 13(1), 1089-1091.

Dekker, R. L., Lennie, T. A., Hall, L. A., Peden, A. R., Chung, M. L., \& Moser, D. K. (2011). Developing a shortened measure of negative thinking for use in patients with heart failure. Heart \& Lung: The Journal of Acute and Critical Care, 40(3), 60-69.

DeVellis, R.F. (2012). Scale development: Theory and applications ( $3^{\text {rd }}$ Ed.). Los Angeles: Sage.

disorders with Type 2 diabetes in Bahrain, a country with a very high prevalence of Type 2 diabetes. Journal of Endocrinological Investigation, 31(11), 1020-1024.

Dorner, B. (2010). Position of the American Dietetic Association: individualized nutrition approaches for older adults in health care communities. Journal of the American Dietetic Association, 110(10), 1549-1553. 
Egede, L. E., \& Osborn, C. Y. (2010). Role of motivation in the relationship between depression, self-care, and glycemic control in adults with type 2 diabetes. The Diabetes Educator, 36(2), 276-283.

Engum, A. (2007). The role of depression and anxiety in onset of diabetes in a large population-based study. Journal of Psychosomatic Research, 62(1), 31-38.

Feil, D. G., Zhu, C. W., \& Sultzer, D. L. (2012). The relationship between cognitive impairment and diabetes self-management in a population-based community sample of older adults with Type 2 diabetes. Journal of Behavioral Medicine, 35(2), 190-199.

Finfgeld-Connett, D. (2005). Clarification of social support. Journal of Nursing Scholarship, 37(1), 4-9.

Fisher, L., Mullan, J. T., Arean, P., Glasgow, R. E., Hessler, D., \& Masharani, U. (2010). Diabetes distress but not clinical depression or depressive symptoms is associated with glycemic control in both cross-sectional and longitudinal analyses. Diabetes Care, 33(1), 23-28.

Fisher, L., Skaff, M. M., Mullan, J. T., Arean, P., Glasgow, R., \& Masharani, U. (2008). A longitudinal study of affective and anxiety disorders, depressive affect and diabetes distress in adults with type 2 diabetes. Diabetic Medicine, 25(9), 1096-1101.

Fisher, R. A. (1915). Frequency distribution of the values of the correlation coefficient in samples from an indefinitely large population. Biometrika, 10(4), 507-521. 
Fitzgerald, J. T., Davis, W. K., Connell, C. M., Hess, G. E., Funnell, M. M., \& Hiss, R. G. (1996). Development and validation of the Diabetes Care Profile. Evaluation \& The Health Professions, 19(2), 208-230.

Flaherty, J. A., Gaviria, F. M., \& Pathak, D. S. (1983). The measurement of social support: The Social Support Network Inventory. Comprehensive Psychiatry, 24(6), 521529.

Formosa, C., \& Muscat, R. (2016). Improving Diabetes Knowledge and Self-Care Practices. Journal of the American Podiatric Medical Association, 106(5), 352356.

Fortmann, A. L., Gallo, L. C., \& Philis-Tsimikas, A. (2011). Glycemic control among Latinos with type 2 diabetes: The role of social-environmental support resources. Health Psychology, 30(3), 251-258.

Fortmann, A. L., Gallo, L. C., Walker, C., \& Philis-Tsimikas, A. (2010). Support for disease management, depression, self-care, and clinical indicators among Hispanics with type 2 diabetes in San Diego County, United States of America. Revista Panamericana de Salud Pública, 28(3), 230-234.

Franks, M. M., Hemphill, R. C., Seidel, A. J., Stephens, M. A. P., Rook, K. S., \& Salem, J. K. (2012). Setbacks in diet adherence and emotional distress: a study of older patients with type 2 diabetes and their spouses. Aging \& Mental Health, 16(7), 902910. 
Friedman, E., Son, H., Thomas, S. A., Chapa, D. W., \& Lee, H. J. (2013). Poor social support is associated with increases in depression but not anxiety over 2 years in heart failure outpatients. The Journal of Cardiovascular Nursing, 29(1), 20-28.

Funnell, M. M., Anderson, R. M., Austin, A., \& Gillespie, S. J. (2007). Individualization of diabetes self-management education. The Diabetes Educator, 33(1), 45-49.

Furler, J., Walker, C., Blackberry, I., Dunning, T., Sulaiman, N., Dunbar, J., ... \& Young, D. (2008). The emotional context of self-management in chronic illness: A qualitative study of the role of health professional support in the self-management of type 2 diabetes. BMC Health Services Research, 8(1), 214-223.

Gallegos-Carrillo, K., García-Peña, C., Durán-Muñoz, C. A., Flores, Y. N., \& Salmeron, J. (2009). Relationship between social support and the physical and mental wellbeing of older Mexican adults with diabetes. Revista de Investigación Clínica, 61(5), 383-391.

Gao, J., Wang, J., Zheng, P., Haardörfer, R., Kegler, M. C., Zhu, Y., \& Fu, H. (2013). Effects of self-care, self-efficacy, social support on glycemic control in adults with type 2 diabetes. BMC Family Practice, 14(1), 66-73.

Gavazzi, S. M., Reese, M. J., \& Sabatelli, R. M. (1998). Conceptual development and empirical use of the Family Intrusiveness Scale. Journal of Family Issues, 19(1), $65-74$.

Glasgow, R. E., \& Toobert, D. J. (1988). Social environment and regimen adherence among type II diabetic patients. Diabetes Care, 11(5), 377-386. 
Glasgow, R. E., Kurz, D., King, D., Dickman, J. M., Faber, A. J., Halterman, E., ... \& Ritzwoller, D. (2012). Twelve-month outcomes of an Internet-based diabetes selfmanagement support program. Patient Education and Counseling, 87(1), 81-92.

Glasgow, R. E., Toobert, D. J., Barrera, M., \& Strycker, L. A. (2005). The Chronic Illness Resources Survey: cross-validation and sensitivity to intervention. Health Education Research, 20(4), 402-409.

Gloster, A. T., Rhoades, H. M., Novy, D., Klotsche, J., Senior, A., Kunik, M., ... \& Stanley, M. A. (2008). Psychometric properties of the Depression Anxiety and Stress Scale21 in older primary care patients. Journal of Affective Disorders, 110(3), 248-259.

Gomersall, T., Madill, A., \& Summers, L. K. (2011). A metasynthesis of the selfmanagement of type 2 diabetes. Qualitative Health Research, 21(6), 853-871.

Gomes-Villas Boas, L. C., Foss, M. C., Freitas, M. C. F. D., \& Pace, A. E. (2012). Relationship among social support, treatment adherence and metabolic control of diabetes mellitus patients. Revista Latino-Americana De Enfermagem, 20(1), 5258.

Gonzalez, J. S., Fisher, L., \& Polonsky, W. H. (2011). Depression in diabetes: have we been missing something important?. Diabetes Care, 34(1), 236-239.

Gonzalez, J. S., Peyrot, M., McCarl, L. A., Collins, E. M., Serpa, L., Mimiaga, M. J., \& Safren, S. A. (2008). Depression and diabetes treatment nonadherence: A metaanalysis. Diabetes Care, 31(12), 2398-2403. 
Gottlieb, B. H., \& Bergen, A. E. (2010). Social support concepts and measures. Journal of Psychosomatic Research, 69(5), 511-520.

Göz, F., Karaoz, S., Goz, M., Ekız, S., \& Cetın, I. (2007). Effects of the diabetic patients' perceived social support on their quality-of-life. Journal of Clinical Nursing, 16(7), 1353-1360.

Haas, L., Maryniuk, M., Beck, J., Cox, C. E., Duker, P., Edwards, L., ... \& Youssef, G. (2013). National standards for diabetes self-management education and support. Diabetes Care, 36(Supplement 1), S100-S108.

Halali, F., Mahdavi, R., Mobasseri, M., Jafarabadi, M. A., \& Avval, S. K. (2016). Perceived barriers to recommended dietary adherence in patients with type 2 diabetes in Iran. Eating Behaviors, 21, 205-210.

Hall, L. A. (1983). Social supports, everyday stressors, and maternal mental health (Unpublished doctoral dissertation). University of North Carolina, Chapel Hill, NC.

Hall, L. A., \& Kiernan, B. S. (1992). Psychometric assessment of a measure of the quality of primary intimate relationships. Health Values, 16(4), 30-39.

Hall, L. A., Schaefer, E. S., \& Greenberg, R. S. (1987). Quality and quantity of social support as correlates of psychosomatic symptoms in mothers with young children. Research in Nursing \& Health, 10 (4), 287-298.

Heisler, M. (2006). Building peer support programs to manage chronic disease: seven models for success. Oakland, CA, California Health Care Foundation. Retrieved 
from: http://www.chcf.org/publications/2006/12/building-peer-support-programs$\underline{\text { to-manage-chronic-disease-seven-models-for-success }}$

Hemphill, R. C., Stephens, M. A. P., Rook, K. S., Franks, M. M., \& Salem, J. K. (2013). Older adults' beliefs about the timeline of type 2 diabetes and adherence to dietary regimens. Psychology \& Health, 28(2), 139-153.

Hempler, N. F., Ekholm, O., \& Willaing, I. (2013). Differences in social relations between persons with type 2 diabetes and the general population. Scandinavian Journal of Public Health, 41(4), 340-343. doi: 10.1177/1403494813482535.

Herman, W. H., Ma, Y., Uwaifo, G., Haffner, S., Kahn, S. E., Horton, E. S., ... \& BarrettConnor, E. (2007). Differences in A1C by race and ethnicity among patients with impaired glucose tolerance in the Diabetes Prevention Program. Diabetes care, 30(10), 2453-2457.

Hessler, D. M., Fisher, L., Naranjo, D., \& Masharani, U. (2011). Young adult African American patients with type 2 diabetes: A high risk patient sub-group with few supports for good diabetes management. Journal of Health Psychology, 17(4):535544.

Hilliard, M. E., Joyce, P., Hessler, D., Butler, A. M., Anderson, B. J., \& Jaser, S. (2016). Stress and A1c among people with diabetes across the lifespan. Current Diabetes Reports, 16(8), 1-10.

Howteerakul, N., Suwannapong, N., Rittichu, C., \& Rawdaree, P. (2007). Adherence to regimens and glycemic control of patients with type 2 diabetes attending a tertiary hospital clinic. Asia-Pacific Journal of Public Health, 19(1), 43-49. 
Kaplan, S. H., Billimek, J., Sorkin, D. H., Ngo-Metzger, Q., \& Greenfield, S. (2013). Reducing racial/ethnic disparities in diabetes: The Coached Care (R2D2C2) Project. Journal of General Internal Medicine, 28(10), 1340-1349.

Karlsen, B., \& Bru, E. (2014). The relationship between diabetes-related distress and clinical variables and perceived support among adults with type 2 diabetes: A prospective study. International Journal of Nursing Studies, 51(3), 438-447.

Karlsen, B., Oftedal, B., \& Bru, E. (2012). The relationship between clinical indicators, coping styles, perceived support and diabetes-related distress among adults with type 2 diabetes. Journal of Advanced Nursing, 68(2), 391-401.

Katon, W. J. (2008). The comorbidity of diabetes mellitus and depression. The American Journal of Medicine, 121(11), S8-S15.

Kaur, G., Tee, G. H., Ariaratnam, S., Krishnapillai, A. S., \& China, K. (2013). Depression, anxiety and stress symptoms among diabetics in Malaysia: a cross sectional study in an urban primary care setting. BMC Family Practice, 14(1), 1-13.

Kim, C. J., Schlenk, E. A., Kim, D. J., Kim, M., Erlen, J. A., \& Kim, S. E. (2015). The role of social support on the relationship of depressive symptoms to medication adherence and self-care activities in adults with type 2 diabetes. Journal of Advanced Nursing 71(9), 2164-2175.

Kim, K. H. C., Bursac, Z., DiLillo, V., White, D. B., \& West, D. S. (2009). Stress, race, and body weight. Health Psychology, 28(1), 131-135. 
Kirk, J. K., D’Agostino, R. B., Bell, R. A., Passmore, L. V., Bonds, D. E., Karter, A. J., \& Narayan, K. V. (2006). Disparities in HbA1c levels between African-American and Non-Hispanic White adults with diabetes: A meta-analysis. Diabetes Care, 29(9), $2130-2136$.

Kirkman MS, Briscoe VJ, Clark N, et al. Diabetes in older adults. Diabetes Care. 2012 ;35(12):2650-2664.

Kollannoor-Samuel, G., Chhabra, J., Fernandez, M. L., Vega-López, S., Pérez, S. S., Damio, G., ... \& Pérez-Escamilla, R. (2011). Determinants of fasting plasma glucose and glycosylated hemoglobin among low income Latinos with poorly controlled type 2 diabetes. Journal of Immigrant and Minority Health, 13(5), 809817.

Komar-Samardzija, M., Braun, L. T., Keithley, J. K., \& Quinn, L. T. (2012). Factors associated with physical activity levels in African-American women with type 2 diabetes. Journal of the American Academy of Nurse Practitioners, 24(4), 209-217.

Langford, C. P. H., Bowsher, J., Maloney, J. P., \& Lillis, P. P. (1997). Social support: A conceptual analysis. Journal of Advanced Nursing, 25(1), 95-100.

Lee, Y. J., Shin, S. J., Wang, R. H., Lin, K. D., Lee, Y. L., \& Wang, Y. H. (2016). Pathways of empowerment perceptions, health literacy, self-efficacy, and self-care behaviors to glycemic control in patients with type 2 diabetes mellitus. Patient education and counseling, 99(2), 287-294. 
Ley, S. H., Hamdy, O., Mohan, V., \& Hu, F. B. (2014). Prevention and management of type 2 diabetes: dietary components and nutritional strategies. The Lancet, 383(9933), 1999-2007.

Lin, E. H., Rutter, C. M., Katon, W., Heckbert, S. R., Ciechanowski, P., Oliver, M. M., ... \& Von Korff, M. (2010). Depression and advanced complications of diabetes a prospective cohort study. Diabetes Care, 33(2), 264-269.

Linares, A. M., Hall, L., \& Ashford, K. (2015). Psychometric Testing of the Autonomy and Relatedness Inventory-Spanish Version. Journal of Nursing Measurement, 23(1), 27E-37E.

Lloyd S.H. \& Lovibond, P.F. (1995). Manual for the Depression Anxiety Stress Scales. (2nd. Ed.) Sydney: Psychology Foundation.

Lloyd, C., Smith, J., \& Weinger, K. (2005). Stress and diabetes: A review of the links. Diabetes Spectrum, 18(2), 121-127.

Lopez, J. M., Bailey, R. A., Rupnow, M. F., \& Annunziata, K. (2014). Characterization of type 2 diabetes mellitus burden by age and ethnic groups based on a nationwide survey. Clinical therapeutics, 36(4), 494-506.

Lovibond, P. F., \& Lovibond, S. H. (1995). The structure of negative emotional states: Comparison of the Depression Anxiety Stress Scales (DASS) with the Beck Depression and Anxiety Inventories. Behaviour Research and Therapy, 33(3), 335343. 
Lustman, P. J., \& Clouse, R. E. (2005). Depression in diabetic patients: The relationship between mood and glycemic control. Journal of Diabetes and its Complications, 19(2), 113-122.

Marcy, T. R., Britton, M. L., \& Harrison, D. (2011). Identification of barriers to appropriate dietary behavior in low-income patients with type 2 diabetes mellitus. Diabetes Therapy, 2(1), 9-19.

Martin LR, Williams SL, Haskard KB, DiMatteo MR. The challenge of patient adherence. Ther Clin Risk Manag. 2005; 1(3):189-199.

Mathew, R., Gucciardi, E., De Melo, M., \& Barata, P. (2012). Self-management experiences among men and women with type 2 diabetes mellitus: A qualitative analysis. BMC Family Practice, 13(1), 122-134. doi:10.1186/1471-2296-13-122

Mayberry, L. S., \& Osborn, C. Y. (2012). Family support, medication adherence, and glycemic control among adults with type 2 diabetes. Diabetes Care, 35(6), 12391245.

Mayberry, L. S., \& Osborn, C. Y. (2014). Family involvement is helpful and harmful to patients' self-care and glycemic control. Patient Education and Counseling, 97(3), $418-425$.

Mayberry, L. S., Rothman, R. L., \& Osborn, C. Y. (2014). Family members' obstructive behaviors appear to be more harmful among adults with type 2 diabetes and limited health literacy. Journal of Health Communication, 19(sup2), 132-143. 
McDowell, I. (2006). Measuring health: A guide to rating scales and questionnaires. Oxford University Press.

McEwen, M. M., Pasvogel, A., Gallegos, G., \& Barrera, L. (2010). Type 2 diabetes selfmanagement social support intervention at the US-Mexico border. Public Health Nursing, 27(4), 310-319.

Miller, S. T. (2011). Diabetes and psychological profile of younger rural African American women with type 2 diabetes. Journal of Health Care for the Poor and Underserved, 22(4), 1239-1252.

Misra, R., \& Lager, J. (2009). Ethnic and gender differences in psychosocial factors, glycemic control, and quality of life among adult type 2 diabetic patients. Journal of Diabetes and its Complications, 23(1), 54-64.

Murano, I., Asakawa, Y., Mizukami, M., Takihara, J., Shimizu, K., \& Imai, T. (2014). Factors increasing physical activity levels in diabetes mellitus: a survey of patients after an inpatient diabetes education program. Journal of Physical Therapy Science, 26(5), 695-699.

Murrock, C. J., Taylor, E., \& Marino, D. (2013). Dietary challenges of managing type 2 diabetes in African-American women. Women \& Health, 53(2), 173-184.

Nakahara, R., Yoshiuchi, K., Kumano, H., Hara, Y., Suematsu, H., \& Kuboki, T. (2006). Prospective study on influence of psychosocial factors on glycemic control in Japanese patients with type 2 diabetes. Psychosomatics, 47(3), 240-246. 
Newlin, K., Melkus, G. D., Tappen, R., Chyun, D., \& Koenig, H. G. (2008). Relationships of religion and spirituality to glycemic control in Black women with type 2 diabetes. Nursing Research, 57(5), 331-339.

Nicklett, E. J., \& Liang, J. (2010). Diabetes-related support, regimen adherence, and health decline among older adults. The Journals of Gerontology Series B: Psychological Sciences and Social Sciences, 65(3), 390-399.

Nielsen, A. B., de Fine Olivarius, N., Gannik, D., Hindsberger, C., \& Hollnagel, H. (2006). Structured personal diabetes care in primary health care affects only women's HbA1c. Diabetes Care, 29(5), 963-969.

Nouwen, A., Winkley, K., Twisk, J., Lloyd, C. E., Peyrot, M., Ismail, K., ... \& European Depression in Diabetes (EDID) Research Consortium. (2010). Type 2 diabetes mellitus as a risk factor for the onset of depression: A systematic review and metaanalysis. Diabetologia, 53(12), 2480-2486.

Nozaki, T., Morita, C., Matsubayashi, S., Ishido, K., Yokoyama, H., Kawai, K., ... \& Kubo, C. (2009). Relation between psychosocial variables and the glycemic control of patients with type 2 diabetes: a cross-sectional and prospective study. BioPsychoSocial medicine, 3(1), 4-13.

Nundy, S., Dick, J. J., Solomon, M. C., \& Peek, M. E. (2013). Developing a behavioral model for mobile phone-based diabetes interventions. Patient Education and Counseling, 90(1), 125-132. 
Osborn, C. Y., \& Egede, L. E. (2010). Validation of an Information-MotivationBehavioral Skills model of diabetes self-care (IMB-DSC). Patient Education and Counseling, 79(1), 49-54.

Osborn, C. Y., Bains, S. S., \& Egede, L. E. (2010). Health literacy, diabetes self-care, and glycemic control in adults with type 2 diabetes. Diabetes Technology \& Therapeutics, 12(11), 913-919.

Osborn, C. Y., Cavanaugh, K., Wallston, K. A., Kripalani, S., Elasy, T. A., Rothman, R. L., \& White, R. O. (2011). Health literacy explains racial disparities in diabetes medication adherence. Journal of Health Communication, 16(sup3), 268-278.

Osborne, R. H., Elsworth, G. R., \& Whitfield, K. (2007). The Health Education Impact Questionnaire (heiQ): An outcomes and evaluation measure for patient education and self-management interventions for people with chronic conditions. Patient Education and Counseling, 66(2), 192-201.

Pan, A., Lucas, M., Sun, Q., van Dam, R. M., Franco, O. H., Manson, J. E., ... \& Hu, F. B. (2010). Bidirectional association between depression and type 2 diabetes mellitus in women. Archives of Internal Medicine, 170(21), 1884-1891.

Pastors, J. G., Warshaw, H., Daly, A., Franz, M., \& Kulkarni, K. (2002). The evidence for the effectiveness of medical nutrition therapy in diabetes management. Diabetes Care, 25(3), 608-613.

Paukert, A. L., LeMaire, A., \& Cully, J. A. (2009). Predictors of depressive symptoms in older veterans with heart failure. Aging \& Mental Health, 13(4), 601-610. 
Penckofer, S., Doyle, T., Byrn, M., \& Lustman, P. J. (2014). State of the science depression and type 2 diabetes. Western Journal of Nursing Research, 36(9) 1158-1182

Pender (2011). The Health Promotion Model Manual. Retrieved from http://nursing.umich.edu/faculty-staff/nola-j-pender.

Pender, N. J., Murdaugh, C. L., \& Parsons, M. A. (2002). Health Promotion in Nursing Practice. Upper Saddle River, N.J.: Prentice Hall.

Peyrot, M., Peeples, M., Tomky, D., Charron-Prochownik, D., \& Weaver, T. (2007). Development of the American Association of Diabetes Educators' diabetes selfmanagement assessment report tool. The Diabetes Educator, 33(5), 818-826.

Piette, J. D., Resnicow, K., Choi, H., \& Heisler, M. (2013). A diabetes peer support intervention that improved glycemic control: mediators and moderators of intervention effectiveness. Chronic Illness, 9(4), 258-267.

Powers, M. A., Bardsley, J., Cypress, M., Duker, P., Funnell, M. M., Fischl, A. H., ... \& Vivian, E. (2017). Diabetes self-management education and support in type 2 diabetes: a joint position statement of the American Diabetes Association, the American Association of Diabetes Educators, and the Academy of Nutrition and Dietetics. The Diabetes Educator, 43(1), 40-53.

Preacher, K. J., \& Hayes, A. F. (2004). SPSS and SAS procedures for estimating indirect effects in simple mediation models. Behavior Research Methods, Instruments, \& Computers, 36(4), 717-731. 
Raymond, K. L., \& Lovell, G. P. (2015). Food addiction symptomology, impulsivity, mood, and body mass index in people with type two diabetes. Appetite, 95, 383389.

Raymond, M.R. (1986). Missing data in evaluation research. Evaluation and the Health Professions, 9(4), 395-420.

Raymond, M.R., \& Roberts, D.M. (1987). A comparison of methods for treating incomplete data in selection research. Educational and Psychological Measurement, 47(1), 13-26.

Richards, L., \& Morse, J. M. (2012). Readme first for a user's guide to qualitative methods. Thousand Oaks, CA: Sage Publications.

Rothman, R. L., Mulvaney, S., Elasy, T. A., VanderWoude, A., Gebretsadik, T., Shintani, A., ... \& Schlundt, D. (2008). Self-management behaviors, racial disparities, and glycemic control among adolescents with type 2 diabetes. Pediatrics, 121(4), e912e919.

Sallis, J.F., Grossman, R.M., Pinski, R.B., Patterson, T.L., and Nader, P.R. (1987). The development of scales to measure social support for diet and exercise behaviors. Preventive Medicine, 16, 825-836.

Samuel-Hodge, C. D., Keyserling, T. C., Park, S., Johnston, L. F., Gizlice, Z., \& Bangdiwala, S. I. (2009). A randomized trial of a church-based diabetes selfmanagement program for African Americans with type 2 diabetes. The Diabetes Educator, 35(3), 439-454. 
Samuel-Hodge, C. D., Watkins, D. C., Rowell, K. L., \& Hooten, E. G. (2008). Coping styles, well-being, and self-care behaviors among African Americans with type 2 diabetes. The Diabetes Educator, 34(3), 501-510.

Sarason, I.G., Levine, H.M., Basham, R.B., et al. (1983). Assessing social support: The Social Support Questionnaire. Journal of Personality and Social Psychology, 44, 127- 139.

Sarason, I.G., Sarason, B.R.., Shearin, E.N., \& Pierce, G.R. (1987). A brief measure of social support: Practical and theoretical implications. Journal of Social and Personal Relationships, 4, 497-510.

Schaefer, E. S., \& Edgerton, M. (1979). Marital Autonomy and Relatedness Inventory (Unpublished doctoral dissertation). University of North Carolina, Chapel Hill, NC.

Schafer, L. C., McCaul, K. D., \& Glasgow, R. E. (1986). Supportive and nonsupportive family behaviors: Relationships to adherence and metabolic control in persons with type I diabetes. Diabetes Care, 9(2), 179-185.

Scherrer, J. F., Garfield, L. D., Chrusciel, T., Hauptman, P. J., Carney, R. M., Freedland, K. E., ... \& Lustman, P. J. (2011). Increased risk of myocardial infarction in depressed patients with type 2 diabetes. Diabetes Care, 34(8), 1729-1734.

Schmitt, A., Gahr, A., Hermanns, N., Kulzer, B., Huber, J., \& Haak, T. (2013). The Diabetes Self-Management Questionnaire (DSMQ): development and evaluation of an instrument to assess diabetes self-care activities associated with glycaemic control. Health and Quality of Life Outcomes, 11(1), 138-152. 
Schneiderman, N., Llabre, M., Cowie, C. C., Barnhart, J., Carnethon, M., Gallo, L. C., ... \& Teng, Y. (2014). Prevalence of diabetes among hispanics/latinos from diverse backgrounds: the hispanic community health study/study of latinos (HCHS/SOL). Diabetes Care, 37(8), 2233-2239.

Semenkovich, K., Brown, M. E., Svrakic, D. M., \& Lustman, P. J. (2015). Depression in type 2 diabetes mellitus: prevalence, impact, and treatment. Drugs, 75(6), 577-587.

Shallcross, A. J., Ojie, M. J., Chaplin, W., Levy, N., Odedosu, T., Ogedegbe, G., \& Spruill, T. M. (2015). Race/ethnicity moderates the relationship between chronic life stress and quality of life in type 2 diabetes. Diabetes Research and Clinical Practice, $108(1), 150-156$

Sherbourne, C. D., \& Stewart, A. L. (1991). The MOS social support survey. Social Science \& Medicine, 32(6), 705-714.

Shyu, Y. I. L., Tang, W. R., Liang, J., \& Weng, L. J. (2006). Psychometric testing of the social support survey on a Taiwanese sample. Nursing Research, 55(6), 411-417.

Siripitayakunkit, A., Hanucharurnkul, S., Melkus, G. D. E., Vorapongsathorn, T., Rattarasarn, C., \& Arpanantikul, M. (2010). Factors contributing to integrating lifestyle in Thai women with type 2 diabetes. Thai Journal of Nursing Research, 12(3), 166-178.

Smalls, B. L., Gregory, C. M., Zoller, J. S., \& Egede, L. E. (2015). Direct and indirect effects of neighborhood factors and self-care on glycemic control in adults with type 2 diabetes. Journal of Diabetes and its Complications, 29(2), 186-191. 
Smith, K. J., Béland, M., Clyde, M., Gariépy, G., Pagé, V., Badawi, G., ... \& Schmitz, N. (2013). Association of diabetes with anxiety: A systematic review and metaanalysis. Journal of Psychosomatic Research, 74(2), 89-99.

Sobel, M. E. (1982). Asymptotic confidence intervals for indirect effects in structural equation models. Sociological Methodology, 13(1982), 290-312.

Soto, J. A., Dawson-Andoh, N. A., \& BeLue, R. (2011). The relationship between perceived discrimination and generalized anxiety disorder among African Americans, Afro Caribbeans, and non-Hispanic Whites. Journal of Anxiety Disorders, 25(2), 258-265.

Standards of medical care in diabetes-2014. (2014). Diabetes Care, 37, 14-80.

Stanley, M. A., Beck, J. G., \& Zebb, B. J. (1998). Psychometric properties of the MSPSS in older adults. Aging \& Mental Health, 2(3), 186-193.

Steffen, P. R., Hinderliter, A. L., Blumenthal, J. A., \& Sherwood, A. (2001). Religious coping, ethnicity, and ambulatory blood pressure. Psychosomatic Medicine, 63(4), 523-530.

Stephens, M. A. P., Fekete, E. M., Franks, M. M., Rook, K. S., Druley, J. A., \& Greene, K. (2009). Spouses' use of pressure and persuasion to promote osteoarthritis patients' medical adherence after orthopedic surgery. Health Psychology, 28(1), 48.

Stephens, M. A. P., Franks, M. M., Rook, K. S., Iida, M., Hemphill, R. C., \& Salem, J. K. (2013). Spouses' attempts to regulate day-to-day dietary adherence among patients with type 2 diabetes. Health Psychology, 32(10), 1029. 
Stephens, M. A. P., Rook, K. S., Franks, M. M., Khan, C., \& Iida, M. (2010). Spouses use of social control to improve diabetic patients' dietary adherence. Families, Systems, \& Health, 28(3), 199-208.

Streiner, D.L., Norman, G.R. \& Cairney, J. (2015). Health measurement scales: A practical guide to their development and use ( $5^{\text {th }}$ Ed.). Oxford, England: Oxford University Press.

Strom, J. L., \& Egede, L. E. (2012). The impact of social support on outcomes in adult patients with type 2 diabetes: A systematic review. Current Diabetes Reports, 12(6), 769-781.

Suhl, E., \& Bonsignore, P. (2006). Diabetes self-management education for older adults: General principles and practical application. Diabetes Spectrum, 19(4), 234-240.

Sukkarieh-Haraty, O., \& Howard, E. (2015). Is social support universally adaptive in diabetes?: A correlational study in an Arabic-speaking population with type 2 diabetes. Holistic Nursing Practice, 29(1), 37-47.

Talbot, F., Nouwen, A., Gingras, J., Gosselin, M., \& Audet, J. (1997). The assessment of diabetes-related cognitive and social factors: the Multidimensional Diabetes Questionnaire. Journal of Behavioral Medicine, 20(3), 291-312.

Thomas, J. L., Jones, G. N., Scarinci, I. C., \& Brantley, P. J. (2007). Social support and the association of type 2 diabetes and depressive and anxiety disorders among lowincome adults seen in primary care clinics. Journal of Clinical Psychology in Medical Settings, 14(4), 351-359. 
Thoolen, B. J., De Ridder, D. T., Bensing, J. M., Gorter, K. J., \& Rutten, G. E. (2006). Psychological outcomes of patients with screen-detected type 2 diabetes: The influence of time since diagnosis and treatment intensity. Diabetes Care, 29(10), $2257-2262$.

Toobert, D. J., Hampson, S. E., \& Glasgow, R. E. (2000). The summary of diabetes selfcare activities measure: results from 7 studies and a revised scale. Diabetes Care, 23(7), 943-950.

Treharne, G. J., Lyons, A. C., \& Kitas, G. D. (2004). Medication adherence in rheumatoid arthritis: effects of psychosocial factors. Psychology, health \& medicine, 9(3), 337349.

Trinacty, C. M., Adams, A. S., Soumerai, S. B., Zhang, F., Meigs, J. B., Piette, J. D., \& Ross-Degnan, D. (2007). Racial differences in long-term self-monitoring practice among newly drug-treated diabetes patients in an HMO. Journal of General Internal Medicine, 22(11), 1506-1513.

Vaingankar, J. A., Abdin, E., \& Chong, S. A. (2012). Exploratory and confirmatory factor analyses of the Multidimensional Scale of Perceived Social Support in patients with schizophrenia. Comprehensive Psychiatry, 53(3), 286-291.

Van de Mortel, T. F. (2008). Faking it: social desirability response bias in self-report research. The Australian Journal of Advanced Nursing, 25(4), 40.

Vaux, A., Phillips, J., Holly, L., Thomson, B., Williams, D., \& Stewart, D. (1986). The social support appraisals (SS-A) scale: Studies of reliability and validity. American Journal of Community Psychology, 14(2), 195-218. 
Venkatesh, S., \& Weatherspoon, L. (2013). Social and health care provider support in diabetes self-management. American Journal of Health Behavior, 37(1), 112-121.

Vest, B. M., Kahn, L. S., Danzo, A., Tumiel-Berhalter, L., Schuster, R. C., Karl, R., ... \& Fox, C. H. (2013). Diabetes self-management in a low-income population: impacts of social support and relationships with the health care system. Chronic Illness, 9(2) $145-155$

Wagner, J. A., Perkins, D. W., Piette, J. D., Lipton, B., \& Aikens, J. E. (2009). Racial differences in the discussion and treatment of depressive symptoms accompanying type 2 diabetes. Diabetes Research and Clinical Practice, 86(2), 111-116.

Walker, R. J., Gebregziabher, M., Martin-Harris, B., \& Egede, L. E. (2015). Quantifying direct effects of social determinants of health on glycemic control in adults with type 2 diabetes. Diabetes Technology \& Therapeutics, 17(2), 80-87.

Walker, R. J., Gebregziabher, M., Martin-Harris, B., \& Egede, L. E. (2014). Relationship between social determinants of health and processes and outcomes in adults with type 2 diabetes: Validation of a conceptual framework. BMC Endocrine Disorders, 14(1), 82-92.

Waltz, C., Strickland, O.L., \& Lenz, E. (2010). Measurement in nursing and health research (4th Ed.). New York, NY: Springer.

Watkins, Y. J., Quinn, L. T., Ruggiero, L., Quinn, M. T., \& Choi, Y. K. (2013). Spiritual and Religious beliefs and practices and social support's relationship to diabetes self-care activities in African Americans. The Diabetes Educator, 39(2), 231-239. 
Weaver, R. R., Lemonde, M., Payman, N., \& Goodman, W. M. (2014). Health capabilities and diabetes self-management: the impact of economic, social, and cultural resources. Social Science \& Medicine, 102, 58-68.

Weinert, C. (1987). A social support measure: PRQ85. Nursing Research, 36(5), 273-277.

Weinstock, R. S., Teresi, J. A., Goland, R., Izquierdo, R., Palmas, W., Eimicke, J. P., ... \& IDEATel Consortium. (2011). Glycemic control and health disparities in older ethnically diverse underserved adults with diabetes. Diabetes Care, 34(2), 274279.

Westaway, M. S., Seager, J. R., Rheeder, P., \& Van Zyl, D. G. (2005). The effects of social support on health, well-being and management of diabetes mellitus: A black South African perspective. Ethnicity \& Health, 10(1), 73-89.

White, P., Smith, S. M., Hevey, D., \& O'Dowd, T. (2009). Understanding type 2 diabetes including the family member's perspective. The Diabetes Educator, 35(5), 810-817.

Wolever, R. Q., Dreusicke, M., Fikkan, J., Hawkins, T. V., Yeung, S., Wakefield, J., ... \& Skinner, E. (2010). Integrative health coaching for patients with type 2 diabetes a randomized clinical trial. The Diabetes Educator, 36(4), 629-639.

Wong, M., Gucciardi, E., Li, L., \& Grace, S. L. (2005). Gender and nutrition management in type 2 diabetes. Canadian Journal of Dietetic Practice and Research, 66(4), $215-220$. 
Wu, S. F. V., Huang, Y. C., Lee, M. C., Wang, T. J., Tung, H. H., \& Wu, M. P. (2013). Self-efficacy, self-care behavior, anxiety, and depression in Taiwanese with type 2 diabetes: A cross-sectional survey. Nursing \& Health Sciences, 15(2), 213-219.

Yang, J., Li, S., \& Zheng, Y. (2009). Predictors of depression in Chinese communitydwelling people with type 2 diabetes. Journal of Clinical Nursing, 18(9), 12951304.

Yilmaz, F. T., Sabanciogullari, S., Aldemir, K., \& Kumsar, A. K. (2015). Does social support affect development of cognitive dysfunction in individuals with diabetes mellitus? Saudi Medical Journal, 36(12), 1425-1431.

Yu, D. S., Lee, D. T., \& Woo, J. (2004). Psychometric testing of the Chinese version of the medical outcomes study social support survey (MOS-SSS-C). Research in Nursing \& Health, 27(2), 135-143.

Ziemer, D. C., Kolm, P., Weintraub, W. S., Vaccarino, V., Rhee, M. K., Twombly, J. G., ... \& Phillips, L. S. (2010). Glucose-independent, black-white differences in hemoglobin A1c levels: a cross-sectional analysis of 2 studies. Annals of Internal Medicine, 152(12), 770-777.

Zimet, G. D., Powell, S. S., Farley, G. K., Werkman, S., \& Berkoff, K. A. (1990). Psychometric characteristics of the multidimensional scale of perceived social support. Journal of Personality Assessment, 55(3-4), 610-617.

Zimet, G.D., Dahlem, N.W., Zimet, S.G. \& Farley, G.K. (1988). The Multidimensional Scale of Perceived Social Support. Journal of Personality Assessment, 52, 30-41. 


\title{
APPENDIX A
}

Study Measures

\section{Demographic Characteristics and Medical History}

\author{
All answers are confidential
}

Participant ID

Age

Date

Sex: Put $(\mathbf{X})$ in the appropriate box:

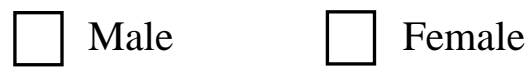

Date of Birth

Marital Status: Put (X) in the appropriate box:

$\square$ Married $\square$ Divorced $\square$ Widowed

married

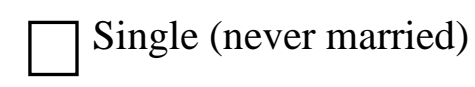

$\square$ Living with someone as if

Employment Status: Put (X) in the appropriate box:

$\square$ Full time $\square$ Part time $\square$ Unemployed

What was your age when you first diagnosed with Type 2 Diabetes? Years

Please list the diabetes medications you take: 
Did anyone teach you how to take care of your diabetes? Put $(\mathbf{X})$ in the appropriate box:<smiles>C1CC2CCC12</smiles>

If yes, list all of the people who taught you how to take care of your diabetes:

Do you have any medical illnesses in addition to diabetes? Put $(\mathbf{X})$ in the appropriate box:

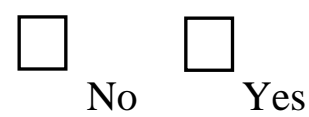

If yes, please list your medical illnesses below:

What is the type of health insurance that you have?

What is the highest level of education you completed? Put $(\mathbf{X})$ in the appropriate box:

$\square$ Did not complete high school

$\square$ Vocational or some college $\square$ High school diploma

$\square$ College degree or higher

What is the total yearly income for your household? Put $(\mathbf{X})$ in the appropriate box:

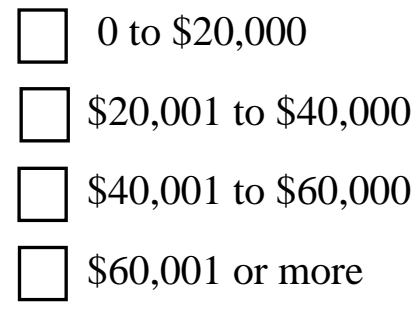

Do you smoke cigarettes? Put $(\mathbf{X})$ in the appropriate box:

No $\square$ Yes

If yes, how many cigarettes do you smoke per day?

Cigarettes 
How often do you have a drink containing alcohol? Put $(\mathbf{X})$ in the appropriate box:

$\square$ Never
$\square$ Monthly or less
$\square$ 2-4 times a month
$\square$ 2-3 times a week
$\square$ 4 or more times a week




\section{SUMMARY OF DIABETES SELF-CARE ACTIVITIES QUESTIONNAIRE}

The questions below ask you about your diabetes self-care activities during the past 7 days. If you were sick during the past 7 days, please think back to the last 7 days that you were not sick. Circle one number from each line.

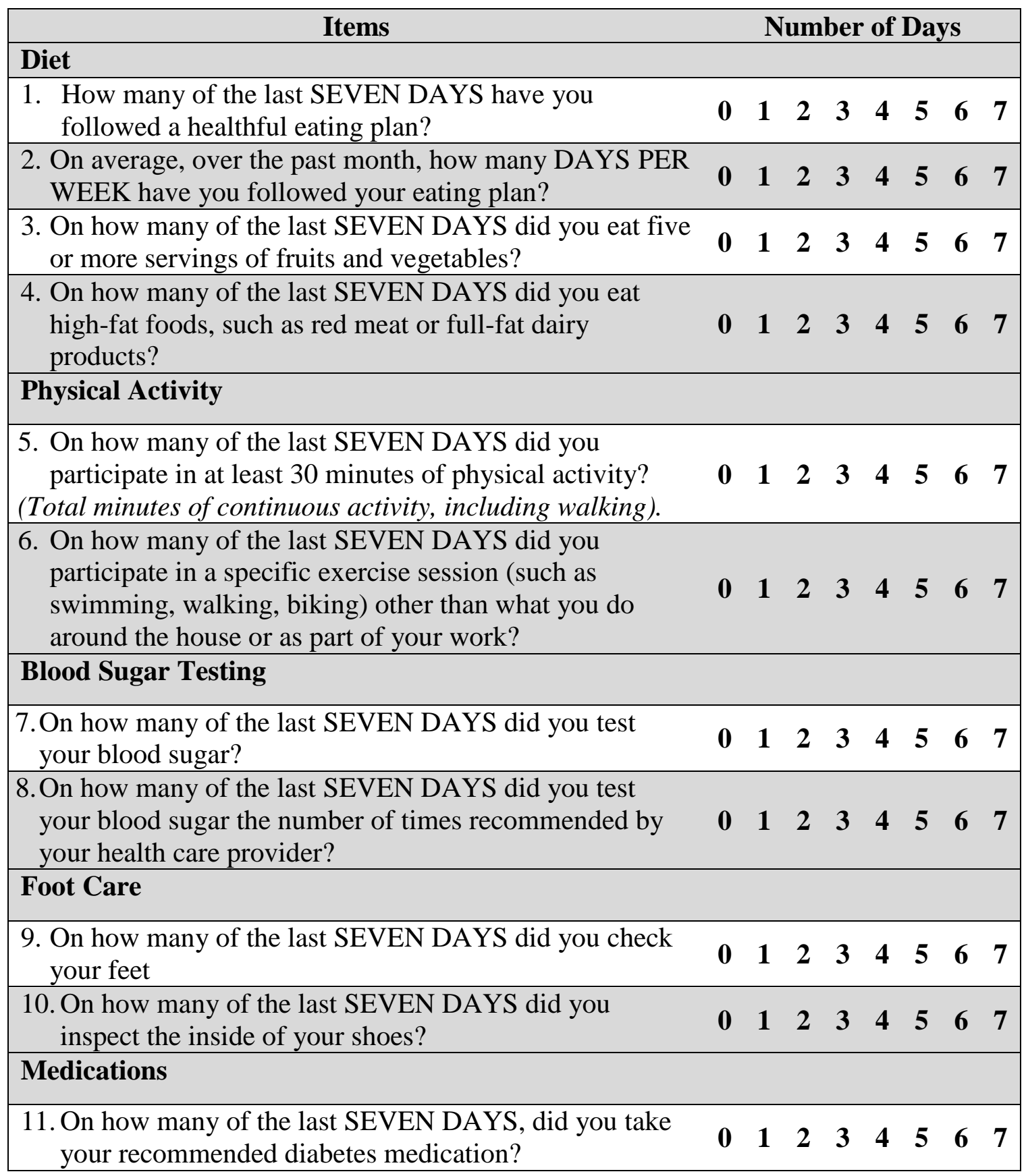




\section{MEDICAL OUTCOMES STUDY SOCIAL SUPPORT SURVEY}

People sometimes look to others for companionship, assistance, or other types of support. How often is each of the following kinds of support available to you if you need it?

Circle one number from each line.

\begin{tabular}{|c|c|c|c|c|c|}
\hline Questions & $\begin{array}{l}\text { None } \\
\text { of the } \\
\text { time }\end{array}$ & $\begin{array}{l}\text { A little } \\
\text { of the } \\
\text { time }\end{array}$ & $\begin{array}{l}\text { Some } \\
\text { of the } \\
\text { time }\end{array}$ & $\begin{array}{l}\text { Most of } \\
\text { the time }\end{array}$ & $\begin{array}{l}\text { All } \\
\text { of the } \\
\text { time }\end{array}$ \\
\hline $\begin{array}{l}\text { 1. Someone you can count } \\
\text { on to listen } \\
\text { to you when you need to } \\
\text { talk }\end{array}$ & 1 & 2 & 3 & 4 & 5 \\
\hline $\begin{array}{l}\text { 2. Someone to give you } \\
\text { information to } \\
\text { help you understand a } \\
\text { situation }\end{array}$ & 1 & 2 & 3 & 4 & 5 \\
\hline $\begin{array}{l}\text { 3. Someone to give you } \\
\text { good advice } \\
\text { about a crisis }\end{array}$ & 1 & 2 & 3 & 4 & 5 \\
\hline $\begin{array}{l}\text { 4. Someone to confide in or } \\
\text { talk } \\
\text { to about yourself or your } \\
\text { problems }\end{array}$ & 1 & 2 & 3 & 4 & 5 \\
\hline $\begin{array}{l}\text { 5. Someone whose advice } \\
\text { you really want }\end{array}$ & 1 & 2 & 3 & 4 & 5 \\
\hline $\begin{array}{l}\text { 6. Someone to share your } \\
\text { most private } \\
\text { worries and fears } \\
\text { with }\end{array}$ & 1 & 2 & 3 & 4 & 5 \\
\hline $\begin{array}{l}\text { 7. Someone to turn to for } \\
\text { suggestions about } \\
\text { how to deal with a } \\
\text { personal problem }\end{array}$ & 1 & 2 & 3 & 4 & 5 \\
\hline $\begin{array}{l}\text { 8. Someone who } \\
\text { understands your } \\
\text { problems }\end{array}$ & 1 & 2 & 3 & 4 & 5 \\
\hline $\begin{array}{l}\text { 9. Someone to help you if } \\
\text { you were } \\
\text { confined to bed }\end{array}$ & 1 & 2 & 3 & 4 & 5 \\
\hline $\begin{array}{l}\text { 10. Someone to take you to } \\
\text { the doctor if } \\
\text { you needed it }\end{array}$ & 1 & 2 & 3 & 4 & 5 \\
\hline
\end{tabular}




\begin{tabular}{|c|c|c|c|c|c|}
\hline $\begin{array}{l}\text { 11. Someone to prepare your } \\
\text { meals if } \\
\text { you were unable to do it } \\
\text { yourself }\end{array}$ & 1 & 2 & 3 & 4 & 5 \\
\hline $\begin{array}{l}\text { 12. Someone to help with } \\
\text { daily chores if } \\
\text { you were sick }\end{array}$ & 1 & 2 & 3 & 4 & 5 \\
\hline Questions & $\begin{array}{l}\text { None } \\
\text { of the } \\
\text { time }\end{array}$ & $\begin{array}{l}\text { A little } \\
\text { of the } \\
\text { time }\end{array}$ & $\begin{array}{l}\text { Some } \\
\text { of the } \\
\text { time }\end{array}$ & $\begin{array}{l}\text { Most of } \\
\text { the time }\end{array}$ & $\begin{array}{l}\text { All } \\
\text { of the } \\
\text { time }\end{array}$ \\
\hline $\begin{array}{l}\text { 13. Someone who shows you } \\
\text { love and affection }\end{array}$ & 1 & 2 & 3 & 4 & 5 \\
\hline $\begin{array}{l}\text { 14. Someone to love and } \\
\text { make you feel wanted }\end{array}$ & 1 & 2 & 3 & 4 & 5 \\
\hline 15. Someone who hugs you & 1 & 2 & 3 & 4 & 5 \\
\hline $\begin{array}{l}\text { 16. Someone to have a good } \\
\text { time with }\end{array}$ & 1 & 2 & 3 & 4 & 5 \\
\hline $\begin{array}{l}\text { 17. Someone to get together } \\
\text { with for relaxation }\end{array}$ & 1 & 2 & 3 & 4 & 5 \\
\hline $\begin{array}{l}\text { 18. Someone to do something } \\
\text { enjoyable with }\end{array}$ & 1 & 2 & 3 & 4 & 5 \\
\hline $\begin{array}{l}\text { 19. Someone to do things } \\
\text { with to help you get } \\
\text { your mind off things }\end{array}$ & 1 & 2 & 3 & 4 & 5 \\
\hline
\end{tabular}




\section{SOCIAL SUPPORT QUESTIONNAIRE 6 (SSQ6)}

The following questions ask about people in your life who provide you with help or support. Each question has two parts. For the first part, list all the people you know, excluding yourself, whom you can count on for help or support in the manner described.

Give the person's initials and their relationship to you (see example). Do not list more than one person next to each of the numbers beneath the question. For the second part, circle how satisfied you are with the overall support you have. If you have no support for a question, check the words "No one," but still rate your level of satisfaction.

Do not list more than nine persons per question. Please answer all questions as best you can.

\section{Example:}

Who do you know whom you can trust with information that could get you in trouble?

$\begin{array}{lllll}0 \text { No One } & \text { 1 A.A. (Father) } & \text { 2 D.G. (Spouse) } & \text { 3 L.F. (Friend) } & 4 \\ 5 & 6 & 7 & 8 & 9\end{array}$

How Satisfied?

$\begin{array}{llllll}\text { 1. Very } & \text { 2. Fairly } & \text { 3. A little } & \text { 4. A little } & \text { 5. Fairly } & \text { 6. Very } \\ \text { satisfied } & \text { satisfied } & \text { satisfied } & \text { dissatisfied } & \text { dissatisfied } & \text { dissatisfied }\end{array}$

\section{QUESTIONS:}

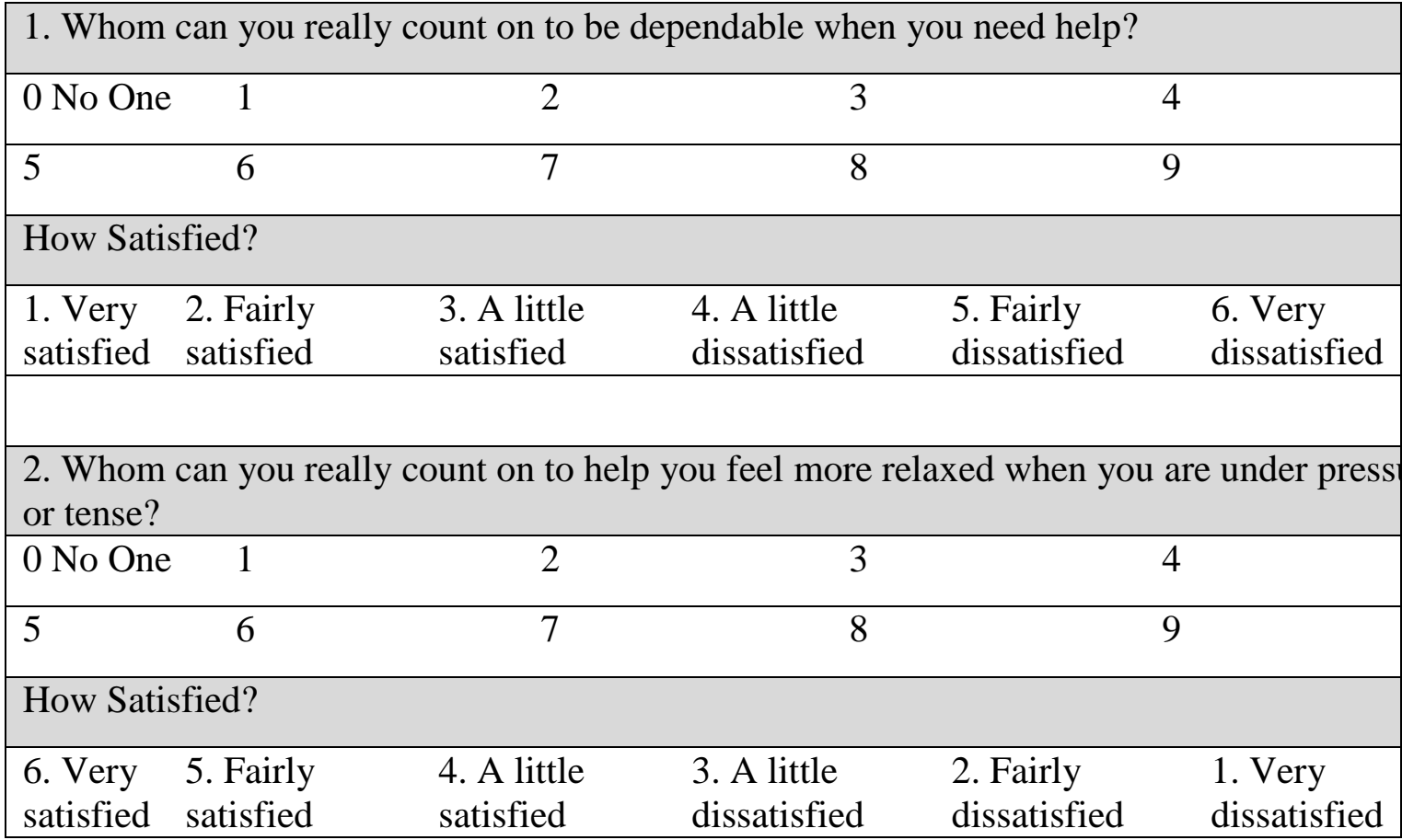




\begin{tabular}{|c|c|c|c|c|}
\hline \multicolumn{5}{|c|}{ 3. Who accepts you totally, including both your worst and your best points? } \\
\hline 0 No One & 2 & 3 & \multicolumn{2}{|c|}{4} \\
\hline 6 & 7 & 8 & \multicolumn{2}{|c|}{9} \\
\hline \multicolumn{5}{|l|}{ How Satisfied? } \\
\hline $\begin{array}{ll}6 . \text { Very } & 5 . \text { Fairly } \\
\text { satisfied } & \text { satisfied } \\
\end{array}$ & $\begin{array}{l}\text { 4. A little } \\
\text { satisfied }\end{array}$ & $\begin{array}{l}\text { 3. A little } \\
\text { dissatisfied }\end{array}$ & $\begin{array}{l}\text { 2. Fairly } \\
\text { dissatisfied }\end{array}$ & $\begin{array}{l}\text { 1. Very } \\
\text { dissatisfied }\end{array}$ \\
\hline \multicolumn{5}{|c|}{ 4. Whom can you really count on to care about you, regardless of what is happening to yo } \\
\hline 0 No One 1 & 2 & 3 & \multicolumn{2}{|c|}{4} \\
\hline 6 & 7 & 8 & \multicolumn{2}{|c|}{9} \\
\hline \multicolumn{5}{|l|}{ How Satisfied? } \\
\hline $\begin{array}{ll}\text { 6. Very } & 5 . \text { Fairly } \\
\text { satisfied } & \text { satisfied }\end{array}$ & $\begin{array}{l}\text { 4. A little } \\
\text { satisfied }\end{array}$ & $\begin{array}{l}\text { 3. A little } \\
\text { dissatisfied }\end{array}$ & $\begin{array}{l}\text { 2. Fairly } \\
\text { dissatisfied }\end{array}$ & $\begin{array}{l}\text { 1. Very } \\
\text { dissatisfied }\end{array}$ \\
\hline \multicolumn{5}{|c|}{$\begin{array}{l}\text { 5. Whom can you really count on to help you feel better when you are feeling generally } \\
\text { down-in-the dumps? }\end{array}$} \\
\hline 0 No One 1 & 2 & 3 & \multicolumn{2}{|c|}{4} \\
\hline 6 & 7 & 8 & \multicolumn{2}{|c|}{9} \\
\hline \multicolumn{5}{|l|}{ How Satisfied? } \\
\hline $\begin{array}{ll}6 . \text { Very } & 5 . \text { Fairly } \\
\text { satisfied } & \text { satisfied } \\
\end{array}$ & $\begin{array}{l}\text { 4. A little } \\
\text { satisfied }\end{array}$ & $\begin{array}{l}\text { 3. A little } \\
\text { dissatisfied }\end{array}$ & $\begin{array}{l}\text { 2. Fairly } \\
\text { dissatisfied }\end{array}$ & $\begin{array}{l}\text { 1. Very } \\
\text { dissatisfied }\end{array}$ \\
\hline \multicolumn{5}{|c|}{ 6. Whom can you count on to console you when you are very upset? } \\
\hline 0 No One 1 & 2 & 3 & \multicolumn{2}{|c|}{4} \\
\hline 6 & 7 & 8 & \multicolumn{2}{|c|}{9} \\
\hline \multicolumn{5}{|l|}{ How Satisfied? } \\
\hline $\begin{array}{ll}\text { 6. Very } & 5 . \text { Fairly } \\
\text { satisfied } & \text { satisfied } \\
\end{array}$ & $\begin{array}{l}\text { 4. A little } \\
\text { satisfied }\end{array}$ & $\begin{array}{l}\text { 3. A little } \\
\text { dissatisfied }\end{array}$ & $\begin{array}{l}\text { 2. Fairly } \\
\text { dissatisfied }\end{array}$ & $\begin{array}{l}\text { 1. Very } \\
\text { dissatisfied }\end{array}$ \\
\hline
\end{tabular}




\section{AUTONMOY AND RELATEDNESS INVENTORY (ARI)}

Who is the most important person in your life? This could be anyone: your mother, your father, your boyfriend, or any other male or female relative or friend, or helping professional such as social worker or minister. Please tell me the relationship of that person to you: -

Next, please indicate how will each of the following statements describes this person. $\underline{\text { Circle }}$ one number from each line.

\begin{tabular}{|c|c|c|c|c|c|}
\hline Items & $\begin{array}{l}\text { Not at } \\
\text { all } \\
\text { like } \\
\text { him/her }\end{array}$ & $\begin{array}{l}\text { Very } \\
\text { Little } \\
\text { like } \\
\text { him/her }\end{array}$ & $\begin{array}{l}\text { Somewhat } \\
\text { like } \\
\text { him/her }\end{array}$ & $\begin{array}{l}\text { Much } \\
\text { like } \\
\text { him/her }\end{array}$ & $\begin{array}{l}\text { Very } \\
\text { much } \\
\text { like } \\
\text { him/her }\end{array}$ \\
\hline $\begin{array}{l}\text { 1. Talks over his/her problems } \\
\text { with me. }\end{array}$ & 1 & 2 & 3 & 4 & 5 \\
\hline 2. Is always trying to change me. & 1 & 2 & 3 & 4 & 5 \\
\hline 3. Respect my opinions. & 1 & 2 & 3 & 4 & 5 \\
\hline $\begin{array}{l}\text { 4. Acts as though I am in the } \\
\text { way. }\end{array}$ & 1 & 2 & 3 & 4 & 5 \\
\hline 5. Is there when I need him /her. & 1 & 2 & 3 & 4 & 5 \\
\hline $\begin{array}{l}\text { 6. Won't take no for an answer } \\
\text { when he/she wants something. }\end{array}$ & 1 & 2 & 3 & 4 & 5 \\
\hline $\begin{array}{l}\text { 7. Tries to understand how I see } \\
\text { Things. }\end{array}$ & 1 & 2 & 3 & 4 & 5 \\
\hline $\begin{array}{l}\text { 8. Gives me as much freedom as } \\
\text { want. }\end{array}$ & 1 & 2 & 3 & 4 & 5 \\
\hline $\begin{array}{l}\text { 9. Is always thinking of things } \\
\text { that would please me. }\end{array}$ & 1 & 2 & 3 & 4 & 5 \\
\hline $\begin{array}{l}\text { 10. Argues back no matter what } \\
\text { I say. }\end{array}$ & 1 & 2 & 3 & 4 & 5 \\
\hline $\begin{array}{l}\text { 11. Encourages me to follow } \\
\text { my own interests. }\end{array}$ & 1 & 2 & 3 & 4 & 5 \\
\hline
\end{tabular}




\begin{tabular}{|l|c|c|c|c|c|}
\hline Items & $\begin{array}{l}\text { Not } \\
\text { at all } \\
\text { like } \\
\text { him/her }\end{array}$ & $\begin{array}{l}\text { Very } \\
\text { Little } \\
\text { like } \\
\text { him/her }\end{array}$ & $\begin{array}{l}\text { Somewhat } \\
\text { like } \\
\text { him/her }\end{array}$ & $\begin{array}{l}\text { Much } \\
\text { like } \\
\text { him/her }\end{array}$ & $\begin{array}{l}\text { Very } \\
\text { much } \\
\text { like } \\
\text { him/her }\end{array}$ \\
\hline 12. Makes fun of me. & $\mathbf{1}$ & $\mathbf{2}$ & $\mathbf{3}$ & $\mathbf{4}$ & $\mathbf{5}$ \\
\hline $\begin{array}{l}\text { 13. Is very willing to help when } \\
\text { I need it. }\end{array}$ & $\mathbf{1}$ & $\mathbf{2}$ & $\mathbf{3}$ & $\mathbf{4}$ & $\mathbf{5}$ \\
\hline $\begin{array}{l}\text { 14. Wants to have the last word } \\
\text { on how we spend our time. }\end{array}$ & $\mathbf{1}$ & $\mathbf{2}$ & $\mathbf{3}$ & $\mathbf{4}$ & $\mathbf{5}$ \\
\hline $\begin{array}{l}\text { 15. Thinks I am worth listening } \\
\text { to. }\end{array}$ & $\mathbf{1}$ & $\mathbf{2}$ & $\mathbf{3}$ & $\mathbf{4}$ & $\mathbf{5}$ \\
\hline $\begin{array}{l}\text { 16. Lets me make up my own } \\
\text { mind. }\end{array}$ & $\mathbf{1}$ & $\mathbf{2}$ & $\mathbf{3}$ & $\mathbf{4}$ & $\mathbf{5}$ \\
\hline $\begin{array}{l}\text { 17. Has a good time with me. } \\
\text { 18. Wants to control everything } \\
\text { I do. }\end{array}$ & $\mathbf{1}$ & $\mathbf{2}$ & $\mathbf{3}$ & $\mathbf{4}$ & $\mathbf{5}$ \\
\hline $\begin{array}{l}\text { 19. Is happy to go along with } \\
\text { my decisions. }\end{array}$ & $\mathbf{1}$ & $\mathbf{2}$ & $\mathbf{3}$ & $\mathbf{4}$ & $\mathbf{5}$ \\
\hline $\begin{array}{l}\text { 20. Says I am a big problem. } \\
\text { 1 }\end{array}$ & $\mathbf{1}$ & $\mathbf{2}$ & $\mathbf{3}$ & $\mathbf{4}$ & $\mathbf{5}$ \\
\hline $\begin{array}{l}\text { 21. Does what he/she can to make } \\
\text { things easier for me. }\end{array}$ & $\mathbf{1}$ & $\mathbf{2}$ & $\mathbf{3}$ & $\mathbf{4}$ & $\mathbf{5}$ \\
\hline $\begin{array}{l}\text { 22. Expects me to everything } \\
\text { his/her way. }\end{array}$ & $\mathbf{1}$ & $\mathbf{2}$ & $\mathbf{3}$ & $\mathbf{4}$ & $\mathbf{5}$ \\
\hline $\begin{array}{l}\text { 23. Makes me feel I can tell him } \\
\text { or her anything. }\end{array}$ & $\mathbf{1}$ & $\mathbf{2}$ & $\mathbf{4}$ & $\mathbf{5}$ \\
\hline $\begin{array}{l}\text { 24. Thinks it's okay if I disagree } \\
\text { with him/her. }\end{array}$ & $\mathbf{1}$ & $\mathbf{2}$ & $\mathbf{4}$ & $\mathbf{5}$ \\
\hline $\begin{array}{l}\text { 25. Asks me to share things } \\
\text { he/she enjoys. }\end{array}$ & $\mathbf{1}$ & $\mathbf{3}$ & $\mathbf{4}$ & $\mathbf{5}$ \\
\hline \begin{tabular}{l} 
26. Finds fault with me. \\
\hline
\end{tabular} & $\mathbf{2}$ & $\mathbf{4}$ & $\mathbf{5}$ \\
\hline
\end{tabular}




\begin{tabular}{|l|c|c|c|c|c|}
\hline Items & $\begin{array}{l}\text { Not at al } \\
\text { Like } \\
\text { him/her }\end{array}$ & $\begin{array}{l}\text { Very } \\
\text { Little } \\
\text { like } \\
\text { him/her }\end{array}$ & $\begin{array}{l}\text { Somewhat } \\
\text { like } \\
\text { him } \\
\text { /her }\end{array}$ & $\begin{array}{l}\text { Much } \\
\text { like } \\
\text { him/her }\end{array}$ & $\begin{array}{l}\text { Very } \\
\text { much } \\
\text { Like } \\
\text { him/her }\end{array}$ \\
\hline 27. Considers my point of view. & $\mathbf{1}$ & $\mathbf{2}$ & $\mathbf{3}$ & $\mathbf{4}$ & $\mathbf{5}$ \\
\hline $\begin{array}{l}\text { 28. Doesn't think about me very } \\
\text { much. }\end{array}$ & $\mathbf{1}$ & $\mathbf{2}$ & $\mathbf{3}$ & $\mathbf{4}$ & $\mathbf{5}$ \\
\hline $\begin{array}{l}\text { 29. Tries to comfort me when } \\
\text { things go wrong. }\end{array}$ & $\mathbf{1}$ & $\mathbf{2}$ & $\mathbf{3}$ & $\mathbf{4}$ & $\mathbf{5}$ \\
\hline $\begin{array}{l}\text { 30. Acts as if he/she doesn't } \\
\text { know me } \\
\text { when he/she is angry. }\end{array}$ & $\mathbf{1}$ & $\mathbf{2}$ & $\mathbf{3}$ & $\mathbf{4}$ & $\mathbf{5}$ \\
\hline $\begin{array}{l}\text { 31. Wants me to tell him/her } \\
\text { about things that are } \\
\text { bothering me. }\end{array}$ & $\mathbf{1}$ & $\mathbf{2}$ & $\mathbf{3}$ & $\mathbf{4}$ & $\mathbf{5}$ \\
\hline $\begin{array}{l}\text { 32. Let me do anything I want } \\
\text { to do. }\end{array}$ & $\mathbf{1}$ & $\mathbf{2}$ & $\mathbf{3}$ & $\mathbf{4}$ & $\mathbf{5}$ \\
\hline
\end{tabular}




\section{DEPRESSION, ANXIETY, AND STRESS SCALE (DASS-21)}

Please read each statement and circle a number $0,1,2$ or 3 which indicates how much the statement applied to you over the past week. There are no right or wrong answers. Do not spend too much time on any statement.

The rating scale is as follows:

$0=$ Did not apply to me at all - NEVER

$1=$ Applied to me to some degree, or some of the time - SOMETIMES

2 = Applied to me to a considerable degree, or a good part of time - OFTEN

3 = Applied to me very much, or most of the time - ALMOST ALWAYS

Circle one number from each line.

\begin{tabular}{|c|c|c|c|c|}
\hline Items & Never & Sometimes & Ofter & $\begin{array}{l}\text { Almost } \\
\text { Always }\end{array}$ \\
\hline 1. I found it hard to wind down. & $\mathbf{0}$ & 1 & 2 & 3 \\
\hline 2. I was aware of dryness of my mouth & $\mathbf{0}$ & 1 & 2 & 3 \\
\hline $\begin{array}{l}\text { 3. I couldn't seem to experience any positive } \\
\text { feeling at all }\end{array}$ & $\mathbf{0}$ & 1 & 2 & 3 \\
\hline $\begin{array}{l}\text { 4. I experienced breathing difficulty (e.g., } \\
\text { excessively rapid } \\
\text { breathing, breathlessness in the absence of } \\
\text { physical exertion) }\end{array}$ & $\mathbf{0}$ & 1 & 2 & 3 \\
\hline $\begin{array}{l}\text { 5. I found it difficult to work up the initiative } \\
\text { to do things }\end{array}$ & $\mathbf{0}$ & 1 & 2 & 3 \\
\hline 6. I tended to over-react to situations & $\mathbf{0}$ & 1 & 2 & 3 \\
\hline 7. I experienced trembling (e.g., in the hands) & $\mathbf{0}$ & 1 & 2 & 3 \\
\hline $\begin{array}{l}\text { 8. I felt that I was using a lot of nervous } \\
\text { energy }\end{array}$ & $\mathbf{0}$ & 1 & 2 & 3 \\
\hline $\begin{array}{l}\text { 9. I was worried about situations in which I } \\
\text { might panic and } \\
\text { make a fool of myself }\end{array}$ & $\mathbf{0}$ & 1 & 2 & 3 \\
\hline 10. I felt that I had nothing to look forward to & $\mathbf{0}$ & 1 & 2 & 3 \\
\hline 11. I found myself getting agitated & $\mathbf{0}$ & 1 & 2 & 3 \\
\hline 12. I found it difficult to relax & $\mathbf{0}$ & 1 & 2 & 3 \\
\hline 13. I felt down-hearted and blue & $\mathbf{0}$ & 1 & 2 & 3 \\
\hline Items & Never & Sometimes & Often & $\begin{array}{l}\text { Almost } \\
\text { Always }\end{array}$ \\
\hline 14. I was intolerant of anything that kept me & $\mathbf{0}$ & 1 & 2 & 3 \\
\hline
\end{tabular}




\begin{tabular}{|l|c|c|c|c|}
\hline \multicolumn{1}{|c|}{$\begin{array}{l}\text { from getting on with } \\
\text { what I was doing }\end{array}$} & $\mathbf{0}$ & $\mathbf{1}$ & $\mathbf{2}$ & $\mathbf{3}$ \\
\hline 15. I felt I was close to panic & $\mathbf{0}$ & $\mathbf{1}$ & $\mathbf{2}$ & $\mathbf{3}$ \\
\hline $\begin{array}{l}\text { 16. I was unable to become enthusiastic about } \\
\text { anything }\end{array}$ & $\mathbf{0}$ & $\mathbf{1}$ & $\mathbf{2}$ & $\mathbf{3}$ \\
\hline $\begin{array}{l}\text { 17. I felt I wasn't worth much as a person } \\
\text { 18. I felt that I was rather touchy }\end{array}$ & $\mathbf{0}$ & $\mathbf{1}$ & $\mathbf{2}$ & $\mathbf{3}$ \\
\hline $\begin{array}{l}\text { 19. I was aware of the action of my heart in the } \\
\text { absence of Physical exertion } \\
\text { (e.g., sense of heart rate increase, } \\
\text { heart missing a beat) }\end{array}$ & $\mathbf{1}$ & $\mathbf{2}$ & $\mathbf{3}$ \\
\hline $\begin{array}{l}\text { 20. I felt scared without any good reason } \\
\text { 21. I felt that life was meaningless }\end{array}$ & $\mathbf{0}$ & $\mathbf{1}$ & $\mathbf{2}$ & $\mathbf{3}$ \\
\hline
\end{tabular}




\section{APPENDIX B}

Study Approvals

DATE:

TO:

FROM:

IRB NUMBER: STUDY TITLE:

Support and
March 27, 2017 - Letter Revised on 3/28/17

Diane O Chlebowy, $\mathrm{PhD}$

The University of Louisville Institutional Review Board

16.1280

Self-Management as a Mediator of the Relationship between Social

Health Outcomes of African American Adults with Type 2

Diabetes Mellitus

REFERENCE \#: $\quad 637982$

IRB STAFF CONTACT: Jacqueline S. Powell, CIP

Senior IRB Analyst

Jspowe01@Louisville.edu

$852-4101$

This study was reviewed on 03/24/2017 by the Chair of the Institutional Review Board and approved through the Expedited Review Procedure, according to 45 CFR 46.110(b), since this study falls under Category 7: Research on individual or group characteristics or behavior (including, but not limited to, research on perception, cognition, motivation, identity, language, communication, cultural beliefs or practices, and social behavior) or research employing survey, interview, oral history, focus group, program evaluation, human factors evaluation, or quality assurance methodologies

The following items have been approved:

\begin{tabular}{|l|l|l|l|}
\hline \multicolumn{2}{|l|}{ Submission Components } & \multicolumn{3}{l|}{ Approved as Submitted } \\
\hline IRB Study Application & Version 1.0 & $03 / 21 / 2017$ & Approved \\
\hline Protocol
\end{tabular}




\begin{tabular}{|l|l|l|l|}
\hline A1C and BMI Data Collection Form & Version 1.0 & $02 / 27 / 2017$ & Approved \\
\hline $\begin{array}{l}\text { Study Permission by the Family } \\
\text { Health Centers (FHC) }\end{array}$ & Version 1.0 & $01 / 23 / 2017$ & \\
\hline Survey Questionnaires & Version 1.3 & $02 / 14 / 2017$ & Appnowledged \\
\hline HIPAA Partial Waiver & Version 1.0 & $03 / 21 / 2017$ & Approved \\
\hline Combined Consent/RA & Version 1.0 & $03 / 21 / 2017$ & Approved \\
\hline
\end{tabular}

This study now has final IRB approval from 03/24/2017 through 03/23/2018.

For guidance on using iRIS, including finding your approved stamped documents, please follow the instructions at https://louisville.edu/research/humansubjects/iRISSubmissionManual.pdf

\section{Site Approval}

If this study will take place at an affiliated research institution, such as KentuckyOne Health, Norton Healthcare or University of Louisville Hospital, permission to use the site of the affiliated institution is necessary before the research may begin. If this study will take place outside of the University of Louisville Campuses, permission from the organization must be obtained before the research may begin (e.g. Jefferson County Public Schools). Failure to obtain this permission may result in a delay in the start of your research.

\section{Privacy \& Encryption Statement}

The University of Louisville's Privacy and Encryption Policy requires such information as identifiable medical and health records: credit card, bank account and other personal financial information; social security numbers; proprietary research data; dates of birth (when combined with name, address and/or phone numbers) to be encrypted. For additional information: http://security.louisville.edu/PolStds/ISO/PS018.htm.

\section{Implementation of Changes to Previously Approved Research}

Prior to the implementation of any changes in the approved research, the investigator will submit any modifications to the IRB and await approval before implementing the changes, unless the change is being made to ensure the safety and welfare of the subjects enrolled in the research. If such occurs, a Protocol Deviation/Violation should be submitted within five days of the occurrence indicating what safety measures were taken, along with an amendment to revise the protocol. 


\section{Unanticipated Problems Involving Risks to Subjects or Others (UPIRTSOs)}

In general, these may include any incident, experience, or outcome, which has been associated with an unexpected event(s), related or possibly related to participation in the research, and suggests that the research places subjects or others at a greater risk of harm than was previously known or suspected. UPIRTSOs may or may not require suspension of the research. Each incident is evaluated on a case by case basis to make this determination. The IRB may require remedial action or education as deemed necessary for the investigator or any other key personnel. The investigator is responsible for reporting UPIRTSOs to the IRB within 5 working days. Use the UPIRTSO form located within the iRIS system to report any UPIRTSOs.

\section{Continuation Review Requirements}

You are responsible for submitting a continuation review 30 days prior to the expiration date of your research study. Investigators who allow their study approval to expire have committed significant non-compliance with federal regulations. Such lapses may require reporting to federal agencies, a program audit by compliance auditors to ensure that subjects were not enrolled during the expired period, and may lead to findings of serious and continuing noncompliance if expiration were to occur a second time.

1099 Information (If Applicable)

As a reminder, in compliance with University policies and Internal Revenue Service code, all payments (including checks, pre-paid cards, and gift certificates) to research subjects must be reported to the University Controller's Office. Petty Cash payments must also be monitored by the issuing department and reported to the Controller's Office. Before issuing compensation, each research subject must complete a W-9 form. For additional information, please contact the Controller's Office at 852-8237 or controll@louisville.edu

The committee will be advised of this action at a regularly scheduled meeting.

If you have any questions, please contact the IRB analyst listed above or the Human Subjects Protection Program office at hsppofc@louisville.edu.

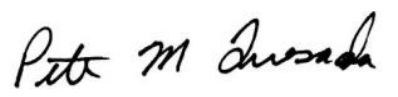

Peter M. Quesada, Ph.D., Chair

Social/Behavioral/Educational Institutional Review Board

$\mathrm{PMQ} / \mathrm{jpp}$ 
Full Accreditation since June 2005 by the Association for the Accreditation of Human Research Protection Programs, Inc.

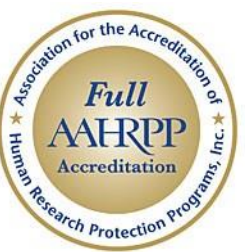




\section{เรู่อ \\ Family Health Centers}

Care for your Health \& Wellness

January 23, 2017

Tariq N. Al-Dwaikat

University of Louisville School of Nursing

555 S. Floyd Street

Louisville,

Kentucky 40202

Dear Mr. Al-Dwaikat:

I am happy to let you know that your request to conduct research has been approved by both the Family Health Centers' Chief Executive Officer and the Chief Medical Officer (Please see approved form attached).

I have spoken with several of the staff members at the Portland and East Broadway sites and they are willing to assist you in having contact with the population that you are interested in interviewing. When

you received a decision from the Internal Review Board please forward me a copy so that we might have it on file.

Let me know if you have any questions or if I might be of further assistance.

Sincerely,

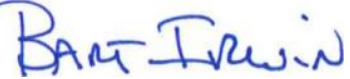

Bart Irwin, MSSW, PhD

Chief Administrative Officer 
Family Health Centers, Inc. Request to Conduct Research

(rev. .04.04.12)

Name of Principal Investigator: Dr. Diane Orr Chlebowy

Name of Student (if not principle investigator): Tariq N. Al-Dwaikat

E-mail Address: dochle01@louisville.edu,tnaldw01@louisville.edu

Phone Number(s): Dr. Chlebowy: 502-852-8384, Tariq: 502-852-6944

Mailing Address: 555 S. Floyd St Louisville, KY 40202

School: $\quad$ School of Nursing University of Louisville

Faculty Advisor or Instructor: $\quad$ Dr. Diane Orr Chlebowy

Beginning Date: $\quad$ 02-10-2017 Completion Date: $\quad$ 06-30-2017

Are you and FHC employee? Yes, No If so, what department?

Where will the research be conducted? Family Health Centers at Portland

Name of Project: "Self-Management as a Mediator of the Relationship between Social Support and Health

Outcomes of African American Adults with Type 2 Diabetes Mellitus"

Brief Description of Proposed Research (attach additional information if needed): I would like to meet with the patients during their regular visits to the diabetes clinic at Family Health Care Center at Portland to obtain their permission to participate in my study and then I'll ask the patients to fill out 5 short questionnaires that will take approximately 15 minutes. After data collection I will give each patient a $\$ 10$ gift card as an appreciation for their participation. I need also to access their records for the AIC and BMI data. 
Does your school require you to submit the project to an Institutional Review Board? Yes

Are you requesting Family Health Centers to provide you access to Protected Health Information? Yes

Will you be asking your subjects to sign consent forms? Yes

If this study does not require an IRB, I understand that any use of FHC data or study results outside of the class in which the student is enrolled requires the written permission of FHC.

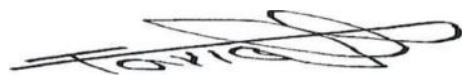

Signature:

Date: $\quad 01-19-2017$

Other information may be requested based upon the responses presented on this form. Please return to Bart Irwin, $\mathrm{PhD}$, Family Health Centers, Inc., 2215 Portland Avenue, Louisville, Kentucky 40212 Phone: 502.772.8558

istoris B Neque m B. Wagner, Chief Executive Officer $1 / 23 / 17$

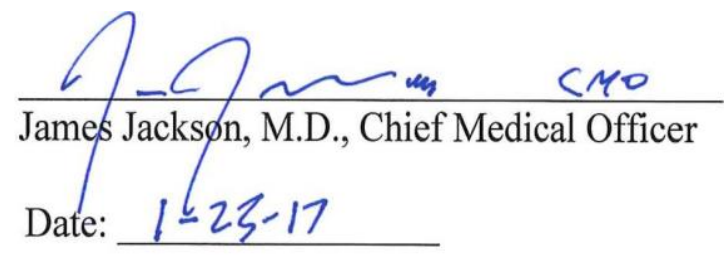




\title{
APPENDIX C
}

\author{
Approval to use SDSCA
}

\section{Dear Tariq Al-Dwaikat,}

Thank you for your payment of $\$ 25$ for permission to use the Summary of Diabetes Self Care Activities (SDSCA) in your study. Now that we have received your payment, you have our permission to use the English version of the Summary of Diabetes Self-Care Activities Questionnaire in your research project and we will be able to provide answers to any questions you may have. We have attached the 2000 Diabetes Care article with the SDSCA psychometric information. At the end of the article, there is an appendix with the English version of the questionnaire, and the scoring information. We have also attached a user-friendly copy of the English version of the SDSCA instrument.

If you need a translation of the SDSCA please contact me first, as the SDSCA has been translated into many languages.

Please be sure to check our website first for the most frequently asked questions:

\section{http://www.ori.org/sdsca}

We wish you every success with your research,

Deborah

Deborah J. Toobert, PhD

Senior Research Scientist

Oregon Research Institute

1776 Millrace Drive

Eugene, Oregon 97403

http://www.ori.org/

Phone:(541) 485-2123

Home office (541) 338-8037

Fax: (541) 434-1505

email: deborah@ori.org 
Approval to use published manuscript in the dissertation

Dear Tariq Al-Dwaikat,

Thank you for your messages of $26 \& 27$ of July. I apologize for the delay in responding as I have been on vacation. It is taking a while to catch up!

Authors are free to reuse content from their articles as long as it is properly cited that the Journal of Nursing Measurement as the original source. Posting the articles/dissertations to your institutional repository is acceptable but please do acknowledge the journal and publisher. The best link to use is the DOI as that will always point to the version of record even if the journal changes hosting platforms in the future.

It's also worth mentioning that Springer is a signatory of the STM Permissions Guidelines, which allows authors to republish a select number of tables or figures at no cost if they're reproducing the content in the journal or book of another publisher that participates. Specifically, it allows the following free of charge:

- Use of up to three figures (including tables) from a journal article or book chapter, but:

- not more than five figures from a whole book or journal issue/edition;

- not more than six figures from an annual journal volume; and

- not more than three figures from works published by a single publisher for an article, and not more than three figures from works published by a single publisher for a book chapter (and in total not more than thirty figures from a single publisher for re-publication in a book, including a multi-volume book, with different authors per chapter)

- Use of single text extracts of less than 400 words from a journal article or book chapter, but

- not more than a total of 800 words from a whole book or journal issue/edition

Most requests can be handled through the Copyright Clearance Center (www.copyright.com).

Kind Regards

Janice L. Hinkle, PhD, RN, CNRN

Editor-in-Chief, Journal of Nursing Measurement 


\title{
CURRICULUM VITAE
}

\author{
Tariq Al-Dwaikat, RN, BSN, MA, PhD Student
}

11501 Maple Brook Drive Apt 202

Louisville, Kentucky 40241

(502) 852-6944 (Office)

(502) 819-8328 (mobile)

tdwaikat@gmail.com

\section{Education}

$\underline{\text { Dates }}$

2011

University

Virginia

2005

Academic Leadership

\section{$\underline{\text { Dates }}$}

August 2005- June 2008 $\underline{\text { Degree }}$

MA

Major: Psychology

Minor: Applied Behavior Analysis

B.S. Nursing

\section{Institution}

West Virginia

Morgantown, West
Jordan University of Science and Technology Irbid, Jordan

\section{Title}

Clinical Nursing Instructor

\section{Institution}

School of Nursing Jordan University of Science and Technology Irbid, Jordan 
June 2011 - June $2013 \quad$ Lecturer

Jordan RN Licensure

Licensure: Jordan Nurse Registration 9829

\section{Professional Memberships and Activities}

Midwest Nursing Research Society

Honors and Awards

2014

2005

2005

Research/Scholarship

As a graduate student, Tariq Al-Dwaikat is committed to improving research and his scholarship and research skills in the academic setting. During his work as a graduate research assistant, he was dedicated to establish his research-related skills; such as reviewing the literature, collecting data, entering data using data files, analyzing data, and many other activities including writing abstracts and presenting research results. He received Nursing Graduate Student Award for his poster presentation at Research! Louisville, 2014 for his poster presentation. Tariq Al-Dwaikat presented at regional and local conferences. Tariq Al-Dwaikat has special interest in studying the variables that influence the ability of adults diagnosed with type 2 diabetes to manage their disease, in order to promote understanding of these variables and develop interventions that are beneficial for them.

$\underline{\text { Publications }}$

Al-Dwaikat, Tariq N., and Hall, L.A. (2017)."Systematic Review and Critical Analysis of Measures of Social Support Used in Studies of Persons with Type 2 Diabetes." Journal of Nursing Measurement 25(2): 74E-107E.

\section{Abstracts and Presentations}




\section{$\underline{\text { Regional }}$}

Al Dwaikat, T. N., Lynn, H.A. (2017). Critical Analysis of Measures of Social Support Used in Studies of Persons with Type II Diabetes. Midwest Nursing Research Society Annual Conference. Minneapolis, Minnesota.

Al Dwaikat, T. N., Chlebowy, D.O., Crawford, T., \& Kubiak, N. (2016). Relationships of Sociodemographic Characteristics with Diabetes Biomarkers and Dietary Adherence in African American Adults with Type 2 Diabetes. Midwest Nursing Research Society Annual Conference. Milwaukee, Wisconsin.

\section{$\underline{\text { Local }}$}

Al-Dwaikat T.N., Chlebowy, D.O., \& Crawford, T.N. (2017). Relationships of Sociodemographic Characteristics with Glycemic Control and Dietary Adherence in Adults with Type 2 Diabetes: Findings from National Health and Nutrition Examination Survey 2007-2012. Research! Louisville. University of Louisville.

Al-Dwaikat T.N., Chlebowy, D.O., \& Crawford, T.N. (2017). Relationships of Sociodemographic Characteristics with Glycemic Control and Dietary Adherence in Adults with Type 2 Diabetes: Findings from National Health and Nutrition Examination Survey 2007-2012. Research! Louisville Nursing Symposium. Jewish Hospital.

Al Dwaikat, T.N., Chlebowy, D.O., Crawford, T., \& Kubiak, N. (2015). Relationship of Sociodemographic Characteristics with Diabetes Biomarkers and Dietary Adherence in African American Adults with Type 2 Diabetes.

Grider, T., Chlebowy, D.O., McGown, S., Crawford, T., \& Al Dwaikat, T.N. (2015). Suitability Assessment of Diabetes Education Materials: Recommendations for Future Evidence-based Practice. KentuckyOne West Region Research Day. Louisville, Kentucky.

Slaughter, K., Chlebowy, D.O., Al Dwaikat, T.N. (2015). Impact of Demographic Variables on Dietary Adherence in African American Adults with Type 2 Diabetes: A Literature Review. University-wide Undergraduate Research \& Community Engagement Symposium, University of Louisville.

Al Dwaikat, T.N., \& Chlebowy, D.O. (2014). Motivational Interviewing and Diabetes Self-Management Behaviors in Non-Hispanic White and African American Adults: A Review of the Literature. Research! Louisville. University of Louisville.

Grider, T., Chlebowy, D.O., McGown, S., Crawford, T., \& Al Dwaikat, T.N. (2014). Suitability Assessment of Diabetes Education Materials: Recommendations for Future Evidence-based Practice. Research! Louisville Nursing Research Symposium. Louisville, Kentucky. 
Chlebowy, D.O., \& Al Dwaikat, T.N. (2014). Fit and Faithful. American Diabetes Association, Live Empowered Program. Louisville, Kentucky.

Chlebowy, D.O., \& Al Dwaikat, T. N. (2014). Power Over Diabetes. American Diabetes Association, Live Empowered Program. Louisville, Kentucky.

Elizabeth Buchanan, Diane Orr Chlebowy, Mary-Beth Coty, Tariq Al-Dwaikat.

Relationships of Sociodemographic Characteristics with Mobile Application Use in Adults with Type 2 Diabetes. Undergraduate Research Symposium. University of Louisville. 